\title{
Cochrane
}

Cochrane Database of Systematic Reviews

\section{Treatment with disease-modifying drugs for people with a first clinical attack suggestive of multiple sclerosis (Review)}

Filippini G, Del Giovane C, Clerico M, Beiki O, Mattoscio M, Piazza F, Fredrikson S, Tramacere I, Scalfari A, Salanti G

Filippini G, Del Giovane C, Clerico M, Beiki O, Mattoscio M, Piazza F, Fredrikson S, Tramacere I, Scalfari A, Salanti G. Treatment with disease-modifying drugs for people with a first clinical attack suggestive of multiple sclerosis. Cochrane Database of Systematic Reviews 2017, Issue 4. Art. No.: CD012200. DOI: 10.1002/14651858.CD012200.pub2.

www.cochranelibrary.com 
TABLE OF CONTENTS

HEADER

ABSTRACT

PLAIN LANGUAGE SUMMARY . . .

SUMMARY OF FINDINGS FOR THE MAIN COMPARISON . . . . . . . . . . . . . . . . . . . . . . . 5

BACKGROUND . . . . . . . . . . . . . . . . . . . . . . . . . . . . . . . . . . . . . 8

OBJECTIVES . . . . . . . . . . . . . . . . . . . . . . . . . . . . . . . . . . . . .

METHODS . . . . . . . . . . . . . . . . . . . . . . . . . . . . . . . . 11

RESULTS . . . . . . . . . . . . . . . . . . . . . . . . . . . . . . 15

Figure 1. . . . . . . . . . . . . . . . . . . . . . . . . . . . . . . . . . . . . 16

Figure 2. . . . . . . . . . . . . . . . . . . . . . . . . . . . . . . . . . . . . . 18

Figure 3. . . . . . . . . . . . . . . . . . . . . . . . . . . . . . . . . . . . . .

Figure $4 . \quad$. . . . . . . . . . . . . . . . . . . . . . . . . . . . . . . . . . . . . 23

Figure 5. . . . . . . . . . . . . . . . . . . . . . . . . . . . . . . . . . . . . . 24

Figure 6. . . . . . . . . . . . . . . . . . . . . . . . . . . . . . . . . . . . . . 25

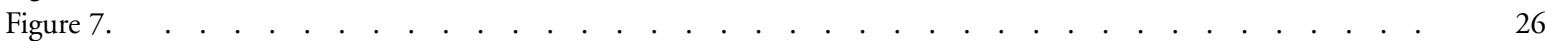

Figure 8. . . . . . . . . . . . . . . . . . . . . . . . . . . . . . . . . . . . . . . 27

ADDITIONAL SUMMARY OF FINDINGS . . . . . . . . . . . . . . . . . . . . . . . . . . . . . . . . . .

DISCUSSION . . . . . . . . . . . . . . . . . . . . . . . . . . . . . . . . . . . . . . 30

AUTHORS' CONCLUSIONS . . . . . . . . . . . . . . . . . . . . . . . . . . . . . . . . . . . . . . .

ACKNOWLEDGEMENTS . . . . . . . . . . . . . . . . . . . . . . . . . . . . . . . . . . . . . . .

REFERENCES . . . . . . . . . . . . . . . . . . . . . . . . . . . . . . . . . . . . . . . . . . . . . . . . .

CHARACTERISTICS OF STUDIES . . . . . . . . . . . . . . . . . . . . . . . . . . . . . . 40

DATA AND ANALYSES . . . . . . . . . . . . . . . . . . . . . . . . . . . . . . . . . . . 72

Analysis 1.1. Comparison 1 Active intervention versus placebo, Outcome 1 Occurrence of at least one serious adverse event over 24 months. . . . . . . . . . . . . . . . . . . . . . . . . . . . . . . . . . . . . . . . 74

Analysis 1.2. Comparison 1 Active intervention versus placebo, Outcome 2 Occurrence of at least one serious adverse event over 36 months.

Analysis 1.3. Comparison 1 Active intervention versus placebo, Outcome 3 Withdrawing from the study or discontinuing the drug due to adverse events over 24 months.

Analysis 1.4. Comparison 1 Active intervention versus placebo, Outcome 4 Withdrawing from the study or discontinuing the drug due to adverse events over 12 months.

Analysis 1.5. Comparison 1 Active intervention versus placebo, Outcome 5 Time to conversion to CDMS over 24 months.

Analysis 1.6. Comparison 1 Active intervention versus placebo, Outcome 6 Time to conversion to CDMS over 12 months.

Analysis 1.7. Comparison 1 Active intervention versus placebo, Outcome 7 Withdrawing from the study or discontinuing the drug for any reason over 24 months.

Analysis 1.8. Comparison 1 Active intervention versus placebo, Outcome 8 Withdrawing from the study or discontinuing the drug for any reason over 12 months.

Analysis 2.1. Comparison 2 Early versus delayed treatment, Outcome 1 Time to conversion to CDMS at different followup years.

ADDITIONAL TABLES . . . . . . . . . . . . . . . . . . . . . . . . . . . . . 82

APPENDICES . . . . . . . . . . . . . . . . . . . . . . . . . . . . . . . . . . . . . 89

CONTRIBUTIONS OF AUTHORS . . . . . . . . . . . . . . . . . . . . . . . . . . . . . . . . . . . . . . .

DECLARATIONS OF INTEREST . . . . . . . . . . . . . . . . . . . . . . . . . . . . . . . . . . . . 90

SOURCES OF SUPPORT . . . . . . . . . . . . . . . . . . . . . . . . . . . . . . . . . . . . . . . . . 91

DIFFERENCES BETWEEN PROTOCOL AND REVIEW . . . . . . . . . . . . . . . . . . . . . . . . . . . . 91

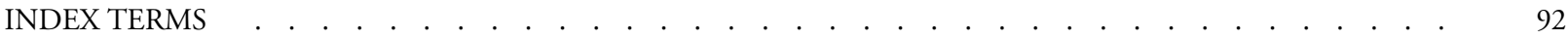

Treatment with disease-modifying drugs for people with a first clinical attack suggestive of multiple sclerosis (Review)

Copyright @ 2017 The Cochrane Collaboration. Published by John Wiley \& Sons, Ltd. 


\title{
[Intervention Review]
}

\section{Treatment with disease-modifying drugs for people with a first clinical attack suggestive of multiple sclerosis}

\author{
Graziella Filippini $^{1}$, Cinzia Del Giovane ${ }^{2}$, Marinella Clerico ${ }^{3}$, Omid Beiki ${ }^{4}, 5$, Miriam Mattoscio ${ }^{6}$, Federico Piazza ${ }^{3}$, Sten Fredrikson \\ ${ }^{4}$, Irene Tramacere ${ }^{1}$, Antonio Scalfari ${ }^{6}$, Georgia Salanti $^{7}$ \\ ${ }^{1}$ Scientific Direction, Fondazione IRCCS, Istituto Neurologico Carlo Besta, Milan, Italy. ${ }^{2}$ Cochrane Italy, Department of Diagnostic, \\ Clinical and Public Health Medicine, University of Modena and Reggio Emilia, Modena, Italy. ${ }^{3}$ University of Turin, Division of \\ Neurology, AOU San Luigi Gonzaga, Orbassano, Italy. ${ }^{4}$ Department of Clinical Neuroscience, Karolinska Institutet, Stockholm, \\ Sweden. ${ }^{5}$ Department of Epidemiology and Biostatistics, Kermanshah University of Medical Sciences, Kermanshah, Iran. ${ }^{6}$ Department \\ of Medicine, Division of Brain Sciences, Centre for Neuroscience, Wolfson Neuroscience Laboratories, Imperial College London, \\ London, UK. ${ }^{7}$ Institute of Social and Preventive Medicine (ISPM), University of Bern, Bern, Switzerland
}

Contact address: Graziella Filippini, Scientific Direction, Fondazione IRCCS, Istituto Neurologico Carlo Besta, via Celoria, 11, Milan, 20133, Italy. graziella.filippini@istituto-besta.it.

Editorial group: Cochrane Multiple Sclerosis and Rare Diseases of the CNS Group.

Publication status and date: New, published in Issue 4, 2017.

Citation: Filippini G, Del Giovane C, Clerico M, Beiki O, Mattoscio M, Piazza F, Fredrikson S, Tramacere I, Scalfari A, Salanti G. Treatment with disease-modifying drugs for people with a first clinical attack suggestive of multiple sclerosis. Cochrane Database of Systematic Reviews 2017, Issue 4. Art. No.: CD012200. DOI: 10.1002/14651858.CD012200.pub2.

Copyright (C) 2017 The Cochrane Collaboration. Published by John Wiley \& Sons, Ltd.

\section{A B S T R A C T}

\section{Background}

The treatment of multiple sclerosis has changed over the last 20 years. The advent of disease-modifying drugs in the mid-1990s heralded a period of rapid progress in the understanding and management of multiple sclerosis. With the support of magnetic resonance imaging early diagnosis is possible, enabling treatment initiation at the time of the first clinical attack. As most of the disease-modifying drugs are associated with adverse events, patients and clinicians need to weigh the benefit and safety of the various early treatment options before taking informed decisions.

\section{Objectives}

1. to estimate the benefit and safety of disease-modifying drugs that have been evaluated in all studies (randomised or non-randomised) for the treatment of a first clinical attack suggestive of MS compared either with placebo or no treatment;

2. to assess the relative efficacy and safety of disease-modifying drugs according to their benefit and safety;

3. to estimate the benefit and safety of disease-modifying drugs that have been evaluated in all studies (randomised or non-randomised) for treatment started after a first attack ('early treatment') compared with treatment started after a second attack or at another later time point ('delayed treatment').

\section{Search methods}

We searched the Cochrane Multiple Sclerosis and Rare Diseases of the CNS Group Trials Register, MEDLINE, Embase, CINAHL, LILACS, clinicaltrials.gov, the WHO trials registry, and US Food and Drug Administration (FDA) reports, and searched for unpublished studies (until December 2016).

Treatment with disease-modifying drugs for people with a first clinical attack suggestive of multiple sclerosis (Review)

Copyright $\odot 2017$ The Cochrane Collaboration. Published by John Wiley \& Sons, Ltd. 


\section{Selection criteria}

We included randomised and observational studies that evaluated one or more drugs as monotherapy in adult participants with a first clinical attack suggestive of MS. We considered evidence on alemtuzumab, azathioprine, cladribine, daclizumab, dimethyl fumarate, fingolimod, glatiramer acetate, immunoglobulins, interferon beta-1b, interferon beta-1a (Rebif®, Avonex®), laquinimod, mitoxantrone, natalizumab, ocrelizumab, pegylated interferon beta-1a, rituximab and teriflunomide.

\section{Data collection and analysis}

Two teams of three authors each independently selected studies and extracted data. The primary outcomes were disability-worsening, relapses, occurrence of at least one serious adverse event (AE) and withdrawing from the study or discontinuing the drug because of AEs. Time to conversion to clinically definite MS (CDMS) defined by Poser diagnostic criteria, and probability to discontinue the treatment or dropout for any reason were recorded as secondary outcomes. We synthesized study data using random-effects meta-analyses and performed indirect comparisons between drugs. We calculated odds ratios (OR) and hazard ratios (HR) along with relative $95 \%$ confidence intervals (CI) for all outcomes. We estimated the absolute effects only for primary outcomes. We evaluated the credibility of the evidence using the GRADE system.

\section{Main results}

We included 10 randomised trials, eight open-label extension studies (OLEs) and four cohort studies published between 2010 and 2016. The overall risk of bias was high and the reporting of AEs was scarce. The quality of the evidence associated with the results ranges from low to very low.

\section{Early treatment versus placebo during the first 24 months' follow-up}

There was a small, non-significant advantage of early treatment compared with placebo in disability-worsening $(6.4 \%$ fewer (13.9 fewer to 3 more) participants with disability-worsening with interferon beta-1a (Rebif囚) or teriflunomide) and in relapses (10\% fewer (20.3 fewer to 2.8 more) participants with relapses with teriflunomide). Early treatment was associated with $1.6 \%$ fewer participants with at least one serious $\mathrm{AE}$ ( 3 fewer to 0.2 more). Participants on early treatment were on average $4.6 \%$ times $(0.3$ fewer to 15.4 more) more likely to withdraw from the study due to AEs. This result was mostly driven by studies on interferon beta 1-b, glatiramer acetate and cladribine that were associated with significantly more withdrawals for AEs. Early treatment decreased the hazard of conversion to CDMS (HR 0.53, 95\% CI 0.47 to 0.60 ).

\section{Comparing active interventions during the first 24 months' follow-up}

Indirect comparison of interferon beta-1a (Rebifß) with teriflunomide did not show any difference on reducing disability-worsening (OR $0.84,95 \%$ CI 0.43 to 1.66). We found no differences between the included drugs with respect to the hazard of conversion to CDMS. Interferon beta-1a (Rebif®) and teriflunomide were associated with fewer dropouts because of AEs compared with interferon beta- $1 \mathrm{~b}$, cladribine and glatiramer acetate (ORs range between 0.03 and 0.29 , with substantial uncertainty).

\section{Early versus delayed treatment}

We did not find evidence of differences between early and delayed treatments for disability-worsening at a maximum of five years' follow-up (3\% fewer participants with early treatment (15 fewer to 11.1 more)). There was important variability across interventions; early treatment with interferon beta- $1 \mathrm{~b}$ considerably reduced the odds of participants with disability-worsening during three and five years' follow-up (OR 0.52 , 95\% CI 0.32 to 0.84 and OR $0.57,95 \%$ CI 0.36 to 0.89 ). The early treatment group had $19.6 \%$ fewer participants with relapses (26.7 fewer to 12.7 fewer) compared to late treatment at a maximum of five years' follow-up and early treatment decreased the hazard of conversion to CDMS at any follow-up up to 10 years (i.e. over five years' follow-up HR 0.62 , $95 \%$ CI 0.53 to 0.73 ). We did not draw any conclusions on long-term serious AEs or discontinuation due to AEs because of inadequacies in the available data both in the included OLEs and cohort studies.

\section{Authors' conclusions}

Very low-quality evidence suggests a small and uncertain benefit with early treatment compared with placebo in reducing disabilityworsening and relapses. The advantage of early treatment compared with delayed on disability-worsening was heterogeneous depending on the actual drug used and based on very low-quality evidence. Low-quality evidence suggests that the chances of relapse are less with early treatment compared with delayed. Early treatment reduced the hazard of conversion to CDMS compared either with placebo, no treatment or delayed treatment, both in short-and long-term follow-up. Low-quality evidence suggests that early treatment is associated with fewer participants with at least one serious AE compared with placebo. Very low-quality evidence suggests that, compared with 
placebo, early treatment leads to more withdrawals or treatment discontinuation due to AEs. Difference between drugs on short-term benefit and safety was uncertain because few studies and only indirect comparisons were available. Long-term safety of early treatment is uncertain because of inadequately reported or unavailable data.

\section{PLAIN LANGUAGE SUMMARY}

\section{Disease-modifying drugs for people with a first clinical attack suggestive of multiple sclerosis}

This summary presents data about the benefit and side effects of some disease-modifying drugs used at the time when multiple sclerosis is diagnosed after a first clinical attack. We reviewed the available evidence to answer three questions: 1) is early treatment beneficial and safe? 2) which drug is best for early treatment? 3) is early treatment better than later treatment?

Sufficient data were available from 22 studies on the following drugs: cladribine (Movectro), glatiramer acetate (Copaxone), interferon beta-1b (Betaferon), interferon beta-1a (Rebif; Avonex), and teriflunomide (Aubagio).

\section{First question: is early treatment beneficial and safe?}

\section{Disability-worsening}

Among people who took Aubagio or Rebif, 28 people out of 100 experienced disability-worsening over two years' treatment compared to 34 people out of 100 who took placebo ( $6 \%$ absolute benefit). The overall quality of the included studies is very low, so our confidence in this result is low.

\section{Relapse}

Early treatment was associated with lower proportions of people who had a second attack - ie who received a diagnosis of MS - during the first two years' treatment, compared to people who took placebo. Among people who took Aubagio, 32 people out of 100 experienced recurrent relapses over two years' treatment compared to 42 people out of 100 who took placebo ( $10 \%$ absolute benefit). Again, the overall quality of evidence is very low.

\section{Serious side effects}

Among people who took Aubagio, Avonex, Betaferon, Copaxone, Movectro, or Rebif, there is probably little or no difference in serious side effects over two years' treatment compared with people who took placebo.

\section{Side effects}

Among people who took Betaferon, 11 people out of 100 experienced side effects compared to one person out of 100 people who took placebo (10\% absolute harm). Among people who took Movectro, seven people out of 100 experienced side effects compared to two out of 100 people who took placebo ( $5 \%$ absolute harm). Among people who took Copaxone, six people out of 100 experienced a side effect compared to two out of 100 people who took placebo ( $4 \%$ absolute harm).

\section{Second question: which drug is best for early treatment?}

\section{Disability-worsening}

Indirect comparison of Rebif with Aubagio did not show any difference on reducing disability-worsening over two years' treatment. However, there were few studies and the overall quality of evidence is very low.

\section{Relapse}

Only one study on Aubagio was available, so we cannot compare the effects of each drug compared with one other.

\section{Side effects}

Rebif and Aubagio were associated with fewer dropouts because of side effects compared with Betaferon, Copaxone, or Movectro.

\section{Third question: is early treatment better than later treatment?}

\section{Disability-worsening}

Treatment with disease-modifying drugs for people with a first clinical attack suggestive of multiple sclerosis (Review)

Copyright $\odot 2017$ The Cochrane Collaboration. Published by John Wiley \& Sons, Ltd. 
Among people who received early treatment with Avonex, Betaferon, Copaxone, or Rebif, 37 people out of 100 experienced disabilityworsening at a maximum of five years' follow-up compared with 40 people out of 100 who received later treatment (3\% absolute benefit). However, the great variability between the studies and the low quality of the evidence make our confidence in this result low.

\section{Relapse}

Early treatment was associated with lower proportions of people who had a second attack at any follow-up up to 10 years, compared to people who received later treatment. Among people who received early treatment with Betaferon, Copaxone, or Rebif, 64 people out of 100 experienced recurrent relapses at a maximum of five years' follow-up compared to 83 people out of 100 who received these drugs later (19\% absolute benefit).

\section{Side Effects}

We did not draw any conclusions on long-term serious side effects or treatment discontinuation due to side effects because of inadequacies in the available data in the included studies.

\section{Conclusion}

The low-quality evidence of the included studies suggests a small and uncertain benefit with early treatment compared with placebo or later treatment in reducing disability-worsening and relapses.

We cannot draw conclusions on the long-term safety of these drugs when administered as early treatment because of inadequately reported or unavailable data.

Until convincing evidence of any difference on benefit between disease-modifying drugs becomes available, the drugs that have been in use in clinical practice for many years and whose safety profile is better understood are probably the most sensible choice for early treatment. 


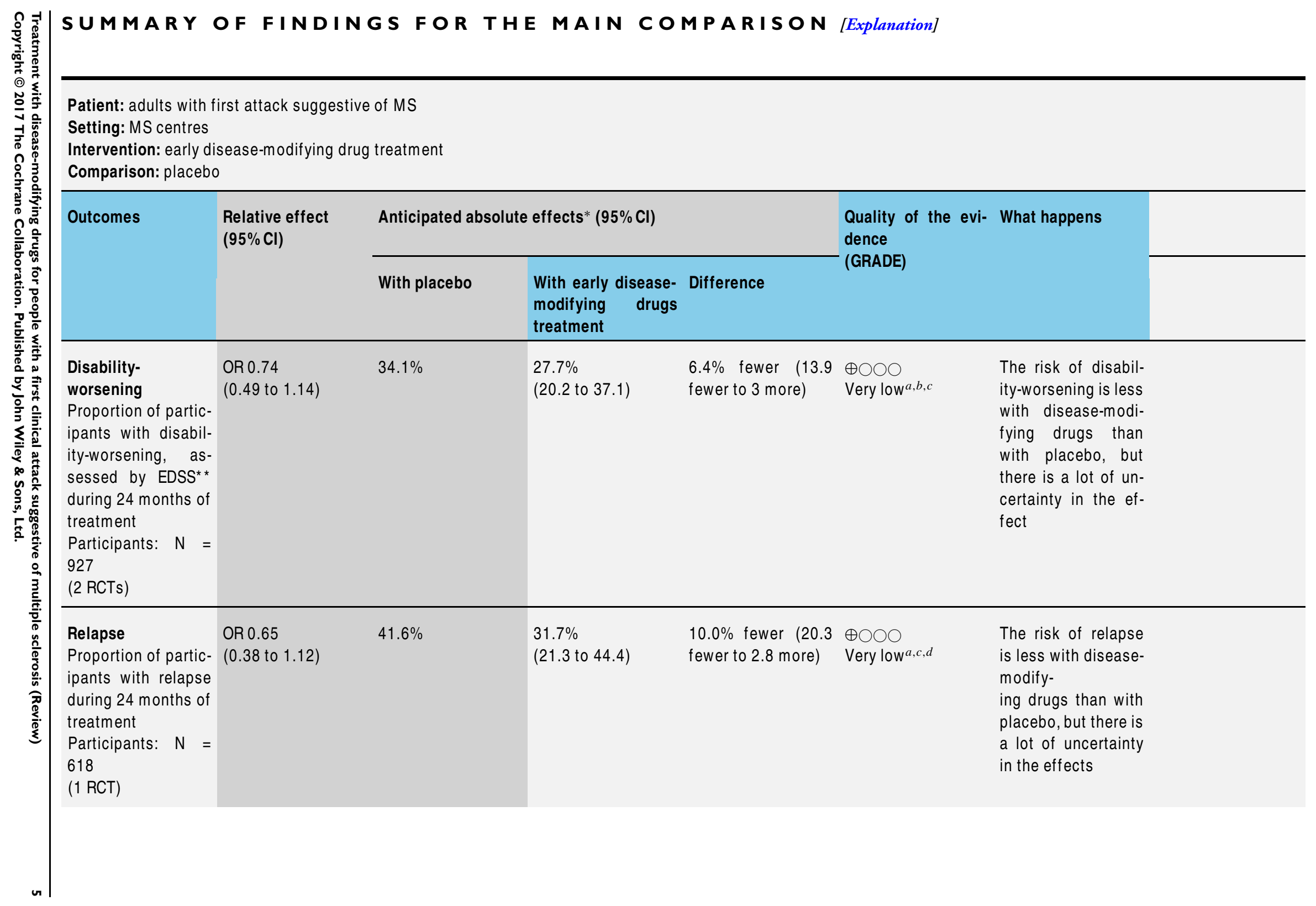




\begin{tabular}{|c|c|c|c|c|c|c|}
\hline $\begin{array}{l}\text { Occurrence of at } \\
\text { least one serious } \\
\text { adverse event Pro- } \\
\text { portion of partici- } \\
\text { pants with at least } \\
\text { one serious adverse } \\
\text { event during } 24 \\
\text { months of treatment } \\
\text { Participants: N = } \\
3385 \\
\text { (7 RCTs) }\end{array}$ & $\begin{array}{l}\text { OR } 0.78 \\
(0.60 \text { to } 1.03)\end{array}$ & $8.0 \%$ & $\begin{array}{l}6.3 \% \\
(5.0 \text { to } 8.2)\end{array}$ & $\begin{array}{l}1.6 \% \text { fewer } \\
\text { ( } 3 \text { fewer to } 0.2 \text { more) }\end{array}$ & $\begin{array}{l}\oplus \oplus \bigcirc \bigcirc \\
\text { Low }^{a, e}\end{array}$ & $\begin{array}{l}\text { Compared } \\
\text { to placebo, disease- } \\
\text { modify- } \\
\text { ing drugs were asso- } \\
\text { ciated with less risk } \\
\text { of serious adverse } \\
\text { events }\end{array}$ \\
\hline $\begin{array}{l}\text { Withdrawls or drug } \\
\text { discontinuation due } \\
\text { to adverse events } \\
\text { during } 24 \text { months of } \\
\text { treatment } \\
\text { Participants: } N= \\
2693 \\
\text { (5 RCTs) }\end{array}$ & $\begin{array}{l}\text { OR } 2.43 \\
(0.91 \text { to } 6.49)\end{array}$ & $3.5 \%$ & $\begin{array}{l}8.0 \% \\
(3.2 \text { to } 18.9)\end{array}$ & $\begin{array}{l}4.6 \% \text { more } \\
(0.3 \text { fewer to } 15.4 \\
\text { more) }\end{array}$ & $\begin{array}{l}\oplus \bigcirc \bigcirc \bigcirc \\
\text { Very low }{ }^{a, f, g}\end{array}$ & $\begin{array}{l}\text { Compared to } \\
\text { placebo interferon } \\
\text { beta 1-b, glatiramer } \\
\text { acetate, and cladrib- } \\
\text { ine were associated } \\
\text { with higher risk of } \\
\text { withdrawals due to } \\
\text { adverse events }\end{array}$ \\
\hline
\end{tabular}

* The risk in the intervention group (and its $95 \%$ confidence interval) is based on the assumed risk in the comparison group and the relative effect of the intervention (and its $95 \% \mathrm{Cl}$ ).

${ }^{*}$ EDSS: expanded disability status scale

Cl: Confidence interval; OR: Odds ratio

\section{GRADE Working Group grades of evidence}

High quality: We are very confident that the true effect lies close to that of the estimate of the effect.

Moderate quality: We are moderately confident in the effect estimate: The true effect is likely to be close to the estimate of the effect, but there is a possibility that it is substantially different.

Low quality: Our confidence in the effect estimate is limited: The true effect may be substantially different from the estimate of the effect.

Very low quality: We have very little confidence in the effect estimate: The true effect is likely to be substantially different from the estimate of effect

${ }^{a} \mathrm{High}$ risk of bias for blinding of participants and outcome assessment and incomplete outcome data.

${ }^{b}$ Surrogate outcome in both studies contributing to this estimate.

${ }^{c}$ The confidence interval does not rule out a null effect or benefit.

${ }^{d}$ Only one study contributed to this estimate. 


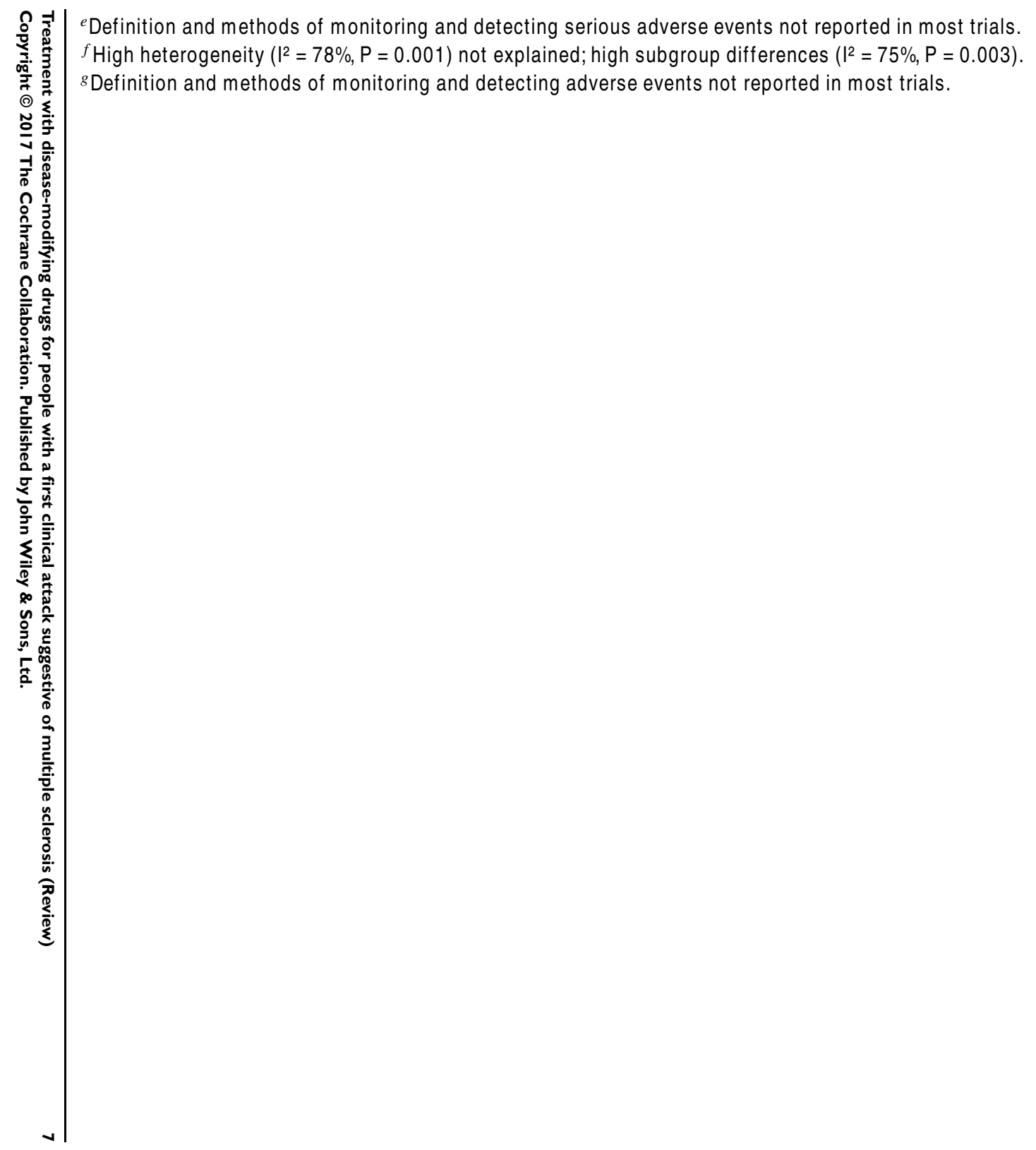




\section{B A C K G R O U N D}

\section{Description of the condition}

Since the revision of the McDonald criteria in 2010 (Polman 2011), multiple sclerosis (MS) can be diagnosed at the time of a first clinical attack when magnetic resonance imaging (MRI) shows the presence of focal lesions in the white matter of the central nervous system, which are considered typical for MS in terms of distribution, morphology, evolution and signal abnormalities on conventional MRI sequences (Filippi 2016). Opinion leaders have recommended early action as "treating at first clinical attack may be the most effective strategy to manage disease progression" (Freedman 2014). Revised guidelines of the Association of British Neurologists (Scolding 2015) and NHS England (NHS England 2014) suggest that treatment should be advised for patients within 12 months of a first attack, if MRI establishes a diagnosis of MS according to the 2010 McDonald criteria or predicts a high likelihood of recurrent attacks. The benefit of starting early treatment with disease-modifying drugs has been demonstrated by some short-term trials that showed delay of a second attack in participants given interferons beta (ETOMS 2001) or glatiramer acetate (PRECISE 2009) compared with those on placebo. On the basis of these results, interferons beta and glatiramer acetate were approved by national regulatory agencies for treating MS at clinical onset (EMA 2015a). However, the available evidence does not indicate that the prevention of recurrent attacks has an effect on disability (CHAMPS 2012 (10 years FU); Frischer 2009), and large variability of long-term disability-worsening has been reported, even among people with frequent early relapses (Scalfari 2013).

Once the decision for early treatment is made, patients and their healthcare providers need to select one of several disease-modifying drugs. Most of the evidence about the relative efficacy and safety of interventions is non-specific to early treatment. In a previously published review, moderate- to high-quality evidence suggested that alemtuzumab, natalizumab and fingolimod were associated with greater benefit for preventing recurrent attacks compared with placebo, and evidence of moderate quality indicated that natalizumab was associated with greater benefit for preventing disability-worsening among all treatments evaluated (Tramacere 2015). Despite alemtuzumab and natalizumab having been proven to exert higher relapse suppression, because of safety concerns, the guidelines of the Association of British Neurologists recommended their use as second-line treatment, or as treatment for people with rapidly evolving relapsing-remitting MS. Beta interferons, glatiramer acetate, teriflunomide, dimethyl fumarate and fingolimod are recommended as first-line agents (Scolding 2015). Australian and New Zealand guidelines allow neurologists the discretionary use of all disease-modifying drugs as first-line treatments (Broadley 2014).

\section{Description of the intervention}

We considered all disease-modifying drugs that are used, approved or off-label, or are currently under marketing authorisation or investigation for people with a first clinical attack. We considered that all agents used or under investigation for relapsing-remitting MS could be given to people with a first attack complying with the 2010 McDonald criteria. More specifically, we are interested in drugs that have been approved for a first attack complying with 2010 McDonald criteria.

- Beta interferons (Betaferon/Betaseron ${ }^{\circledR}$; Extavia $^{\circledR}$; Rebif ${ }^{\circledR}$; Avonex ${ }^{\circledR}$ ) and glatiramer acetate (Copaxone ${ }^{\circledR}$ ) (EMA 2015a; FDA 2012a; FDA 2012b; FDA 2013). These medications are administered subcutaneously, except for beta interferon 1a (Avone ${ }^{\circledR}$ ), which is administered via intramuscular injections. Approved for relapsing-remitting MS

- Natalizumab (Tysabri ${ }^{\circledR}$ ) (EMA 2006; FDA 2006)

administered by intravenous infusion at a dose of $300 \mathrm{mg}$ every four weeks

- Fingolimod (Gilenya ${ }^{\circledR}$ ) (EMA 2011; FDA 2010) given at an oral dose of $0.5 \mathrm{mg}$ once daily

- Teriflunomide (Aubagio ${ }^{\circledR}$ ) (EMA 2013a; FDA 2012) given at an oral dose of $7 \mathrm{mg}$ or $14 \mathrm{mg}$ once daily

- Dimethyl fumarate (Tecfidera ${ }^{\circledR}$ ) (EMA 2014a; FDA 2013) given at an oral dose of $240 \mathrm{mg}$ twice daily

- Alemtuzumab (Lemtrada ${ }^{\circledR}$ ) (EMA 2013b; FDA 2014a) administered intravenously in two annual treatment courses - the first at a dose of $12 \mathrm{mg}$ daily on five consecutive days $(60 \mathrm{mg}$ total dose), and the second, 12 months later, on three consecutive days (36 mg total dose)

- Daclizumab (Zinbryta ${ }^{\circledR}$ ) administered by subcutaneous or intravenous injections and approved by the European Medicines Agency (EMA) (EMA 2016) and the Food and Drug Administration (FDA) (FDA 2016)

- Ocrelizumab (Ocrevus $\left.{ }^{\circledR}\right)$ (FDA 2017) administered intravenously at an initial single dose of $300 \mathrm{mg}$ followed two weeks later by a second $300 \mathrm{mg}$ intravenous infusion. Subsequent doses of $600 \mathrm{mg}$ intravenously every six months. Approved for relapsing forms of MS and primary progressive MS

- Pegylated interferon beta-1a (Plegridy ${ }^{\circledR}$ ) (EMA 2014b; FDA 2014b) given by subcutaneous injection at a dose of $125 \mu \mathrm{g}$ every 14 days

- Cladribine (Movectro ${ }^{\circledR}$ ) approved in Russia and Australia in 2010 (Murphy 2010). EMA (EMA 2015b) and FDA in 2011 did not approve it because of a suspected increase in cancer risk. A meta-analysis failed to confirm these concerns (Pakpoor 2015)

- Mitoxantrone (Novantrone ${ }^{\circledR}$ ) approved in 2000 in the USA (FDA 2000), Europe and other countries for relapsingremitting and progressive MS. It is administered as a short intravenous infusion every three months. Safety concerns include cardiotoxicity and acute leukaemia

- Azathioprine (Imuran ${ }^{\circledR}$ ) used in many countries on the basis of placebo-controlled randomised controlled trials (RCTs)

Treatment with disease-modifying drugs for people with a first clinical attack suggestive of multiple sclerosis (Review) 
published more than two decades ago. However, since interferons beta were approved, azathioprine is no longer recommended as first-line therapy (Goodin 2002). It is taken orally, $2 \mathrm{mg} / \mathrm{kg}$ or 3 $\mathrm{mg} / \mathrm{kg}$ per day. Intravenous immunoglobulins are used for people with severe and frequent relapses, for whom other treatments were contraindicated (Scolding 2015)

- Rituximab (Rituxan ${ }^{\circledR}$ or Mabthera ${ }^{\circledR}$ ) administered intravenously. Currently under marketing authorisation or investigation

- Laquinimod (Nerventra ${ }^{\circledR}$ ) given at an oral dose of $0.6 \mathrm{mg}$ daily. The drug received a negative opinion from EMA (EMA 2014c). Studies of laquinimod in relapsing-remitting MS are ongoing (Active Biotech 2014).

\section{How the intervention might work}

Immunosuppressive or immunomodulatory effects are common to all treatments included in the review.

- Approved interventions

- Beta interferons are naturally occurring cytokines that possess antiviral activity and a wide range of anti-inflammatory properties. Recombinant beta interferons are believed to directly increase expression and concentration of anti-inflammatory agents, while downregulating expression of pro-inflammatory cytokines (Kieseier 2011).

- Glatiramer acetate exerts an immunomodulatory action by inducing tolerance or anergy of myelin-reactive lymphocytes (Schmied 2003). Glatiramer acetate may promote neuroprotective repair processes (Aharoni 2014).

- Natalizumab is a humanised monoclonal antibody directed against the alfa4 integrin. This integrin is essential in the process by which lymphocytes gain access to the brain by allowing cells to penetrate the blood-brain barrier. Natalizumab binds alfa $4 \beta 1$ and alfa $4 \beta 7$ integrin on the surface of circulating $\mathrm{T}$ lymphocytes, preventing interaction with cellular adhesion molecules that facilitate extravasation and migration from the circulation to the central nervous system (CNS) (Millard 2011).

- Fingolimod is a sphingosine-1-phosphate (S1P) receptor modulator that prevents lymphocyte egress from lymphoid tissues, thereby reducing autoaggressive lymphocyte infiltration into the CNS. S1P receptors are also expressed by many CNS cell types and have been shown to influence cell proliferation, morphology and migration. Fingolimod crosses the blood-brain barrier and therefore may have direct CNS effects (Chun 2010).

- Teriflunomide acts as an inhibitor of dihydroorotate dehydrogenase (DHODH), a mitochondrial enzyme involved in pyrimidine synthesis for DNA replication in rapidly proliferating cells. The drug reduces T lymphocyte and B lymphocyte activation and proliferation, and may attenuate the inflammatory response to autoantigens in MS. However, the exact mechanism of action for teriflunomide is not fully understood. Some observations suggest that the drug may have immunological effects outside of its ability to inhibit pyrimidine synthesis in rapidly proliferating cells (Claussen 2012; Oh 2013).

- Dimethyl fumarate derives from fumaric acid, promotes anti-inflammatory activity and can inhibit expression of pro-inflammatory cytokines and adhesion molecules. Actions of neuroprotective and myelin-protective mechanisms have been proposed (Linker 2011; Wilms 2010).

- Alemtuzumab is a monoclonal antibody to CD52 on the cell surface of lymphocytes and monocytes. Its effects are thought to be mediated by extended B and T lymphocyte depletion followed by a distinctive pattern of $\mathrm{T}$ and $\mathrm{B}$ cell repopulation that begins within weeks of treatment and leads to a rebalanced immune system, including an increased percentage of regulatory and memory $\mathrm{T}$ cells. Effects of alemtuzumab persisted after it was cleared from the circulation (Lycke 2015).

- Daclizumab is a monoclonal antibody to the interleukin-2 receptor CD25 that is expressed on immune cells. The exact mechanism is not well understood. Daclizumab interrupts interleukin-2-mediated cell activation, thereby preventing expansion of autoreactive T lymphocytes and inhibiting survival of activated T cells (Wuest 2011).

- Ocrelizumab is a recombinant monoclonal antibody designed to selectively target CD20-positive B lymphocytes, a specific type of immune cell thought to be a key contributor to myelin and axonal nerve cell damage. The drug depletes CD20 $\mathrm{B}$ cells, it increases antibody-dependent cell-mediated cytotoxicity effects and reduces complement-dependent cytotoxicity effects (Kappos 2011).

- Pegylated interferon beta-1a (PEG-IFN) is the drug obtained by PEGylation of IFN beta-1a (Avonex ${ }^{\circledR}$ ) (i.e. joining of a polyethylene glycol group (PEG) molecule to the IFN beta1a molecule). PEGylation has been applied to increase IFN stability, solubility and half-life, and to reduce dosing frequency (Hu 2012).

- Cladribine is a chemotherapeutic drug approved for treatment of people with hairy-cell leukaemia, a subtype of chronic lymphoid leukaemia. Short courses of cladribine induce prolonged lymphopenia by selectively interfering with DNA synthesis and repair in $\mathrm{T}$ and $\mathrm{B}$ lymphocytes lasting months to years (Leist 2011).

- Mitoxantrone is a cytotoxic drug that intercalates with DNA and inhibits both DNA and RNA synthesis, thus reducing the number of lymphocytes (Fox 2004).

- Interventions used off-label

- Azathioprine is a cytotoxic immunosuppressive drug that acts as a prodrug for mercaptopurine, inhibiting an enzyme required for DNA synthesis. Thus it most strongly affects proliferating cells, such as $\mathrm{T}$ cells and B cells of the immune system (Tiede 2003). 
○ Intravenous immunoglobulins may improve remyelination of demyelinated axons through mediation of cytokines. However, their mechanism of action in MS remains unclear (Stangel 1999).

- Rituximab is a monoclonal antibody to CD20 expressed on pre- $\mathrm{B}$ and mature $\mathrm{B}$ cells; it acts by depleting these cells in the circulation and the CNS. Although MS was traditionally considered a T cell-mediated disease, accumulating evidence suggests that B cells may play a role (Lycke 2015; Naismith 2010).

- Interventions currently under marketing authorisation or investigation

- Laquinimod may have an immunomodulatory effect on the peripheral and central nervous systems. This drug modulates the function of various myeloid antigen-presenting cell populations, which then downregulate pro-inflammatory $\mathrm{T}$ cell responses. Furthermore, data indicate that laquinimod acts directly on resident cells within the CNS to reduce demyelination and axonal damage. However, exactly how the drug works remains unknown (Varrin-Doyer 2014).

\section{Why it is important to do this review}

\section{Uncertainty}

Many treatment options are available, and patients and their clinicians may choose to start with a drug of moderate efficacy and general safety or with a drug of high efficacy and a complex safety profile. Consequently, a comprehensive appreciation of the benefits and risks of all treatment approaches is urgently needed (Scolding 2015; Wingerchuk 2014).

\section{Early treatment}

Interferons and glatiramer acetate are indicated by the FDA and the EMA for treatment of people who have experienced a first attack and are at high risk of recurrent attacks. Other immunotherapies have been reported to delay recurrent attacks, although their effect on disability prevention remains unclear. In addition, various national guidelines provide conflicting information about effects of these treatments and their use as first-line or second-line therapy (see Description of the condition). This uncertainty results from several factors, including intermediate outcomes and short follow-up periods in the clinical trials included in published reviews. Immunotherapies administered early in the disease can delay intermediate outcomes (i.e. short-term relapses), but suppression of early relapses may not necessarily correlate with longterm disability prevention (Frischer 2009; Scalfari 2013). Therefore an effect on disability cannot be claimed solely on the basis of relapse prevention (EMA 2015a). Given that most evidence has been derived from short-term trials with low power to investigate rare adverse events, safety outcomes have not been extensively investigated. Consequently, a demonstration and quantification of the benefit and safety of the early treatment versus delayed treatment is still required.

\section{Choice of interventions for early treatment}

Patients and their doctors must be given information about the relative benefit and safety of the various treatment options if they are to make informed decisions. Various disease-modifying drugs have been shown to have different benefit/acceptability profiles. Differences in benefit are as important to consider as differences in safety. For example, local injection site reactions and flu-like symptoms have emerged as the main adverse effects of interferons beta, and cardiotoxicity and acute leukaemia as major safety issues for mitoxantrone. Investigators have described fatal cases of progressive multi-focal leucoencephalopathy in people treated with natalizumab (EMA 2006), fingolimod (EMA 2011) and dimethyl fumarate (EMA 2014a). To support informed decision-making, there is a need to identify, systematically collect and synthesise information about relative safety and efficacy between interventions administered to people with the first attack suggestive of MS.

\section{Relevance}

In July 2014, Cochrane Multiple Sclerosis launched a 'Priority Setting Survey' and invited consumers and MS societies to answer a questionnaire identifying priority research questions considered to have the most relevant impact for all stakeholders. The question - "Early onset of treatment may avoid disease progression?" - was one of the most frequently reported by people with MS and family members. The question - "Does early treatment with aggressive disease-modifying drugs improve the prognosis for people with MS?" - addresses one of the top $10 \mathrm{MS}$ priorities reported by the James Lind Alliance in collaboration with the UK MS Society 2012. This review aims to answer these two questions by comparing all disease-modifying drugs with placebo; it also plans to provide an assessment of the relative effects of each drug compared with one other and a ranking of treatments according to benefit and safety. The significance of this project is underlined by the fact that evaluation of disease-modifying drugs for people with a first clinical attack has been identified as a priority and is featured in the Cochrane Priority Review List 2015/16.

Most published reviews have compared a single treatment versus placebo and have made inferences about benefits and safety. This information is unlikely to be useful in practice, as people with MS have several treatment options. Network meta-analysis (NMA), which is an extension of the traditional pairwise meta-analysis, collates information from studies comparing different treatments in order to form a 'network of interventions'. This provides information about the relative effects of all interventions included in the network, even those not directly compared in any trial and 
a hierarchy of treatments ordered by efficacy and safety. None of the existing comparative effectiveness reviews have specifically addressed disease-modifying drugs in early treatment. As the number of people who choose to start treatment soon after diagnosis increases, it is important for healthcare providers to know the relative benefit and safety of the various treatment options in this particular setting.

Another important limitation of existing reviews is that all include randomised controlled trials. Although this study design is theoretically associated with low risk of bias, it has several shortcomings. First, randomised trials do not provide patient followup for a long period; consequently, this design is not appropriate when rare safety outcomes are of interest. Second, randomised trials are typically undertaken in highly selected conditions and do not represent real-world settings. Consequently, the generalisability of findings is doubtful. For these reasons, interest in including non-randomised studies in the decision-making process is growing (Faria 2015), and innovative methods have been developed for combining data obtained through different study designs (Schmitz 2013; Verde 2015).

Overall, we believe that despite the wealth of information and the plethora of studies and reviews on treatments for MS, uncertainty surrounds the relative ranking of disease-modifying drugs when treatment starts early. In particular, the issue of safety is less well studied, as evidence from non-randomised studies that provide useful information on adverse events has not been systematically considered. We believe that having access to high-quality health information is an essential component of good decision-making processes and helps people take control of their health. Our certainty comes from the results of studies previously undertaken by Cochrane Multiple Sclerosis, wherein people with MS and their family members told us that they want access to high-quality information about MS provided by sources they can trust (Colombo 2014; Colombo 2016; Hill 2012; Synnot 2014).

\section{Potential to change or influence clinical practice or health policy}

The review aimed to provide critical information necessary in making informed healthcare decisions on treatments for people with MS, their neurologists and family members. Notably, marked variability in treatment decisions has been reported, likely as the result of physician preference and opinion (Palace 2013). Disease-modifying drugs are expensive and their use has significant economic implications for the healthcare system. These treatments are associated with high risk of adverse events, which indirectly further increases treatment costs. Identifying treatment that offers a better benefit and safety profile, with particular attention to safety, may help to reduce costs.

\section{O B J E C T IVES}

The review aimed to answer three research questions:

- is early treatment efficacious and safe compared to placebo or no treatment?

- are there differences in efficacy and safety between the various drugs administered for early treatment?

- is early treatment better than delayed treatment?

Consequently, the objectives were:

- to estimate the benefit and safety of disease-modifying drugs that have been evaluated in all studies (randomised or nonrandomised) for the treatment of a first clinical attack suggestive of MS compared either with placebo or no treatment;

- to assess the relative efficacy and safety of disease-modifying drugs according to their benefit and safety;

- to estimate the benefit and safety of disease-modifying drugs that have been evaluated in all studies (randomised or nonrandomised) for treatment started after a first attack ('early treatment') compared with treatment started after a second attack or at another later time point ('delayed treatment').

\section{MET HO D S}

\section{Criteria for considering studies for this review}

\section{Types of studies}

We included RCTs, open-label extension (OLE) studies, controlled clinical trials, cohort studies and registries. Inclusion of non-randomised controlled studies was supported by the aim to provide additional evidence about long-term outcomes (in particular safety outcomes) and populations that are typical of real world practice.

An OLE study follows on from a RCT. At the end of the RCT or after the occurrence of a primary outcome event (e.g. conversion to MS), participants receiving placebo were offered the option to switch to the active treatment during an 'open-label' follow-up. In these studies efficacy and safety were evaluated comparing the early-treatment group with the delayed-treatment group.

We included studies with follow-up of at least one year. We excluded non-comparative studies.

\section{Types of participants}

Adults (aged 18 years or older) with a first clinical attack suggestive of MS as defined in the original articles. We included participants with optic neuritis, isolated brainstem or cerebellar syndrome or 
spinal cord or other clinical syndrome as a first attack and monofocal or multi-focal first attacks.

\section{Types of interventions}

The following interventions administered as monotherapy were eligible for inclusion: alemtuzumab, azathioprine, cladribine, daclizumab, dimethyl fumarate, fingolimod, glatiramer acetate, immunoglobulins, interferon beta-1b (Betaseron $\left.{ }^{\circledR}\right)$, subcutaneous interferon beta-1a (Rebif®), intramuscular interferon beta1a (Avonex®), laquinimod, mitoxantrone, natalizumab, ocrelizumab, pegylated interferon beta-1a, rituximab and teriflunomide. We included regimens irrespective of their dose and assumed that treatments are 'jointly randomisable' across trial participants (Salanti 2012). To address the first two review questions we included studies comparing disease-modifying drugs with placebo, no treatment or another active treatment. To address the third question we included studies comparing early treatment versus delayed treatment with disease-modifying drugs. We excluded combination treatments, non-pharmacological treatments, and interventions consisting of over-the-counter drugs.

\section{Types of outcome measures}

Primary outcomes

\section{Primary efficacy outcomes}

\section{Disability-worsening}

We measured this as the proportion of participants who experienced disability-worsening (as defined by the study authors) at 24 months, 36 months or at the end of the study. Most investigators used the expanded disability status scale (EDSS) (Kurtzke 1983). EDSS is based on the results of a neurological examination and the patient's ability to walk. Scores range from 0 (no neurological abnormality) to 10 (death from multiple sclerosis). Disabilityworsening is often defined as a sustained (3 months or 6 months) increase of at least one point in EDSS recorded over a relapse-free period.

\section{Relapses}

We measured this as the proportion of participants who experienced new relapses over 12 months, 24 months and 36 months or at the end of the study. A relapse is defined as a newly developed or recently worsened symptom of neurological dysfunction that lasted more than 24 hours with or without objective confirmation and that stabilised or resolved either partly or completely.

\section{Primary safety outcomes}

\section{Occurrence of at least one serious adverse event}

We measured this as the proportion of participants with at least one serious adverse event during the study.

Withdrawing from the study or discontinuing the drug due to adverse events

We measured this as the proportion of participants who withdrew from the study or discontinued the drug due to adverse events during the study.

\section{Secondary outcomes}

Time to conversion to clinically definite multiple sclerosis (CDMS)

As defined by Poser diagnostic criteria (Poser 1983).

Withdrawing from the study or discontinuing the drug for any reason

We measured this as the proportion of participants who discontinued treatment and were followed-up to the end of the study or who were lost to follow-up for any reason.

\section{Search methods for identification of studies}

We did not apply any language restrictions to the search.

\section{Electronic searches}

The Information Specialist searched the Cochrane Multiple Sclerosis and Rare Diseases of the CNS Trials Register, which, among other sources, contains trials from:

- Cochrane Central Register of Controlled Trials

(CENTRAL; 2016, issue 12);

- MEDLINE (PubMed) (1966 to 31 December 2016);

- Embase (Embase.com) (1974 to 31 December 2016);

- Cumulative Index to Nursing and Allied Health Literature (CINAHL) (EBSCOhost) (1981 to 31 December 2016);

- Latin American and Caribbean Health Science Information Database (LILACS) (Bireme) (1982 to 31 December 2016);

- ClinicalTrials.gov (www.clinicaltrials.gov); and

- World Health Organization (WHO) International Clinical Trials Registry Platform (apps.who.int/trialsearch).

Information on the Trials Register or the Review Group and details of the search strategies used to identify trials can be found in the 'Specialised Register' section within the Cochrane Multiple Sclerosis and Rare Diseases of the CNS module. We described 
in Appendix 1 the keywords that we used to search for trials. We performed an expanded search to identify articles of nonrandomised studies in MEDLINE (Appendix 2) and Embase ( Appendix 3).

\section{Searching other resources}

- We handsearched the reference lists of all retrieved articles, texts and other reviews on the topic.

- We contacted study authors and researchers active in this field to ask for additional data, if necessary.

- We searched for FDA and EMA reports.

\section{Data collection and analysis}

\section{Selection of studies}

Two teams of three authors each (MC, MM and AS; OB, FP and GF) independently assessed titles and abstracts to identify relevant studies for inclusion. We obtained the full text of the study when necessary to confirm inclusion. All completed RCTs, OLEs, CCTs, and cohort studies were included if the studies contained clinically relevant benefit and safety outcomes for any of the drugs included in the review and met the inclusion criteria. The reference lists of the articles were screened to identify any studies missed by the electronic database search. Discrepancies in judgement were resolved by discussion between review authors.

\section{Data extraction and management}

The six review authors extracted data independently and in duplicate using an Excel sheet piloted on three articles. We resolved disagreements on extractions by discussion.

\section{Outcome data}

For all dichotomous outcomes, we extracted arm-level data (number of participants with events and number of participants). For time to conversion to CDMS we extracted hazard ratios (HR) and relative standard errors. When timing of outcome measure was not reported at selected time points, we extracted data as close as possible to that time point. When outcome data were not reported or were unclear in the original article we checked reports from the FDA or EMA. If necessary, we sought additional information from the trial investigators. For non-randomised and OLE studies, we preferred adjusted relative treatment effects to unadjusted.

\section{Other extracted data}

- Study design: year of publication, monocentric or multicentric, recruitment period, time between onset of first attack and randomisation method;
- Participants: age, gender, monofocal or multi-focal onset presentation, type of first attack, baseline EDSS, baseline MRI lesions, proportion of participants treated with steroids at the first attack;

- Definitions of relapse and disability-worsening;

- Interventions: route, dose, frequency or duration of treatment/follow-up.

In OLE studies we also extracted the number of participating centres, and the number of participants who entered and completed the study during different follow-up times. For each nonrandomised study, we recorded the analysis method used to reduce confounding.

\section{Assessment of risk of bias in included studies}

\section{RCTs and OLEs}

We assessed the risk of bias of each included study using the Cochrane recommendations for assessment (Higgins 2011). These included: random sequence generation, allocation concealment, blinding of personnel and participants, blinding of outcome assessors, incomplete outcome data, selective outcome reporting, and evidence of major baseline imbalance. We explicitly judged the risk of bias on each criterion as 'low', 'high' or 'unclear'. We judged attrition as having low risk of bias when numbers and causes of dropouts were balanced between arms. To summarise the quality of evidence we considered allocation concealment, blinding of outcome assessors and incomplete outcome data to classify each study as having low risk of bias (when all three criteria were judged at low risk of bias), high risk of bias (when at least one criterion was at high risk of bias), unclear risk of bias when all three criteria were judged as having unclear risk of bias, and moderate risk of bias in the remaining cases.

Participants in OLE studies were informed at the time they were recruited into the RCT that they could be enrolled into an OLE study. Then the participants taking placebo had the possibility to switch to the active treatment when they were diagnosed with CDMS or after they completed the RCT. The participant allocated to the active treatment could decide to enter the OLE study at the end of the RCT and continue taking the treatment. The consequences of the OLE design were that original allocation concealment was lost, participants entering the extension were clearly selected, for example, those who had treatment benefit and did not discontinue treatment due to adverse events. Moreover, participants and outcome assessors were not blinded in the OLE phases. For these reasons, we considered OLE studies at high risk of bias for random sequence generation, allocation concealment and blinding of participants and outcome assessors. We reported the 'Risk of bias' assessments for RTC and OLE studies separately. 


\section{Cohort studies}

We assessed the risk of bias in the cohort studies using the ROBINS-I tool for NRS (Sterne 2016) that includes the following bias domains: confounding, selection of participants into the study, classification of interventions, deviations from intended interventions, missing data, measurement of outcomes and selection of reported result. We judged each domain as pertaining to low, moderate, serious, critical risk of bias or no information about risk of bias and performed an overall 'Risk of bias' assessment for each study according to the criteria reported in the ROBINS-I tool for NRS (Sterne 2016).

\section{Adverse events \\ We evaluated the methods of monitoring and detecting adverse events in each included study answering to the following two ques- tions: firstly, did researchers actively monitor for adverse events, or did they simply provide spontaneous reporting of adverse events that arose; and secondly, did study authors define serious adverse events according to an accepted international classification and report the number of serious adverse events? (Singh 2011). We have reported answers to these questions in a table 'Assessment of adverse events monitoring, definition and reporting of serious ad- verse events'. We used the resulting answers to decide indirectness in GRADE. \\ MC, MM and AS independently assessed the risk of bias of each RCT and OLE study and resolved disagreements by discussion. $\mathrm{OB}, \mathrm{FP}$ and GF independently assessed risk of bias of the cohort studies and resolved disagreements by discussion. The final judg- ments were established by GF and CDG.}

\section{Measures of treatment effect}

We estimated, through pairwise meta-analysis, treatment effects of competing interventions by using odds ratios (ORs) with $95 \%$ confidence intervals ( $95 \%$ CIs) for each binary outcome at each time point and HR with 95\% CIs for conversion to CDMS. We estimated the absolute effects for primary outcomes included in the 'Summary of fIndings' table. We presented the results from NMA of RCTs as summary relative effect sizes according to the type of outcome.

\section{Unit of analysis issues}

For multi-arm trials, intervention groups are all those that can be included in a pairwise comparison of intervention groups, which, if investigated alone, would meet the inclusion criteria. For example, if a study compares 'interferon beta versus natalizumab versus interferon beta plus natalizumab' only one comparison ('interferon beta vs natalizumab') addresses the review objectives. We merged data from study arms involving the same drug at different doses. For outcomes for which data were available as treatment effects (i.e. HR), we used the data from the arm trial at highest dose.

\section{Dealing with missing data}

We considered missing outcome data in the 'Risk of bias' assessment. In some of the studies included in the review, missing outcome rates were considerable and we accounted for the their impact on the outcomes assuming that they were not missing at random. We assumed a relationship between the unknown outcome among missing participants and the known outcome among observed participants by using the 'informative missingness odds ratios' (IMORs) approach, allowing for uncertainty in the missing data imputations (Higgins 2008; White 2008). We assumed in both groups that the odds of relapses or disability-worsening in missing participants were roughly 6 times times the odds in the observed participants with $95 \%$ CI from 3 to 7 (IMOR $=5.95,95 \%$ CI 3 to 7 ). We set these values after discussion with clinicians, who suggested that missing outcomes are most probably unfavourable outcomes. To implement the approach we used the 'metamiss' command in Stata v14 (available from https:/ /www.mrc-bsu.cam.ac.uk/software/stata-software/).

\section{Assessment of heterogeneity}

In standard pairwise meta-analyses, we estimated different heterogeneity variances for each pairwise comparison. In NMA, we assumed a common estimate for the heterogeneity variance for all comparisons. We assessed the presence of statistical heterogeneity within each pairwise comparison by visual inspection of the forest plots and by calculating the $\mathrm{I}^{2}$ statistic (Higgins 2003). The type of drug used in the various studies was a suspected source of heterogeneity and we performed all pairwise meta-analyses in subgroups, considering the $\mathrm{P}$ value from the subgroup analyses as an indication of differences between interventions.

\section{Assessment of reporting biases}

We were not able to assess the possibility of reporting bias as the number of studies were fewer than 10 in all the analyses.

\section{Data synthesis}

We performed pairwise meta-analyses using a random-effects model (using the Mantel-Haenszel estimator for Q) for any treatment versus placebo and for early versus delayed treatment. We performed NMA using a random-effects model for outcomes evaluated in RCTs over 24 months of follow-up. The validity of network estimates in NMA is based on the assumption of transitivity (Salanti 2012). We had planned to assess whether the distribution of potential effect modifiers (among those reported extracted data in Data extraction and management) were balanced across comparisons (Jansen 2013), however, none of the networks that we identified presented enough data to evaluate the assumptions. We 
conducted pairwise meta-analyses in Review Manager 5 (RevMan 5) software (RevMan 2017) and NMA in Stata v14 using the network and network_graphs packages in Stata v14 (available from https://www.mrc-bsu.cam.ac.uk/software/stata-software/).

\section{Subgroup analysis and investigation of heterogeneity}

We used the test for subgroup differences to assess the statistical heterogeneity across comparisons with different active agents within standard pairwise meta-analyses. In the context of NMA, we did not have enough information to assess incoherence, defined as the statistical disagreements between direct and indirect effect sizes, as only indirect evidence was available.

\section{Sensitivity analysis}

We re-ran the analyses of excluding observational studies when relevant.

\section{'Summary of findings' table}

We have presented the main results of the review in two 'Summary of findings' tables, according to recommendations provided in Chapter 11 of the Cochrane Handbook for Systematic Reviews of Interventions (version 5.1.0) (Schunemann 2011). We judged the credibility of the evidence from pairwise meta-analysis in accordance with the methods of the GRADE Working Group (GRADE Working Group 2004). For each outcome the assumed risk in the control group was based on the proportion of events in the included studies.

In the first'Summary of findings' table we included an overall grading of the evidence for four patient-important outcomes with re- gards to the review question 'Are disease-modifying drugs for a first attack suggestive of MS effective and safe compared to placebo?'

- Disability-worsening during 24 months of treatment

- Relapse during 24 months of treatment

- Occurrence of at least one serious adverse event during 24 months of treatment

- Withdrawing from the study or discontinuing the drug due to adverse events during 24 months of treatment

In the second 'Summary of findings' table we included an overall grading of the evidence for two patient-important outcomes with regards to the review question 'Is early treatment with diseasemodifying drugs more efficacious and safe than delayed treatment? ,

- Disability-worsening at a maximum of five years' follow-up from randomisation

- Relapse at a maximum of five years' follow-up from randomisation

\section{RE S U L T S}

\section{Description of studies}

\section{Results of the search}

A flow diagram describes the results of the electronic search (Figure $1)$. 
Figure I. Study flow diagram.DMD: disease-modifying drugs; OLEs: open label extension studies; RCTs: randomised controlled trials

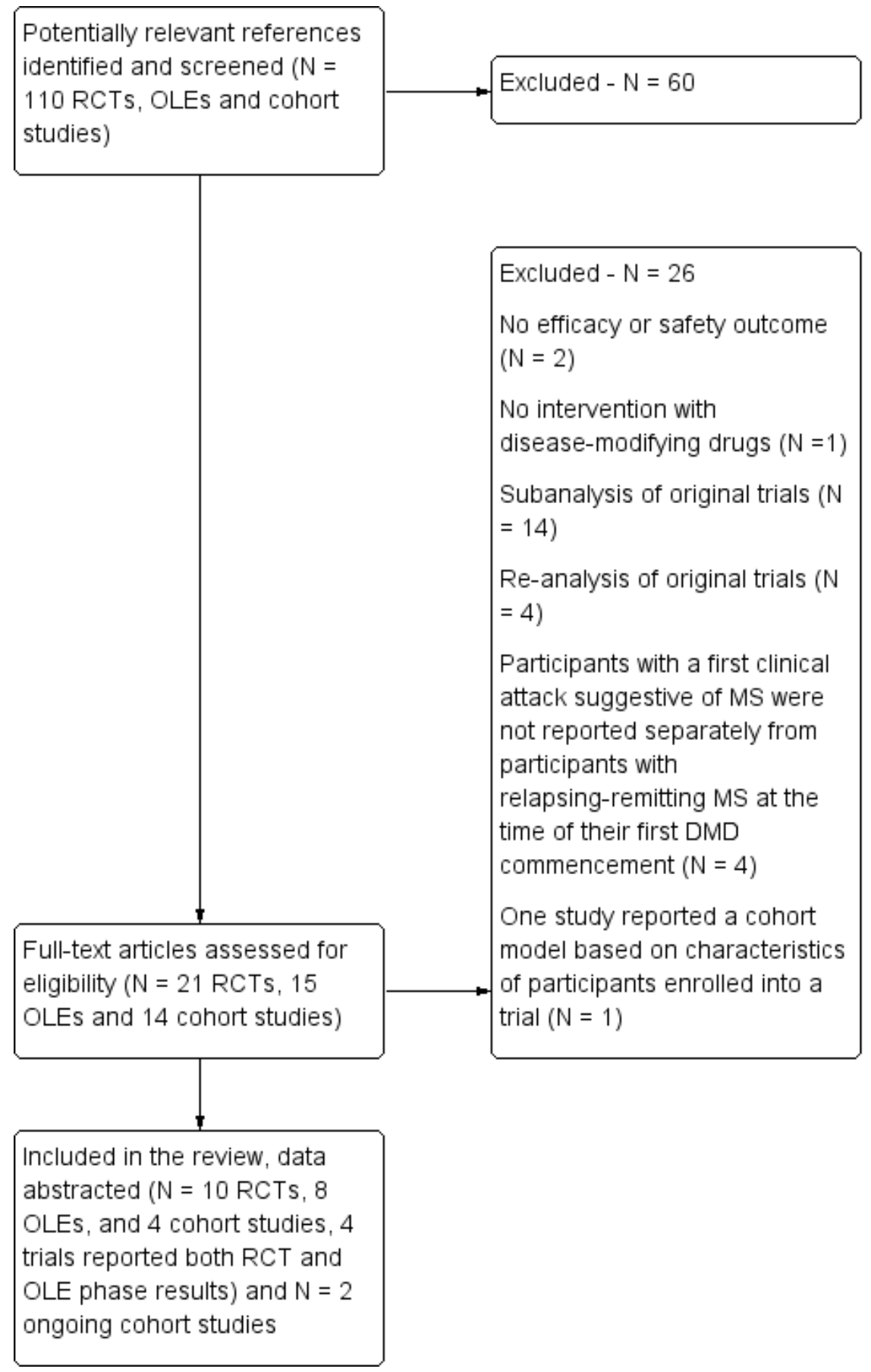




\section{Included studies}

Characteristics of included studies and Table 1 provide details on the characteristics of the included studies. We included 10 RCTs involving 3745 participants and published between 2000 and 2014 (Achiron 2004; BENEFIT 2006; CHAMPS 2000; ETOMS 2001; Motamed 2007; ORACLE 2014; Pakdaman 2007; PRECISE 2009; REFLEX 2012; TOPIC 2014); eight OLEs involving 1868 participants and published between 2006 and 2016 (BENEFIT 2007 (3 years FU); BENEFIT 2009 (5 years FU); BENEFIT 2014 (8.7 years FU); BENEFIT 2016 (11 years FU); CHAMPS 2006 (5 years FU); CHAMPS 2012 (10 years FU); PRECISE 2013 (5 years FU); REFLEX 2016 (3 and 5 years FU)); and four cohort studies involving 4775 participants and published between 2010 and 2016 (ACISS 2010; GERONIMUS 2013; MSBASIS 2016; Tintore 2015).

All RCTs were placebo-controlled studies with a median of two years follow-up. Six (60\%) of the 10 included RCTs assessed interferons in people with a first attack suggestive of MS. BENEFIT 2006 provided data of four OLEs at maximum follow-up of three, five, eight and 11 years from randomisation (BENEFIT 2007 (3 years FU); BENEFIT 2009 (5 years FU); BENEFIT 2014 (8.7 years FU); BENEFIT 2016 (11 years FU)); CHAMPS 2000 provided data of two OLEs with a maximum follow-up of five and 10 years (CHAMPS 2006 (5 years FU); CHAMPS 2012 (10 years FU)); PRECISE 2009 provided data of one OLE with a maximum follow-up of five years (PRECISE 2013 (5 years FU)); and REFLEX 2012 provided data of two OLEs with at maximum follow-up of three and five years (REFLEX 2016 ( 3 and 5 years FU)). Follow-up of the cohort studies ranged from two to six years.

We identified two ongoing cohort studies (NCT01371071; NCT01013350). We will include these studies in a future update of this review. Characteristics of ongoing studies provides details on the characteristics of the two studies.

\section{Excluded studies}

After full-text review we excluded 26 studies (see Characteristics of excluded studies): 14 studies reported sub-analysis of original trials (BENEFIT 2007; BENEFIT 2008; BENEFIT 2011; BENEFIT 2012; BENEFIT 2014a; CHAMPS 2001; CHAMPS 2002a; CHAMPS 2002b; CHAMPS 2002c; CHAMPS 2003; ETOMS 2003; Filippi 2004; REFLEX 2014a; REFLEX 2014b) and four studies reported re-analysis of original trials (BENEFIT 2014b; CHAMPIONS 2015; CHAMPS 2009; Moraal 2009); in four studies participants with a first clinical attack suggestive of MS were not reported separately from participants with relapsingremitting MS at the time of their first disease-modifying drugs commencement (Meyniel 2012; Mowry 2009; MSBASIS 2015; SWISS COHORT STUDY 2013); two studies did not include efficacy or safety outcome (Curkendall 2011; SWISS COHORT STUDY 2016); one cohort study did not evaluate disease-modifying drugs (Kuhle 2015); and one study reported a cohort model based on characteristics of participants enrolled into the BENEFIT trial (Lazzaro 2009).

\section{Risk of bias in included studies}

The risk of bias assessments are summarised separately for RCTs and OLEs in Figure 2. Details on the judgement for each RCT and OLE study and the reason for that judgement are reported in Characteristics of included studies. Risk of bias in the included cohort studies was assessed by ROBINS-I and it is reported in Table 2 . 
Figure 2. Review authors' judgements about each risk of bias item presented as percentages across all included studies and review authors' judgements about each risk of bias item for each included study

Risk of bias graph: review authors' judgements about each risk of bias item presented as percentages across all included studies

Randomised controlled trials
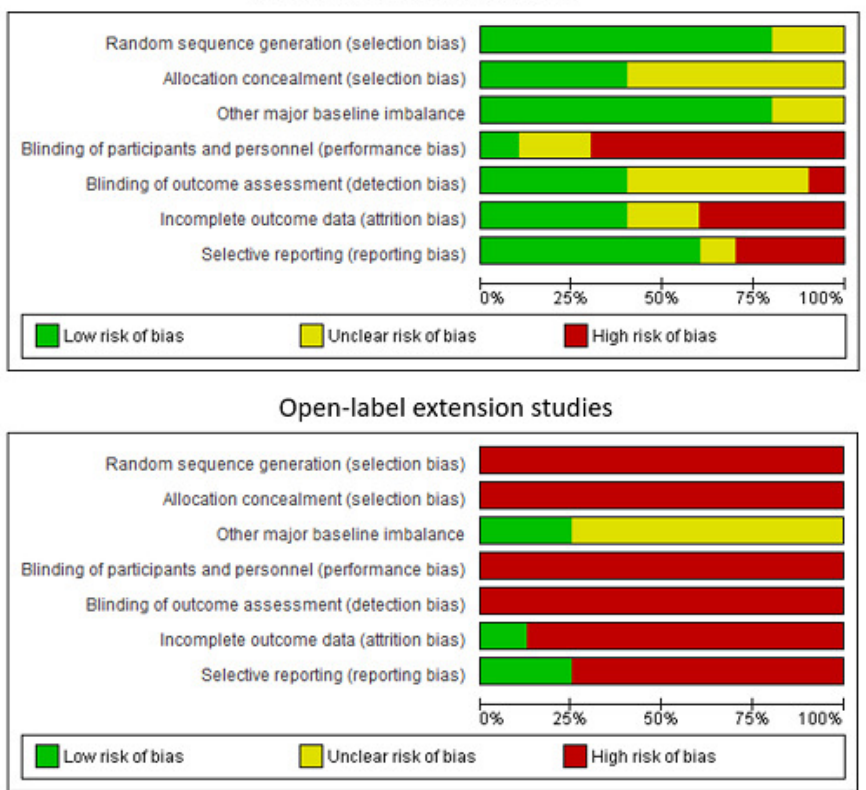

Risk of bias summary: review authors' judgements about each risk of bias item for each included study

Randomised controlled trials

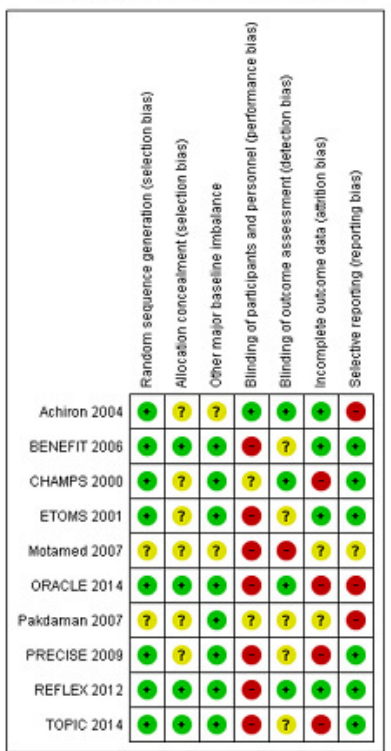

Open-label extension studies

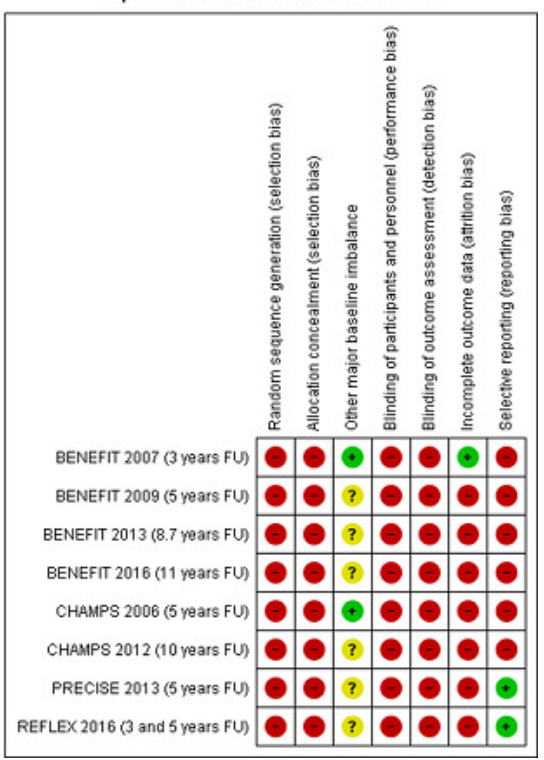




\section{Incomplete outcome data}

We judged four out of 10 RCTs (40\%) to be at low risk of bias because missing outcome data were balanced in numbers across

\section{Random sequence generation}

Eight out of 10 RCTs (80\%) reported adequate methods for allocation sequence and we judged them to be at low risk of bias. Two RCTs (20\%) did not provide enough information to assess allocation sequence and we judged the risk of bias to be unclear for these studies.

\section{Allocation concealment}

Four out of 10 RCTs (40\%) reported adequate methods for allocation concealment and we judged them to be at low risk of bias. Six RCTs $(60 \%)$, did not provide enough information to assess allocation concealment and we judged the risk of bias to be unclear for these studies.

\section{Other major baseline imbalance}

Eight out of 10 RCTs (80\%) were adequate in terms of baseline balance and we judged them to be at low risk of bias. Two RCTs (20\%) did not provide enough information to assess the presence of other baseline imbalance and we judged the risk of bias to be unclear for these studies.

\section{Blinding of participants and personnel}

Only one RCT (10\%) reported adequate methods for blinding participants and personnel to treatment allocation. Two RCTs (20\%) did not provide enough information and we judged the risk of bias to be unclear for these studies. We judged seven RCTs (70\%) to be at high risk of bias (BENEFIT 2006; ETOMS 2001; Motamed 2007; ORACLE 2014; PRECISE 2009; REFLEX 2012; TOPIC 2014).

\section{Blinding of outcome assessors}

Four out of 10 RCTs (40\%) reported adequate methods for blinding outcome assessors to treatment allocation. Five RCTs (50\%) did not provide enough information and we judged the risk of bias to be unclear for these studies. We judged one open-label study to be at high risk of bias for blinding of outcome assessors (Motamed 2007). intervention groups with similar reasons for missing data across groups. Two (20\%) studies (Motamed 2007; Pakdaman 2007) reported insufficient information so that it was uncertain whether or not the handling of incomplete data was appropriate. We judged risk of bias for these two trials to be unclear. We judged four trials $(40 \%)$ to be at a high risk of bias, of which three (CHAMPS 2000; ORACLE 2014; PRECISE 2009) were stopped before the scheduled period of follow-up because the studies had ended prematurely and a low percentage of participants completed the studies. The fourth study (TOPIC 2014) showed more than $40 \%$ of participants lost to follow-up.

\section{Selective outcome reporting}

We judged the majority of included studies (six of 10; 60\%) to be at low risk of bias. The study protocols were available or the published reports included those outcomes that had been prespecified in the methods section of primary articles. One study did not provide enough information to assess this item and the risk of bias was judged to be unclear. In three trials (30\%), we judged risk of bias to be high (Achiron 2004; ORACLE 2014; Pakdaman 2007).

\section{Method of adverse event monitoring}

Five included trials ( 5 out of $10 ; 50 \%$ ) reported that adverse events were actively monitored. Four trials (40\%) reported insufficient information about the method of adverse events monitoring so that it was uncertain whether or not adverse events were monitored appropriately. CHAMPS 2000 reported adverse events only during the first six months of treatment (Table 3).

\section{Serious adverse event definitions}

The majority of included studies (7 out of $10 ; 70 \%$ ) gave insufficient information on serious adverse events definition, the remaining three trials (30\%) provided this definition (Table 3 ).

\section{OLEs}

\section{Random sequence generation}

We judged all eight OLEs to be at high risk of bias for sequence generation because there was no random assignment to the openlabel treatment groups. 


\section{Allocation concealment}

We judged all eight OLEs to be at high risk of bias because there was no allocation concealment with respect to assignment to the open-label treatment groups.

\section{Other major baseline imbalance}

Two out of eight OLEs (25\%) were adequate in terms of baseline balance and we judged them to be at low risk of bias. Six OLEs (75\%) did not provide enough information to assess the presence of other baseline imbalance and we judged the risk of bias to be unclear for these studies.

\section{Blinding of participants and personnel}

None of the eight OLEs blinded participants or personnel to treatment allocation. We judged these studies to be at high risk of bias for blinding of participants and personnel.

\section{Blinding of outcome assessors}

None of the eight OLEs blinded outcome assessors to treatment allocation. We judged these studies to be at high risk of bias for blinding of outcome assessors.

\section{Incomplete outcome data}

Seven $(87 \%)$ of the eight OLEs were likely to be at high risk of attrition bias as participants who dropped out ranged from $23 \%$ to $70 \%$ and proportions and reasons of missing participants differed substantially across intervention groups. Most of the participants who were lost to follow-up may have not responded in the original RCT or have had adverse events that were not included in the analyses, which could overestimate the treatment benefit or underestimate the adverse effect estimates. In one OLE (BENEFIT 2007 (3 years FU)) the majority of participants (about 80\%) contributed outcome data and thus we judged this study to be at low risk of attrition bias.

\section{Selective outcome reporting}

We judged most of the included studies (six of eight; 75\%) to be at high risk of selective reporting bias. We did not find study protocols in the ClinicalTrials.gov database or in the FDA or EMA databases, and judged published reports to be at high risk of this type of reporting bias if they did not report all expected outcomes, including treatment discontinuation due to adverse events or serious adverse events, that were primary outcomes pre-specified in the methods section. The six OLEs were likely to be at high risk of selective reporting bias because these studies did not specify in the methods that they intended to report adverse events and treatment discontinuation due to adverse events or serious adverse events were not reported.

\section{Method of adverse event monitoring}

All the included OLEs reported insufficient information to judge if adverse events were monitored appropriately or not (Table 3).

\section{Serious adverse event definitions}

All the included OLEs did not clearly define 'serious adverse events' (Table 3).

\section{Cohort studies}

We assessed risk of bias according to ROBINS-I tool for nonrandomised studies of interventions (Sterne 2016). We judged two (ACISS 2010; MSBASIS 2016) of the four included cohort studies at critical risk of bias, and the other two studies (GERONIMUS 2013; Tintore 2015) at serious risk of bias (Table 2). None of the cohort studies reported the method they used to monitor and detect adverse events or to define serious adverse events (Table 3).

\section{Effects of interventions}

See: Summary of findings for the main comparison Are disease-modifying drugs for a first attack suggestive of multiple sclerosis (MS) effective and safe compared to placebo?; Summary of findings 2 Is early treatment with disease-modifying drugs more efficacious and safer than delayed treatment?

\section{Research question I: is early treatment efficacious and safe compared to placebo or no treatment?}

Ten RCTs and two cohort studies compared early intervention versus placebo or no treatment.

Their results are synthesised and presented in Summary of findings for the main comparison.

\section{Primary outcomes}

\section{Disability-worsening}

The number of participants who had disability-worsening during 24 months was available from two RCTs (ETOMS 2001, TOPIC 2014) and 927 participants (25\% of those included in the 10 RCTs). The summary OR, which takes into account the missing outcome data, suggested a non-significant reduction of the odds of disability-worsening in early treatment with interferon beta1a (Rebif®) (ETOMS 2001) or teriflunomide (TOPIC 2014) compared with placebo (OR 0.74, 95\% CI 0.49 to $1.14, \mathrm{P}=0.696$ ) with very little heterogeneity $\left(\mathrm{I}^{2}=0 \%\right.$ ) (Figure 3 ). In one cohort study (ACISS 2010) participants treated with disease-modifying drugs at their first attack had greater mean score of EDSS measured at 24 months than participants who were never treated (Table 4). 
Figure 3. Forest plot of comparison: treatment with disease-modifying drugs compared with placebo. Random-effects meta-analysis results of proportion of participants with disability-worsening over 24 months in RCT studies. We assumed in both groups that the odds of disability-worsening in missing participants were 5.95 times the odds in the observed participants with $95 \% \mathrm{Cl}$ from 3 to 7

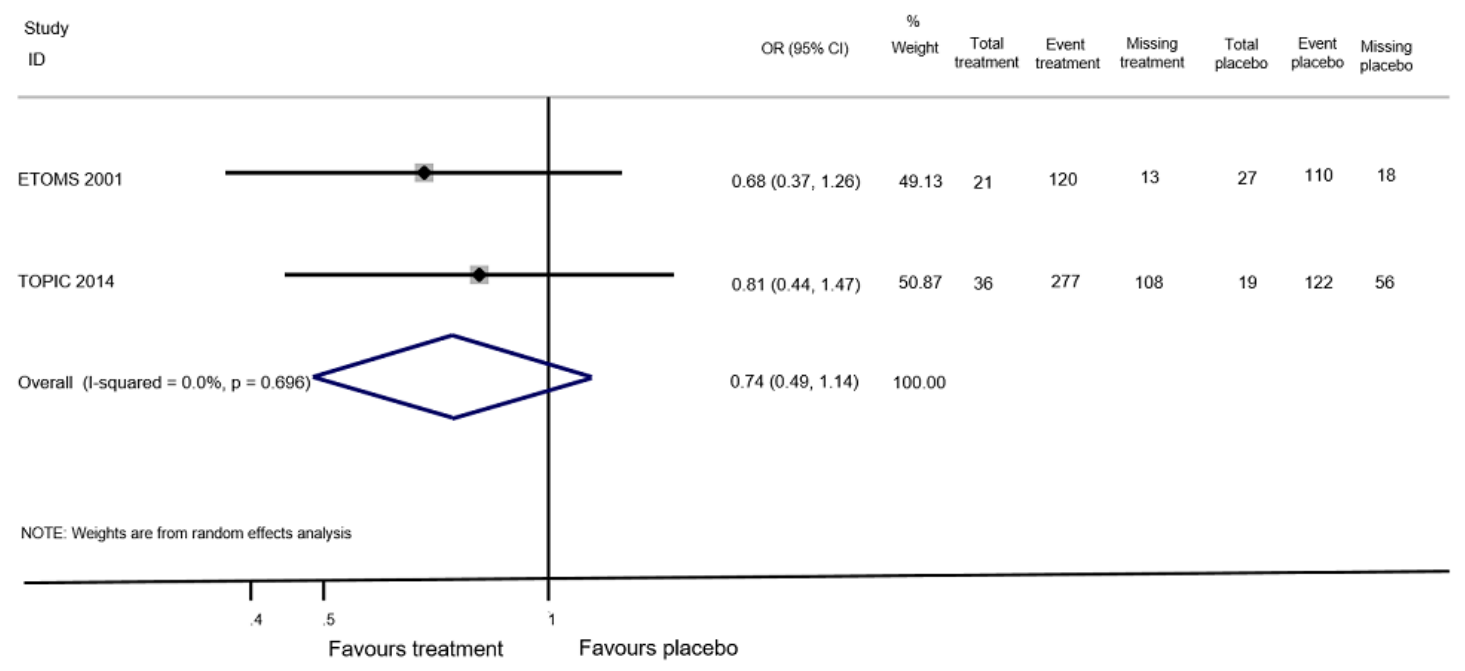

\section{Relapses}

Data from only one trial (TOPIC 2014) with 618 participants (16.5\%) were available to calculate the number of participants who continued to have relapses during the first 24 months of treatment with teriflunomide. The result obtained applying the IMOR method indicated a lower but not significant odds of relapse compared to placebo (OR $0.65,95 \%$ CI 0.38 to 1.12). In one cohort study (ACISS 2010) there was no difference during the first 24 months of treatment in the number of relapses among participants who took disease-modifying drugs for their first attack compared to participants who were not treated (Table 4).

\section{Occurrence of at least one serious adverse event}

Data on adverse events over 24 months were available from seven RCTs (BENEFIT 2006; CHAMPS 2000; ETOMS 2001; ORACLE 2014; PRECISE 2009; REFLEX 2012; TOPIC 2014) (3385 participants; 90\%). The summary OR was 0.78 (95\% CI 0.60 to $1.03, \mathrm{P}=0.08$ ) (Analysis 1.1 ) suggesting, with very little heterogeneity $\left(\mathrm{I}^{2}=0 \%\right)$, that the odds of occurrence of at least one serious adverse event were lower in the active interventions compared with placebo. One trial (Pakdaman 2007) with 202 participants $(5 \%)$ suggested that the odds of occurrence of at least one serious adverse event were greater with interferon beta 1-a (Avonex ${ }^{\circledR}$ ) compared with placebo over 36 months of follow-up; however this difference was very imprecise (OR 1.23, 95\% CI 0.44 to $3.45, \mathrm{P}=0.69$, Analysis 1.2 ).

Withdrawing from the study or discontinuing the drug due to adverse events

Data from five RCTs (BENEFIT 2006; ORACLE 2014; PRECISE 2009; TOPIC 2014; REFLEX 2012) with 2693 participants $(72 \%)$ were reported for this outcome over 24 months. Overall, treatment was associated with greater odds of withdrawal or discontinuation compared with placebo (OR 2.43, 95\% CI 0.91 to $6.49, \mathrm{P}=0.08$ ) (Analysis 1.3 ). There was considerable heterogeneity $\left(\mathrm{I}^{2}=78 \%\right)$; compared to placebo, interferon beta 1-b (Betaseon $\left.{ }^{\circledR}\right)$ (BENEFIT 2006), glatiramer acetate (PRECISE 2009) and cladribine (ORACLE 2014) were associated with significantly more withdrawals due to adverse events, while interferon beta1a (Rebifß) (REFLEX 2012) and teriflunomide (TOPIC 2014) were not significantly different from placebo. Interferon beta 1a (Avonex®) was shown to be associated with fewer withdrawals and discontinuations compared with placebo during the first 12 
months of treatment (OR $0.14,95 \%$ CI 0.02 to 1.12) (CHAMPS

2000) (Analysis 1.4).

\section{Secondary outcomes}

\section{Time to conversion to CDMS}

Seven RCTS reported this outcome at 24 months (BENEFIT 2006; CHAMPS 2000; ETOMS 2001; ORACLE 2014; PRECISE 2009; REFLEX 2012; TOPIC 2014) (3385 participants; 90\%) and in two cohort studies (ACISS 2010; MSBASIS 2016) with 3592 participants (75\% of those included in the four cohort studies). Overall there was a significant advantage of early treatment compared to control groups in reducing the hazard of CDMS during the first 24 months of treatment (HR 0.53, 95\% CI 0.47 to $0.60 ; \mathrm{P}<0.001)$. There was no evidence of heterogeneity $\left(\mathrm{I}^{2}=0 \%\right)$ (Analysis 1.5). Immunoglobulins (Achiron 2004) were associated with a significantly lower hazard to conversion compared with placebo during the first 12 months of treatment (HR 0.36, 95\% CI 0.15 to 0.86 ; $\mathrm{P}=0.02$, Analysis 1.6).

\section{Withdrawing from the study or discontinuing the drug for any reason}

Data at 24 months were available from six RCTs (BENEFIT 2006; CHAMPS 2000; ETOMS 2001; ORACLE 2014; REFLEX 2012; TOPIC 2014) (2931 participants; 78\%). On average placebo and active drugs showed similar odds of discontinuation and dropout (OR 1.00, 95\% CI 0.61 to $1.62, \mathrm{P}=0.99$, Analysis 1.7 ) but there was considerable heterogeneity $\left(\mathrm{I}^{2}=84 \%\right)$. Compared to placebo, interferon beta 1-b (Betaseron $\left.{ }^{\circledR}\right)$ (BENEFIT 2006) and cladribine (ORACLE 2014) were associated with a greater proportion of participants who discontinued treatment or were lost to follow-up for any reason (OR 1.50, 95\% CI 0.95 to 2.3 ; OR 2.30, 95\% CI 1.49 to 3.56), while interferon beta $1 \mathrm{a}$ (Rebif®) and teriflunomide were on average better than placebo. One study showed a very imprecise advantage of placebo over immunoglobulins (Achiron 2004) during the first 12 months of treatment (OR 2.15, 95\% CI 0.37 to 12.35 , Analysis 1.8 ).

\section{Research question 2: are there differences in efficacy and safety between the various drugs administered as early treatments?}

To examine the comparative effect of one disease-modifying drug against another we considered the results from the NMA of RCTs. Evidence was scarce and the assumptions underlying NMA impossible to evaluate.

\section{Primary outcomes}

\section{Disability-worsening}

Only two RCTs reported this outcome over 24 months, one for interferon beta-1a (Rebif ®) (ETOMS 2001) and one for teriflunomide (TOPIC 2014) compared to placebo. Indirect comparison did not indicate a difference between the interventions (interferon beta-1a (Rebif $®)$ versus teriflunomide: OR $0.8495 \%$ CI 0.43 to $1.66)$ in reducing disability-worsening.

\section{Relapses}

Only one study was available for teriflunomide compared with placebo over 24 months (TOPIC 2014).

\section{Occurrence of at least one serious adverse event}

There were no important differences between active drugs with respect to the odds of serious adverse events. The effect sizes from studies examining various drugs were not heterogeneous (in Analysis $1.1, \mathrm{I}^{2}=0 \%$ and $\mathrm{P}=0.72$ for subgroup differences). We did not estimate relative treatment effects between active drugs in an NMA because there was important variation in the definition of serious adverse events violating the transitivity assumption.

Withdrawing from the study or discontinuing the drug due to adverse events

We identified important differences between the drugs, as shown in Analysis 1.3 (test for subgroup differences $\mathrm{P}=0.003$ ). The ORs between active drugs estimated from NMA along with the network plot are shown in Figure 4. As only one study per comparison was available the results pertain to a fixed-effect model. Two treatments, interferon beta- $1 \mathrm{a}$ (Rebif®) and teriflunomide, were associated with significantly fewer withdrawals or discontinuation due to adverse events compared to other treatments. Odds of withdrawing from the study or discontinuing Rebif® were significantly lower compared with Betaseron ${ }^{\circledR}$ (OR 0.03, 95\% CI 0.00 to 0.33 ), cladribine (OR $0.18,95 \%$ CI 0.04 to 0.79 ) and glatiramer acetate (OR $0.21,95 \%$ CI 0.04 to 0.96 ). Teriflunomide presented fewer withdrawals and discontinuations than Betaseron ${ }^{\circledR}(\mathrm{OR} 0.05,95 \%$ CI 0.01 to 0.38$)$, cladribine (OR 0.25 , $95 \%$ CI 0.07 to 0.82 ) and glatiramer acetate (OR 0.29, 95\% CI 0.08 to 1.01). All these estimates have large variations around them. As only placebo-controlled trials were available we were unable to evaluate the plausibility of the transitivity assumption and hence the confidence in the results from NMA is very low. 
Figure 4. Network plot of comparisons and network meta-analysis estimates for the proportion of participants who withdrew from the study because of adverse events in RCT studies. The estimate is located at the intersection of the column-defining treatment and the row-defining treatment. In the lower triangle the comparisons should be read from left to right, a OR value less than I favours the column-defining treatment. In the upper triangle the comparisons should be read from right to left, a OR value larger I favours the rowdefining treatment. Significant results are in italic

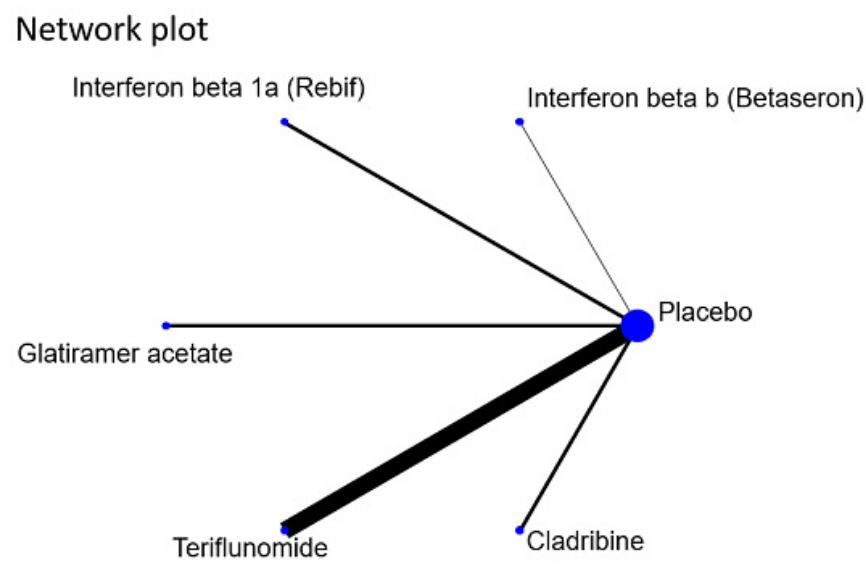

Network estimates

\begin{tabular}{|c|c|c|c|c|c|}
\hline Interferon beta 1a (Rebif) & $1.36(0.48,3.89)$ & $1.39(0.42,4.60)$ & $4.87(1.04,22.71)$ & $5.63(1.27,24.92)$ & $29.33(3.07,280.62)$ \\
\hline $0.73(0.26,2.10)$ & Placebo & $1.02(0.58,1.81)$ & $3.58(1.16,11.03)$ & $4.13(1.44,11.87)$ & $21.54(2.92,159.08)$ \\
\hline $0.72(0.22,2.37)$ & $0.98(0.55,1.72)$ & Teriflunomide & $3.49(0.99,12.33)$ & $4.03(1.22,13.37)$ & $21.03(2.63,168.13)$ \\
\hline $0.21(0.04,0.96)$ & $0.28(0.09,0.86)$ & $0.29(0.08,1.01)$ & Glatiramer acetate & $1.15(0.25,5.40)$ & $6.02(0.61,59.76)$ \\
\hline $0.18(0.04,0.79)$ & $0.24(0.08,0.70)$ & $0.25(0.07,0.82)$ & $0.87(0.19,4.05)$ & Cladribine & $5.21(0.54,50.01)$ \\
\hline $0.03(0.00,0.33)$ & $0.05(0.01,0.34)$ & $0.05(0.01,0.38)$ & $0.17(0.02,1.65)$ & $0.19(0.02,1.84)$ & Interferon beta 1b (Betaseron) \\
\hline
\end{tabular}

\section{Secondary outcomes}

\section{Time to conversion to CDMS}

All interventions were associated with beneficial effects compared with placebo and there were no significant differences between them (test for subgroup differences $P=0.79$, Analysis 1.5 ). This was confirmed by a NMA synthesising data over 24 months ( Figure 5). Note that we were unable to evaluate the transitivity assumption because few studies and only indirect comparisons were available, and hence NMA results have low credibility. 
Figure 5. Network plot of comparisons and network meta-analysis estimates for the time to conversion to CDMS in RCT studies over $\mathbf{2 4}$ months. The estimate is located at the intersection of the column-defining treatment and the row-defining treatment. In the lower triangle the comparisons should be read from left to right, a HR value less than I favours the column-defining treatment. In the upper triangle the comparisons should be read from right to left, a HR value larger than I favours the row-defining treatment. Significant results are in italic

Network plot

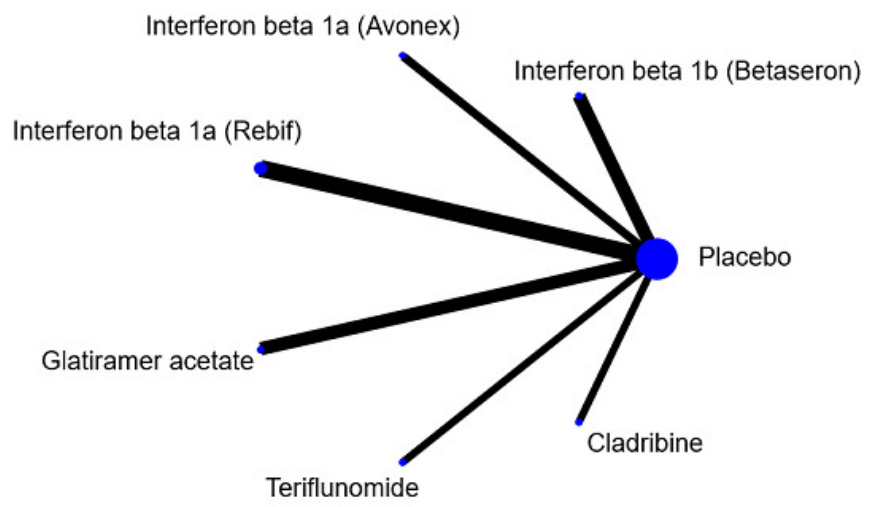

Network estimates

\begin{tabular}{|c|c|c|c|c|c|c|}
\hline Cladribine & $1.32(0.75,2.30)$ & $1.45(0.83,2.53)$ & $1.47(0.81,2.68)$ & $1.50(0.82,2.76)$ & $1.50(0.88,2.56)$ & $2.63(1.70,4.07)$ \\
\hline $0.76(0.44,1.33)$ & Interferon beta 1b (Betaseron) & $1.10(0.67,1.80)$ & $1.12(0.66,1.91)$ & $1.14(0.66,1.97)$ & $1.14(0.72,1.81)$ & $2.00(1.41,2.83)$ \\
\hline $0.69(0.40,1.21)$ & $0.91(0.56,1.49)$ & Glatiramer acetate & $1.02(0.60,1.74)$ & $1.04(0.60,1.80)$ & $1.04(0.66,1.65)$ & $1.82(1.28,2.58)$ \\
\hline $0.68(0.37,1.23)$ & $0.89(0.52,1.53)$ & $0.98(0.57,1.68)$ & Interferon beta 1a (Avonex) & $1.02(0.56,1.84)$ & $1.02(0.61,1.69)$ & $1.79(1.19,2.69)$ \\
\hline $0.67(0.36,1.23)$ & $0.88(0.51,1.52)$ & $0.96(0.56,1.67)$ & $0.98(0.54,1.77)$ & Teriflunomide & $1.00(0.60,1.69)$ & $1.75(1.15,2.68)$ \\
\hline $0.66(0.39,1.13)$ & $0.87(0.55,1.38)$ & $0.96(0.61,1.52)$ & $0.98(0.59,1.63)$ & $1.00(0.59,1.68)$ & Interferon beta 1a (Rebif) & $1.75(1.30,2.36)$ \\
\hline $0.38(0.25,0.59)$ & $0.50(0.35,0.71)$ & $0.55(0.39,0.78)$ & $0.56(0.37,0.84)$ & $0.57(0.37,0.87)$ & $0.57(0.42,0.77)$ & Placebo \\
\hline
\end{tabular}

Withdrawing from the study or discontinuing the drug for any reason

Important differences existed between drugs with respect to the odds of discontinuing or withdrawing from the study for any reason (test for subgroup differences $P=0.005$, Analysis 1.7 ). The network plot and results from NMA are presented in Figure 6. Indirect comparisons were very imprecise due to the low number of events. Note that we were unable to evaluate the transitivity assumption because few studies and only indirect comparisons were available, and hence NMA results have very low credibility. 
Figure 6. Network plot of comparisons and network meta-analysis estimates for the proportion of participants who discontinued treatment and were followed up to the end of the study or who were lost to follow-up for any reason in RCT studies. The estimate is located at the intersection of the column-defining treatment and the row-defining treatment. In the lower triangle the comparisons should be read from left to right, a HR value less than I favours the column-defining treatment. In the upper triangle the comparisons should be read from right to left, a HR value larger I favours the row-defining treatment

\section{Network plot}

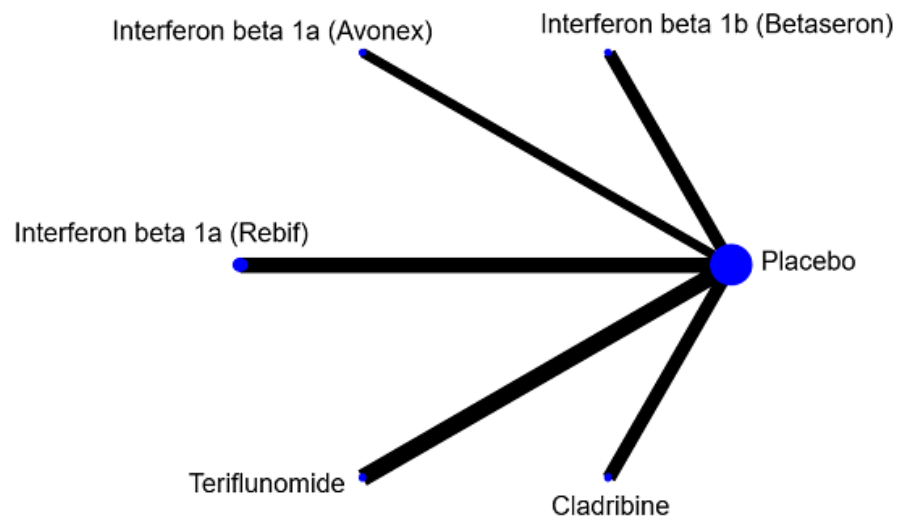

Network estimates

\begin{tabular}{|c|c|c|c|c|c|}
\hline Interferon beta 1a (Rebif) & $1.69(0.30,9.43)$ & $1.94(0.69,5.42)$ & $2.11(0.36,12.18)$ & $2.88(0.51,16.41)$ & $4.46(0.79,25.31)$ \\
\hline $0.59(0.11,3.32)$ & Teriflunomide & $1.15(0.29,4.58)$ & $1.25(0.17,9.09)$ & $1.71(0.24,12.26)$ & $2.65(0.37,18.92)$ \\
\hline $0.52(0.18,1.44)$ & $0.87(0.22,3.46)$ & Placebo & $1.09(0.26,4.51)$ & $1.49(0.37,6.05)$ & $2.30(0.57,9.32)$ \\
\hline $0.47(0.08,2.75)$ & $0.80(0.11,5.82)$ & $0.92(0.22,3.82)$ & Interferon beta 1a (Avonex) & $1.37(0.19,10.11)$ & $2.12(0.29,15.59)$ \\
\hline $0.35(0.06,1.97)$ & $0.58(0.08,4.19)$ & $0.67(0.17,2.74)$ & $0.73(0.10,5.39)$ & Interferon beta $1 \mathrm{~b}$ (Betaseron) & $1.55(0.21,11.23)$ \\
\hline $0.22(0.04,1.27)$ & $0.38(0.05,2.70)$ & $0.43(0.11,1.76)$ & $0.47(0.06,3.47)$ & $0.65(0.09,4.69)$ & Cladribine \\
\hline
\end{tabular}

\section{Research question 3: is early treatment more} effective and safe than delayed treatment?

Eight OLE studies provided data for this comparison. Delayed treatment was defined as treatment given only after a second clinically confirmed attack or at two years after randomisation. The study-specific time until the delayed treatment after randomisation is presented in Table 5. In the description of results below, the follow-up time is the time after randomisation.

The results are synthesised and presented in Summary of findings 2.

Primary outcomes

\section{Disability-worsening}

Data were available at a maximum of three (BENEFIT 2007 (3 years FU); REFLEX 2016 ( 3 and 5 years FU)), five (CHAMPS 2006 ( 5 years FU); BENEFIT 2009 ( 5 years FU); PRECISE 2013 ( 5 years FU); REFLEX 2016 (3 and 5 years FU)), 8.7 (BENEFIT 2014 (8.7 years FU)), 10 and 11 years of follow-up (CHAMPS 2012 (10 years FU); BENEFIT 2016 (11 years FU)). We undertook data synthesis accounting for the large amounts of missing outcome data. Overall, the benefit of early compared to delayed treatment was very imprecise with high heterogeneity (Figure 7). Early treatment with interferon beta- $1 \mathrm{~b}$ (Betaseron ${ }^{\circledR}$ ) appeared to significantly reduce the odds of participants with disability-worsening compared with delayed treatment at a maximum of three and five years' follow-up (BENEFIT 2007 (3 years FU); BENEFIT 2009 ( 5 years FU)). Results of the REFLEX 2016 (3 and 5 years FU) study suggested a non-significant reduction of the odds of par- 
ticipants with disability-worsening in delayed compared with early treatment with interferon beta- $1 \mathrm{a}$ (Rebif囚) at a maximum of three and five years' follow-up. Results on interferon beta-1a (Avonex®) (CHAMPS 2006 (5 years FU); CHAMPS 2012 (10 years FU)) or glatiramer acetate (PRECISE 2013 (5 years FU)) were imprecise. We did not include the outcome data for interferon beta-1b (Betaseron ${ }^{\circledR}$ ) during 11 years' follow-up (BENEFIT 2016 (11 years $\mathrm{FU})$ ) in the analysis as this was a cross-sectional reassessment of the original RCT (investigators conducted participant assessments at their respective centers or via a structured interview by phone) and not appropriate to be combined with the other data (OR 0.82, $95 \%$ CI 0.46 to 1.47 , as estimated from the original study data). One cohort study (Tintore 2015) reported that participants who received early treatment had a lower hazard of attaining an EDSS score of 3.0 compared with delayed treatment (adjusted HR 0.5, $95 \%$ CI 0.3 to 0.9 ) during a mean follow-up time of three years and nine months (Table 4).

Figure 7. Forest plot of comparison: early treatment compared with delayed treatment with diseasemodifying drugs. Random-effects meta-analysis results of proportions of participants with disability-worsening at a maximum of 3 years, 5 years and 10 years of follow-up in open-label extension studies. We assumed in both groups that the odds of disability-worsening in missing participants were 5.95 times the odds in the observed participants with $95 \% \mathrm{Cl}$ from 3 to 7

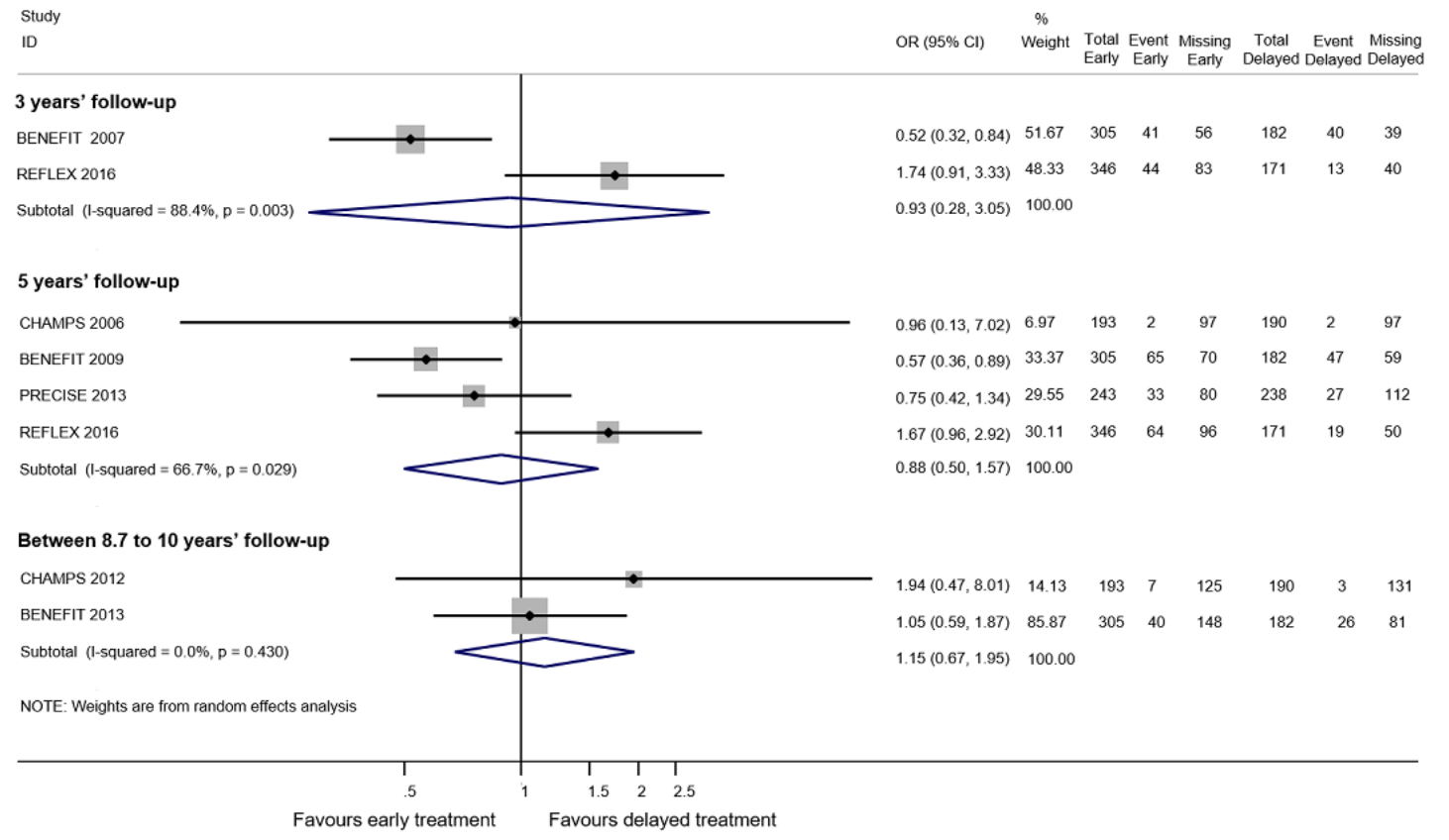

\section{Relapses}

Data at a maximum of five years' follow-up were available in three OLE studies. We undertook data synthesis accounting for the large amounts of missing outcome data. Early treatment with interferon beta 1-b (BENEFIT 2009 ( 5 years FU)), interferon beta 1-a (Rebifß) (REFLEX 2016 (3 and 5 years FU)) and glatiramer acetate (PRECISE 2013 (5 years FU)) significantly reduced the odds of participants with relapses compared to delayed treatment (OR
$0.35,95 \%$ CI 0.26 to $0.48, \mathrm{I}^{2}=0.0 \%$ ) (Figure 8 ). At a maximum of three years' follow-up early treatment with interferon beta 1-a (Rebif®) (REFLEX 2016 (3 and 5 years FU)) decreased the odds of participants with relapse compared to delayed treatment (OR $0.51,95 \%$ CI 0.33 to 0.81 ). Between five and 10 years' followup, the early interferon beta 1-a (Avonex®) group was less likely than the delayed group to experience relapses (OR 0.51, 95\% CI 0.25 to 1.04 ) (CHAMPS 2012 (10 years FU)). 
Figure 8. Forest plot of comparison: Early treatment compared with delayed treatment with diseasemodifying drugs. Random-effects meta-analysis results for proportion of participants with relapse over 5 years follow-up in OLE studies. We assumed in both groups that the odds of relapses in missing participants were 5.95 times the odds in the observed participants with $95 \% \mathrm{Cl}$ from 3 to 7

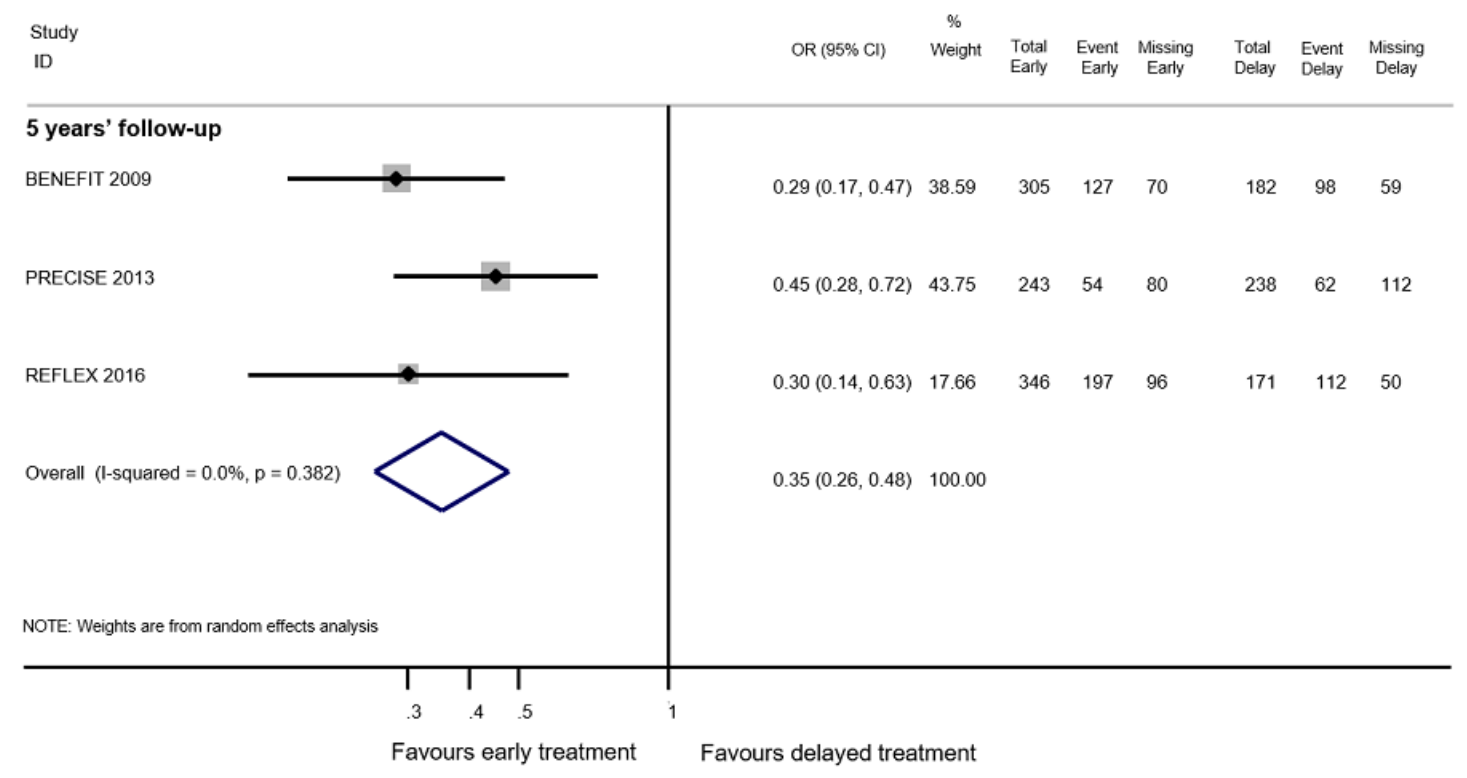

Occurrence of at least one serious adverse event

Definition of serious adverse events according to an accepted international classification was not specified in any of the OLE studies and there was important variation across studies. Additionally, the process of including participants in the OLE phases was likely associated with the occurrence of adverse events and hence the risk of selections bias was very high. Consequently, we presented the data as reported in the studies in Table 6 but we did not draw any conclusions.

Withdrawing from the study or discontinuing the drug due to adverse events

The method of monitoring adverse events was not specified in any of the extension studies and there was varying reliability of the different monitoring approaches. For these reasons and because there was selection of participants in the extension studies we presented results in Table 6 only and we did not draw any conclusions.

\section{Secondary outcomes}

Time to conversion to clinically definite multiple sclerosis
Early treatment with any drug reduced the hazard to conversion to CDMS over any follow-up period (Analysis 2.1). Summary hazard ratios were $0.62\left(95 \%\right.$ CI 0.48 to $\left.0.81, \mathrm{I}^{2}=0 \%\right)$ from five studies reporting the outcome at a maximum follow-up between two and four years, $0.62\left(95 \%\right.$ CI 0.53 to $\left.0.73, \mathrm{I}^{2}=0 \%\right)$ from four studies reporting the outcome at a maximum of five years and $0.65(95 \%$ CI 0.54 to $0.79, \mathrm{I}^{2}=0 \%$ ) from two studies reporting the outcome between 8.7 and 10 years. This beneficial effect of early treatment was also present for longer follow-up; BENEFIT 2016 (11 years FU) reported an HR of 0.67 (95\% CI 0.53 to 0.85$)$ at 11 years (this result was not included in the meta-analysis for the same reason explained above).

Withdrawing from the study or discontinuing the drug for any reason

In OLE studies participants were selected according to their willingness to take an active intervention or continue with the active intervention they were initially randomised to and hence this outcome cannot be measured. We presented results reported in these studies in Table 6 but we did not draw any conclusions.

\section{Subgroup and sensitivity analyses}




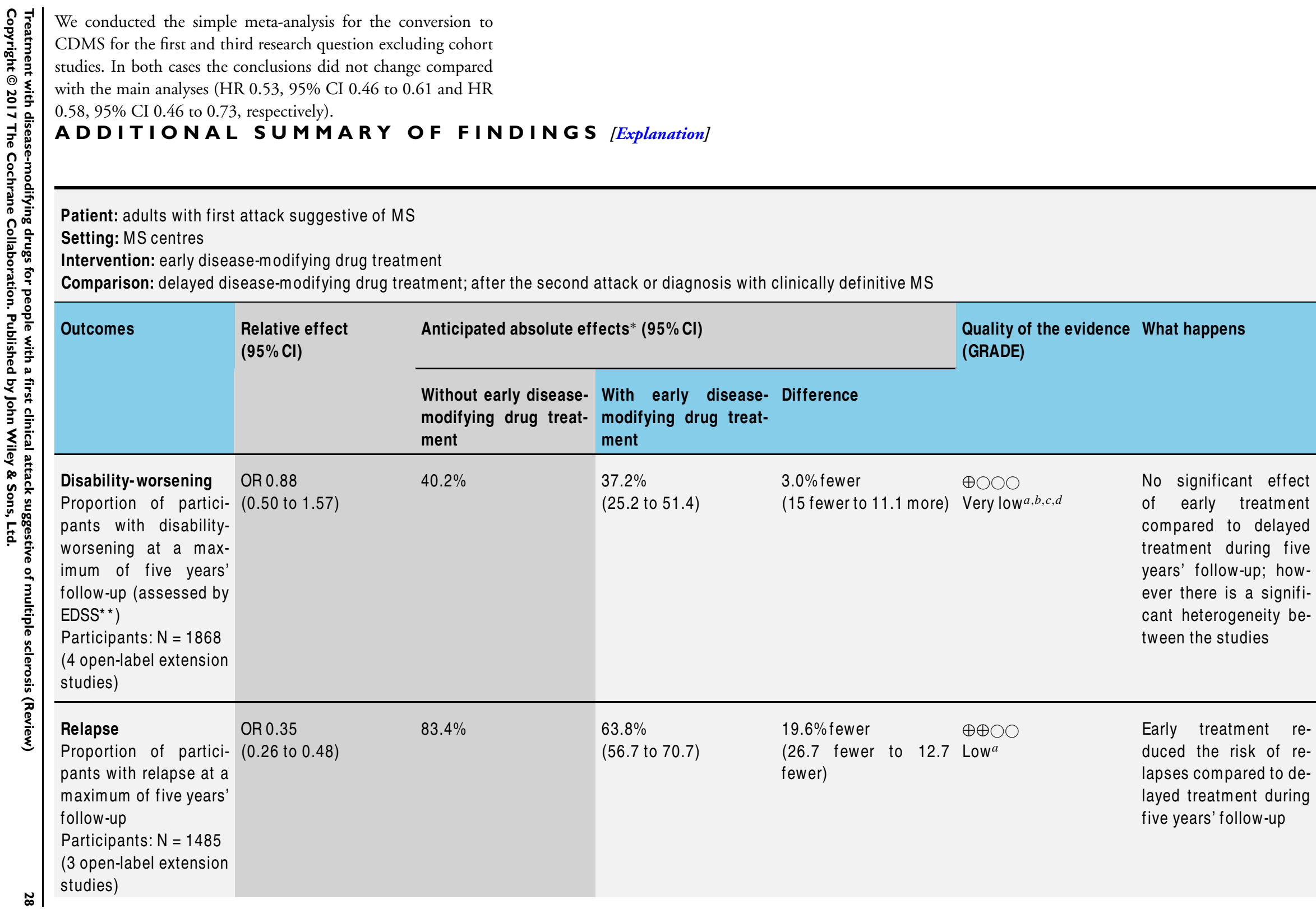


${ }^{*}$ The risk in the intervention group (and its $95 \%$ confidence interval) is based on the assumed risk in the comparison group and the relative effect of the intervention (and its $95 \% \mathrm{Cl})$.

**EDS: expanded disability status scale

Cl: Confidence interval; OR: Odds ratio

\section{GRADE Working Group grades of evidence}

High quality: We are very confident that the true effect lies close to that of the estimate of the effect.

Moderate quality: We are moderately confident in the effect estimate: The true effect is likely to be close to the estimate of the effect, but there is a possibility that it is substantially different.

Low quality: Our confidence in the effect estimate is limited: The true effect may be substantially different from the estimate of the effect.

Very low quality: We have very little confidence in the effect estimate: The true effect is likely to be substantially different from the estimate of effect

${ }^{a}$ High risk of bias for allocation concealment, blinding of outcome assessment and incomplete outcome data.

Surrogate outcome in two out of four studies contributing to this estimate.

${ }^{c}$ High heterogeneity $\left(I^{2}=67 \%, P=0.03\right)$

${ }^{d}$ The confidence interval fails to exclude important benefit or important harms. 


\section{ISCUSSIO N}

\section{Summary of main results}

We analysed all RCTs and open-label extension studies undertaken so far on the use of disease-modifying drugs in participants with a first clinical attack. The review included ten RCTs ( 3745 participants) with a median of two years' follow-up, and eight open-label extension studies (1868 participants) ranging from three to 11 years' follow-up. Most extension studies had major methodological shortcomings. The most common flaws were lack of blinding of outcome assessors and high dropout rates, combined with failure to do an intention-to-treat analysis, even though most trialists specifically declared their intention to do such an analysis. The review also included four cohort studies involving 4775 participants. These cohort studies had serious defects and we judged them to be at critical or serious risk of bias by the ROBINS-I tool.

\section{Disability-worsening}

Is early treatment efficacious and safe compared to placebo or no treatment?

Data were available from two RCTs. The odds of disability-worsening decreased but were not significantly reduced during the first 24 months of interferon beta-1a (Rebif®) or teriflunomide treatment compared to placebo. A small cohort study showed a greater mean score of EDSS measured at 24 months' follow-up in participants receiving an early treatment compared with those who did not receive any treatment.

Are there differences in efficacy and safety between the various drugs administered for early treatment?

There was not enough evidence to answer this question with confidence.

\section{Is early treatment better than delayed treatment?}

Information to answer this question for disability-worsening was available in the open-label extension studies of four RCTs. The available evidence indicated a protective effect of early treatment with interferon beta-1b (Betaseron $\left.{ }^{\circledR}\right)$ compared with delayed treatment during three and five years' follow-up. Early treatment with interferon beta-1a (Rebif $\AA)$, interferon beta-1a (Avonex () ), or glatiramer acetate was not beneficial compared to delayed treatment at any time of follow-up. It is not clear from our analysis why this may be although in view of the great variability of the included extension studies these findings should be interpreted with caution. Early treatment with interferon beta- $1 \mathrm{~b}$ (Betaseron $\left.{ }^{\circledR}\right)$ or interferon beta-1a (Avonex®) was no different from delayed treatment in terms of the proportion of participants who had disability-worsening during 10 years' follow-up.

\section{Relapses}

Is early treatment efficacious and safe compared to placebo or no treatment?

In a single trial the odds of relapses were less but not significantly smaller with early teriflunomide treatment compared with placebo. In one cohort study relapses were not reduced in participants on early disease-modifying drugs compared with participants who were not treated.

\section{Are there differences in efficacy and safety between the} various drugs administered for early treatment?

There was not enough evidence to answer this question with confidence.

\section{Is early treatment better than delayed treatment?}

The results of open-label extension studies showed that early treatment was associated with lower odds of recurrence of relapses during three and five years of follow-up.

\section{Occurence of at least one serious adverse event}

Is early treatment efficacious and safe compared to placebo or no treatment?

Early treatment was associated with fewer chances of having at least one serious adverse event compared with placebo, although this difference was not significant. Information on serious adverse events was scanty and poorly reported in the included randomised trials.

Are there differences in efficacy and safety between the various drugs administered for early treatment?

No evidence was available.

\section{Is early treatment better than delayed treatment?}

This review cannot conclude on long-term serious adverse events because of inadequacies in the available data both in the included open-label extension studies and cohort studies.

Treatment discontinuation or dropout due to adverse events

Is early treatment efficacious and safe compared to placebo or no treatment?

Interferon beta 1-b (Betaseron $\left.{ }^{\circledR}\right)$, glatiramer acetate, and cladribine were associated with significantly higher proportion of participants who withdrew due to adverse events compared to placebo during 24 months of treatment. 
Are there differences in efficacy and safety between the various drugs administered for early treatment?

Indirect comparisons revealed that interferon beta 1-a (Rebif囚) and teriflunomide were associated with significantly lower proportions of participants who withdrew due to adverse events compared to interferon beta $1-b$ (Betaseron $\AA$ ), glatiramer acetate and cladribine. The estimates are very uncertain and it is possible that these differences reflect differences in the methods of monitoring and recording adverse events across studies.

\section{Is early treatment better than delayed treatment?}

This review cannot conclude on long-term adverse events because of inadequate data reported both in the included open-label extension studies and the cohort studies.

\section{Conversion to CDMS}

Is early treatment efficacious and safe compared to placebo or no treatment?

Early treatment was associated with significantly lower hazard of conversion to CDMS over 24 months of follow-up.

\section{Are there differences in efficacy and safety between the various drugs administered for early treatment?}

Indirect comparisons and subgroup differences showed that the disease-modifying drugs did not differ in their effects on efficacy and safety.

\section{Is early treatment better than delayed treatment?}

Open-label extension studies and cohort studies showed that early treatment reduced the hazard of conversion to CDMS at any follow-up up to 10 years.

\section{Treatment discontinuation or dropout for any reason}

\section{Is early treatment efficacious and safe compared to placebo or no treatment?}

Compared to placebo, interferon beta 1-b (Betaseron $\left.{ }^{\circledR}\right)$, and cladribine were associated with significantly higher proportion of participants who discontinued treatment or were lost to followup for any reason during 24 months of treatment. These results are very uncertain therefore these findings should be interpreted with caution.
Are there differences in efficacy and safety between the various drugs administered for early treatment?

Indirect comparisons revealed that the disease-modifying drugs did not differ from each other with regards to this outcome over 24 months of follow-up and it is possible that these differences reflect differences in the methods of monitoring and recording adverse events across studies.

\section{Is early treatment better than delayed treatment?}

This review cannot conclude on this outcome because of inadequate data reported both in the included open-label extension studies and the cohort studies.

\section{Overall completeness and applicability of evidence}

All eligible RCTs, their open-label extensions and cohort studies up to December 2016 were included. Unfortunately, only a small number of included studies reported data on the predefined primary outcomes of the review, that is, short- and long-term disability-worsening and recurrence of relapses. This is an unwelcome finding considering that according to the new MS diagnostic criteria (Polman 2011) most of the participants included in this review currently receive a diagnosis of MS at their first attack and they need evidence about benefit of early disease-modifying treatment with regards to disability-worsening and recurrence of relapses that are the most important outcomes. We decided to include open-label extension studies and cohort studies aiming to collect evidence on the long-term safety of early treatment with disease-modifying drugs, but unfortunately the studies included in the review reported scanty and poorly detailed safety data that did not allow us to draw conclusions, leading to uncertainty about the long-term risk profile of these treatments.

\section{Quality of the evidence}

There were 10 RCTs with 3745 participants included in this review. We only judged one of the included trials (10\%) to be at low risk of bias, when criteria for allocation concealment, blinding of outcome assessors, and complete outcome data were met. In the majority of trials, we judged allocation concealment to be 'unclear' due to lack of details provided in the study reports. Blinding of outcome assessors was also not clearly described in many of the included studies. We judged four studies to have a high risk of bias for incomplete outcome data. Most studies were judged to have a low risk of bias due to major baseline imbalances.

The majority of trials in this review did not provide sufficient information on how a serious adverse event was defined in the study. We combined data on serious adverse events in pairwise metaanalysis, regardless of the definition and whether it was provided, 
so caution is needed in interpreting this outcome. We assessed whether trials reported undertaking active monitoring for adverse events. Fifty percent of included trials reported that they monitored for adverse effects, however many different monitoring techniques may have been used with great variation of the different approaches.

We included eight open-label extension studies (1868 participants) of four RCTs. Given the design of extension studies, in which a highly selected group of participants continued on from the RCT and the majority of participants and outcome assessors were unblinded, we judged most of these studies to be at high risk of bias. We also judged $90 \%$ of the included studies to be at high risk of attrition bias because dropouts ranged from $23 \%$ to $70 \%$ and proportions and reasons for missing participants differed substantially across intervention groups. Serious adverse events were not clearly defined in most extension studies and the majority of them reported insufficient information to judge if adverse events were monitored appropriately or not.

We included four cohort studies with 4775 participants. We assessed risk of bias of these studies according to ROBINS-I tool for non-randomised studies of interventions (Sterne 2016). We judged two studies at critical risk of bias, and the other two studies at serious risk of bias. None of the included cohort studies defined or reported serious adverse events, or whether adverse events were monitored appropriately or not.

For the overall results of disease-modifying drugs as a group versus placebo for the four primary outcomes of disability-worsening, recurrence of relapse, serious adverse events and withdrawals due to adverse events during 24 months of treatment, we graded our confidence in the results as 'very low' or 'low' using the GRADE approach (Summary of findings for the main comparison). For the results of early treatment compared to delayed treatment for the two primary outcomes of disability-worsening and recurrence of relapses during five years' follow-up, we graded our confidence in the results as 'very low' or 'low' (Summary of findings 2).

\section{Potential biases in the review process}

This review has several differences compared to its protocol. We have broadened the research question as a result of the identified data. The initial protocol was focused on detecting differences between the intervention (research question 2) but we realised that we would not be able to answer this question and we added two other aims that we considered clinically important. We also added an outcome (time to conversion to CDMS). Although these decisions were guided by data availability, we think that this has not introduced bias in our review because its scope has become wider rather than narrower.

\section{Agreements and disagreements with other}

\section{studies or reviews}

In this review that included RCTs of seven disease-modifying drugs used in participants who had a first clinical attack suggestive of MS, we found that participants who received interferons, glatiramer acetate, teriflunomide, cladribine had significantly lower hazard of conversion to MS compared to placebo and the effects of these drugs did not differ from each other. Compared with placebo, disease-modifying drugs did not increase the risk of serious adverse events. Interferon beta 1 -a (Rebif $囚)$ and teriflunomide were associated with a lower risk of withdrawals due to adverse events, compared with placebo and the other drugs.

Our findings extend the findings of a previous Cochrane Review that examined only three RCTs of 24 months' duration of interferon beta 1-b (Betaseron $\AA)$, interferon beta 1-a (Rebif $\AA$ ) and interferon beta 1-a (Avonex®) (Clerico 2008). They reported that interferons had lower-than-placebo risk of conversion to CDMS, the frequency of serious adverse events was not significantly different in interferon groups compared to placebo, but active treatment was more likely than placebo to lead to withdrawals due to adverse events. Similar observations have been made by one qualitative review, Freedman 2014 of the same three RCTs of interferons. In one review (Smith 2010) of five RCTs of disease-modifying drugs, which included some of the same RCTs with their extensions during five years' follow-up, the authors concluded that all the three interferons and glatiramer acetate reduced the probability of converting from clinically isolated syndrome to CDMS over a period of two to five years. They reported that the included studies did not describe methods of ascertaining adverse events and that their reporting was sparse. The incidence of adverse events was significantly higher in the interferon and glatiramer acetate groups compared with the placebo groups for most commonly occurring adverse events such as influenza-like syndrome and injection-site reactions. Rates of serious adverse events were no different from placebo in any trial. Most of our findings from direct and indirect comparisons cannot be compared to previous studies since most of them reported only a qualitative description of the trials focusing on efficacy outcomes.

\section{AUTHORS, CONCLUSIONS}

\section{Implications for practice}

Our study has several important findings but some conservative interpretation of the results is warranted, since most of the included treatments have been evaluated in few trials compared with placebo and the overall quality of evidence is low or very low.

Weak evidence of low to very low quality suggests that early treatment reduces the chances of recurrence or relapse compared to placebo, no treatment or delayed treatment both in short- and long-term follow-up. The benefit of early treatment for disability- 
worsening both in short- and long-term follow-up remains unclear.

There are indications that there might be differences in the shortterm safety of the disease-modifying drugs included in this review, but it is not possible to pinpoint them with the available studies. This review cannot conclude on long-term safety of these drugs when administered as early treatment because of inadequatelyreported or unavailable data. Until convincing evidence of any difference on benefit between disease-modifying drugs becomes available, the drugs that have been in use in clinical practice for many years and with a safety profile that is well understood, are probably the most sensible choice for early treatment.

\section{Implications for research}

There are two needs that the research agenda should address. First, randomised trials of direct comparisons between active agents would be useful, avoiding further placebo-controlled studies that do not now comply with the principle of clinical equipoise for treatment of multiple sclerosis (MS). Second, long-term benefit and safety of early treatment with disease-modifying drugs and comparative benefit and safety of different disease-modifying drugs should be mandatory. As the number of disease-modifying drugs that are available for treatment of MS increases, more options are available to people with MS and clinicians. In the absence of comparative trials, national and international registries and other types of large databases may be relevant sources for providing complementary data regarding the long-term benefit and safety of disease-modifying drugs for MS.

\section{ACKNOW LEDGEMENTS}

We thank Andrea Fittipaldo for developing the search strategy methods, Silvana Simi for assisting with writing the Plain language summary, and the Swiss Multiple Sclerosis Society for financial support for conducting the review.

\section{R E F E R E N C E S}

\section{References to studies included in this review}

Achiron 2004 \{published data only\} Achiron A, Kishner I, Sarova-Pinhas I, Raz H, Faibel M,

Stern Y, et al. Intravenous immunoglobulin treatment following the first demyelinating event suggestive of multiple sclerosis: a randomized, double-blind, placebocontrolled trial. Archives of Neurology 2004;61(10): 1515-20. PUBMED: 15477504]

ACISS 2010 \{published data only\}

Fazekas F, Baumhackl U, Berger T, Deisenhammer F, Fuchs S, Kristoferitsch W, et al. Decision-making for and impact of early immunomodulatory treatment: the Austrian Clinically Isolated Syndrome Study (ACISS). European Journal of Neurology 2010;17(6):852-60. PUBMED: 20100231]

BENEFIT 2006 \{published data only\} Kappos L, Polman CH, Freedman MS, Edan G, Hartung $\mathrm{HP}$, Miller DH, et al. Treatment with interferon beta- $1 \mathrm{~b}$ delays conversion to clinically definite and McDonald MS in patients with clinically isolated syndromes. Neurology 2006;67(7):1242-9. PUBMED: 16914693]

BENEFIT 2007 (3 years FU) \{published data only\} Kappos L, Freedman MS, Polman CH, Edan G, Hartung HP, Miller DH, et al. Effect of early versus delayed interferon beta- $1 \mathrm{~b}$ treatment on disability after a first clinical event suggestive of multiple sclerosis: a 3-year follow-up analysis of the BENEFIT study. Lancet 2007;370(9585): 389-97. PUBMED: 17679016]

BENEFIT 2009 (5 years FU) \{published data only\} Kappos L, Freedman MS, Polman CH, Edan G, Hartung HP, Miller DH, et al. Long-term effect of early treatment with interferon beta-1bafter a first clinical event suggestive of multiple sclerosis: 5-year active treatment extension of the phase 3 BENEFIT trial. Lancet Neurology 2009;8(11): 987-97. PUBMED: 19748319]

BENEFIT 2014 (8.7 years FU) \{published data only\} Edan G, Kappos L, Montalbán X, Polman C, Freedman M, Hartung $\mathrm{H}$, et al. Long-term impact of interferon beta- $1 \mathrm{~b}$ in patients with CIS: 8-year follow-up of BENEFIT. Journal of Neurology, Neurosurgery, and Psychiatry 2014;85:1183-9. PUBMED: 24218527]

BENEFIT 2016 (11 years FU) \{published data only\} Kappos L, Edan G, Freedman MS, Montalbán X, Hartung HP, Hemmer B, et al. The 11-year long-term follow-up study from the randomized BENEFIT CIS trial. Neurology 2016;87(10):978-87. PUBMED: 27511182]

\section{CHAMPS 2000 \{published data only\}}

CHAMPS Study Group. Baseline MRI characteristics of patients at high risk for multiple sclerosis: results from the CHAMPS trial. Controlled High-Risk Subjects Avonex Multiple Sclerosis Prevention Study. Multiple Sclerosis 2002; 8(4):330-8. PUBMED: 12166504]

* Jacobs LD, Beck RW, Simon JH, Kinkel RP, Brownscheidle $\mathrm{CM}$, Murray TJ, et al. Intramuscular interferon beta1a therapy initiated during a first demyelinating event in multiple sclerosis. CHAMPS Study Group. New England Journal of Medicine 2000;343(13):898-904. PUBMED: 11006365]

CHAMPS 2006 (5 years FU) \{published data only\} Kinkel RP, Kollman C, O'Connor P, Murray TJ, Simon $\mathrm{J}$, Arnold D, et al. IM interferon beta-1a delays definite 
multiple sclerosis 5 years after a first demyelinating event. Neurology 2006;66(5):678-84. PUBMED: 16436649]

CHAMPS 2012 (10 years FU) \{published data only\}

* Kinkel RP, Dontchev M, Kollman C, Skaramagas TT, O'Connor PW, Simon JH, et al. Association between immediate initiation of intramuscular interferon beta- $1 \mathrm{a}$ at the time of a clinically isolated syndrome and long-term outcomes: a 10-year follow-up of the Controlled High-Risk Avonex Multiple Sclerosis Prevention Study in Ongoing Neurological Surveillance. Archives of Neurology 2012;69 (2):183-90. PUBMED: 21987393]

Simon JH, Kinkel RP, Kollman C, O'Connor P, Fisher E, You X, et al. Ten-year follow-up of the 'minimal MRI lesion' subgroup from the original CHAMPS Multiple Sclerosis Prevention Trial. Multiple Sclerosis 2015;21(4):415-22. PUBMED: 25344370]

ETOMS 2001 \{published data only\}

Comi G, Filippi M, Barkhof F, Durelli L, Edan G, Fernández $\mathrm{O}$, et al. Effect of early interferon treatment on conversion to definite multiple sclerosis: a randomised study. Lancet 2001;357(9268):1576-82. PUBMED: $11377645]$

\section{GERONIMUS 2013 \{published data only\}}

D'Alessandro R, Vignatelli L, Lugaresi A, Baldin E, Granella F, Tola MR, et al. Risk of multiple sclerosis following clinically isolated syndrome: a 4-year prospective study. Journal of Neurology 2013;260(6):1583-93. PUBMED: 23377434]

Motamed 2007 \{published data only\} Motamed MR, Najimi N, Fereshtehnejad SM. The effect of interferon-beta-1a on relapses and progression of disability in patients with clinically isolated syndromes (CIS) suggestive of multiple sclerosis. Clinical Neurology and Neurosurgery 2007;109(4):344-9. PUBMED: 17300863]

MSBASIS 2016 \{published data only\} Spelman T, Meyniel C, Rojas JI, Lugaresi A, Izquierdo G, Grand'Maison F, et al. Quantifying risk of early relapse in patients with first demyelinating events: prediction in clinical practice. Multiple Sclerosis Journal 2016;1:1-12. PUBMED: 27885062]

ORACLE 2014 \{published data only\}

Leist TP, Comi G, Cree BA, Coyle PK, Freedman MS, Hartung HP, et al. Effect of oral cladribine on time to conversion to clinically definite multiple sclerosis in patients with a first demyelinating event (ORACLE MS): a phase 3 randomised trial. Lancet Neurology 2014;13(3):257-67. PUBMED: 24502830]

Pakdaman 2007 \{published data only\} Pakdaman H, Sahraian MA, Fallah A, Pakdaman R, Ghareghozli K, Ghafarpour M, et al. Effect of early interferon beta-1a therapy on conversion to multiple sclerosis in Iranian patients with a first demyelinating event. Acta Neurologica Scandinavica 2007;115(6):429-31. PUBMED: 17511854]

\section{PRECISE 2009 \{published data only\}}

Comi G, Martinelli V, Rodegher M, Moiola L, Bajenaru O, Carra A, et al. Effect of glatiramer acetate on conversion to clinically definite multiple sclerosis in patients with clinically isolated syndrome (PreCISe study): a randomised, double-blind, placebo-controlled trial. Lancet 2009;374 (9700):1503-11. PUBMED: 19815268]

PRECISE 2013 (5 years FU) \{published data only\} Comi G, Martinelli V, Rodegher M, Moiola L, Leocani L, Bajenaru $\mathrm{O}$, et al. Effects of early treatment with glatiramer acetate in patients with clinically isolated syndrome. Multiple Sclerosis 2013;19(8):1074-83. PUBMED: 23234810]

\section{REFLEX 2012 \{published data only\}}

Comi G, De Stefano N, Freedman MS, Barkhof F, Polman $\mathrm{CH}$, Uitdehaag BM, et al. Comparison of two dosing frequencies of subcutaneous interferon beta- $1 \mathrm{a}$ in patients with a first clinical demyelinating event suggestive of multiple sclerosis (REFLEX): a phase 3 randomised controlled trial. Lancet Neurology 2012;11(1):33-41. PUBMED: 22146409]

REFLEX 2016 (3 and 5 years FU) \{published data only\} Comi G, De Stefano N, Freedman M, Barkhof F, Uitdehaag $\mathrm{B}$, de Vos M, et al. Subcutaneous interferon $\beta$-1a in the treatment of clinically isolated syndromes: 3 -year and 5 -year results of the phase III dosing frequency-blind multicentre REFLEXION study. Journal of Neurology, Neurosurgery, and Psychiatry 2016;88(4):285-94. PUBMED: 28039317]

Tintore 2015 \{published data only\}

Tintore M, Rovira À, Río J, Otero-Romero S, Arrambide $\mathrm{G}$, Tur $\mathrm{C}$, et al. Defining high, medium and low impact prognostic factors for developing multiple sclerosis. Brain 2015;138:1863-74. PUBMED: 25902415]

\section{TOPIC 2014 \{published data only\}}

Miller AE, Wolinsky JS, Kappos L, Comi G, Freedman MS, Olsson TP, et al. Oral teriflunomide for patients with a first clinical episode suggestive of multiple sclerosis (TOPIC): a randomised, double-blind, placebo-controlled, phase 3 trial. Lancet Neurology 2014;13(10):977-86. PUBMED: 25192851]

\section{References to studies excluded from this review}

\section{BENEFIT 2007 \{published data only\}} Barkhof F, Polman CH, Radue EW, Kappos L, Freedman MS, Edan G, et al. Magnetic resonance imaging effects of interferon beta- $1 \mathrm{~b}$ in the BENEFIT study: integrated 2-year results. Archives of Neurology 2007;64(9):1292-8. PUBMED: 17846268]

\section{BENEFIT 2008 \{published data only\}} Polman C, Kappos L, Freedman MS, Edan G, Hartung HP, Miller DH, et al. Subgroups of the BENEFIT study: risk of developing MS and treatment effect of interferon beta1b. Journal of Neurology 2008;255(4):480-7. PUBMED: 18004635] 
BENEFIT 2011 \{published data only\}

Hartung HP, Freedman MS, Polman CH, Edan G, Kappos $\mathrm{L}$, Miller $\mathrm{DH}$, et al. Interferon $\beta$-1b-neutralizing antibodies 5 years after clinically isolated syndrome. Neurology 2011; 77(9):835-43. PUBMED: 21849647]

\section{BENEFIT 2012 \{published data only\}}

Penner IK, Stemper B, Calabrese P, Freedman MS, Polman CH, Edan G, et al. Effects of interferon beta$1 \mathrm{~b}$ on cognitive performance in patients with a first event suggestive of multiple sclerosis. Multiple Sclerosis 2012;18 (10):1466-71. PUBMED: 22492127]

BENEFIT 2014a \{published data only\} Ascherio A, Munger KL, White R, Köchert K, Simon KC, Polman $\mathrm{CH}$, et al. Vitamin $\mathrm{D}$ as an early predictor of multiple sclerosis activity and progression. JAMA 2014;71 (3):306-14. PUBMED: 24445558]

BENEFIT 2014b \{published data only\}

Nagtegaal GJ, Pohl C, Wattjes MP, Hulst HE, Freedman MS, Hartung HP, et al. Interferon beta- $1 \mathrm{~b}$ reduces black holes in a randomised trial of clinically isolated syndrome. Multiple Sclerosis 2014;20(2):234-42. PUBMED: 23842212]

CHAMPIONS 2015 \{published data only\} Simon JH, Kinkel RP, Kollman C, O'Connor P, Fisher E, You X, et al. Ten-year follow-up of the 'minimal MRI lesion' subgroup from the original CHAMPS Multiple Sclerosis Prevention Trial. Multiple Sclerosis 2015;21(4):415-22. PUBMED: 25344370 ]

CHAMPS 2001 \{published data only\} CHAMPS Study Group. Interferon -1a for optic neuritis patients at high risk for multiple sclerosis. American Journal of Ophthalmology 2001;132(4):463-71. PUBMED: 11589865]

CHAMPS 2002a \{published data only\}

CHAMPS Study Group. Predictors of short-term disease activity following a first clinical demyelinating event: analysis of the CHAMPS placebo group. Multiple Sclerosis 2002;8(5):405-9. PUBMED: 12356207]

CHAMPS 2002b \{published data only\} Beck RW, Chandler DL, Cole SR, Simon JH, Jacobs LD, Kinkel RP, et al. Interferon beta-1a for early multiple sclerosis: CHAMPS trial subgroup analyses. Annals of Neurology 2002;51(4):481-90. PUBMED: 11921054]

CHAMPS 2002c \{published data only\} CHAMPS Study Group. Baseline MRI characteristics of patients at high risk for multiple sclerosis: results from the CHAMPS trial. Multiple Sclerosis 2002;8(4):330-8. PUBMED: 12166504]

CHAMPS 2003 \{published data only\} O'Connor P. The effects of intramuscular interferon beta1a in patients at high risk for development of multiple sclerosis: a post hoc analysis of data from CHAMPS. Clinical Therapeutics 2003;25(11):2865-74. PUBMED: 14693310]

\section{CHAMPS 2009 \{published data only\}}

O'Connor P, Kinkel RP, Kremenchutzky M. Efficacy of intramuscular interferon beta-1a in patients with clinically isolated syndrome: analysis of subgroups based on new risk criteria. Multiple sclerosis 2009;15(6):728-34. PUBMED: 19482863]

\section{Curkendall 2011 \{published data only\}}

Curkendall SM, Wang C, Johnson BH, Cao Z, Preblick $\mathrm{R}$, Torres AM, et al. Potential health care cost savings associated with early treatment of multiple sclerosis using disease-modifying therapy. Clinical Therapeutics 2011;33 (7):914-25. PUBMED: 21684600]

\section{ETOMS 2003 \{published data only\}}

Barkhof F, Rocca M, Francis G, Van Waesberghe JH, Uitdehaag BM, Hommes OR, et al. Validation of diagnostic magnetic resonance imaging criteria for multiple sclerosis and response to interferon beta1a. Annals of Neurology 2003;53(6):718-24. PUBMED: 12783417]

\section{Filippi 2004 \{published data only\}}

Filippi M, Rovaris M, Inglese M, Barkhof F, De Stefano $\mathrm{N}$, Smith S, et al. Interferon beta-1a for brain tissue loss in patients at presentation with syndromes suggestive of multiple sclerosis: a randomised, double-blind, placebocontrolled trial. Lancet 2004;364(9444):1489-96. PUBMED: 15500893]

Kuhle 2015 \{published data only\} Kuhle J, Disanto G, Dobson R, Adiutori R, Bianchi L, Topping J, et al. Conversion from clinically isolated syndrome to multiple sclerosis: a large multicentre study. Multiple Sclerosis 2015;21(8):1013-24. PUBMED: 25680984]

\section{Lazzaro 2009 \{published data only\}}

Lazzaro C, Bianchi C, Peracino L, Zacchetti P, Uccelli A. Economic evaluation of treating clinically isolated syndrome and subsequent multiple sclerosis with interferon beta1b. Neurological Sciences 2009;30(1):21-31. PUBMED: 19169625]

Meyniel 2012 \{published data only\} Meyniel C, Spelman T, Jokubaitis VG, Trojano M, Izquierdo G, Grand'Maison F, et al. Country, sex, EDSS change and therapy choice independently predict treatment discontinuation in multiple sclerosis and clinically isolated syndrome. PLoS One 2012;7(6):e38661. PUBMED: 22768046]

Moraal 2009 \{published data only\} Moraal B, Pohl C, Uitdehaag BM, Polman CH, Edan G, Freedman MS, et al. Magnetic resonance imaging predictors of conversion to multiple sclerosis in the BENEFIT study. Archives of Neurology 2009;66(11):1345-52. PUBMED: 19901165]

Mowry 2009 \{published data only\} Mowry EM, Pesic M, Grimes B, Deen SR, Bacchetti P, Waubant E. Clinical predictors of early second event in patients with clinically isolated syndrome. Journal of Neurology 2009;256(7):1061-6. PUBMED: 19252775] 
MSBASIS 2015 \{published data only\}

Jokubaitis VG, Spelman T, Kalincik T, Izquierdo G, Grand'Maison F, Duquette P, et al. Predictors of disability worsening in clinically isolated syndrome. Annals of Clinical and Translational Neurology 2015;2(5):479-91. PUBMED: 26000321]

REFLEX 2014a \{published data only\}

Freedman MS, De Stefano N, Barkhof F, Polman CH, Comi G, Uitdehaag BM, et al. Patient subgroup analyses of the treatment effect of subcutaneous interferon $\beta$-1a on development of multiple sclerosis in the randomized controlled REFLEX study. Journal of Neurology 2014;261 (3):490-9. PUBMED: 24413638]

REFLEX 2014b \{published data only\}

De Stefano N, Comi G, Kappos L, Freedman MS, Polman $\mathrm{CH}$, Uitdehaag BM, et al. Efficacy of subcutaneous interferon $\beta$-1a on MRI outcomes in a randomised controlled trial of patients with clinically isolated syndromes. Journal of Neurology Neurosurgery and Psychiatry 2914;85 (6):647-53. PUBMED: 24292999]

SWISS COHORT STUDY 2013 \{published data only\}

Gobbi C, Zecca C, Linnebank M, Müller S, You X, Meier $\mathrm{R}$, et al. Swiss analysis of multiple sclerosis: a multicenter, non-interventional, retrospective cohort study of diseasemodifying therapies. European Neurology 2013;70(1-2): 35-41. PUBMED: 23689307]

SWISS COHORT STUDY 2016 \{published data only\} Disanto G, Benkert P, Lorscheider J, Mueller S, Vehoff J, Zecca C, et al. The Swiss Multiple Sclerosis CohortStudy (SMSC): a prospective Swiss wide investigation of key phases in disease evolution and new treatment options. PLoS One 2016;11(3):e0152347. PUBMED: 27032105]

\section{References to ongoing studies}

\section{NCT01013350 \{unpublished data only\}}

NCT01013350. Prospective observational long-term safety registry of multiple sclerosis patients who have participated in cladribine clinical trials (PREMIERE). (first received 11 November 2009).

NCT01371071 \{published and unpublished data\}

NCT01371071. Cohort study of clinically isolated syndrome and early multiple sclerosis (CIS-COHORT) [Clinically isolated syndrome and newly diagnosed multiple sclerosis: diagnostic, prognostic and therapy - response markers - a Prospective Observational Study (Berlin CIS-COHORT)]. clinicaltrials.gov/show/NCT01371071 (first received 8 June 2011).

\section{Additional references}

\section{Active Biotech 2014}

Active Biotech. Teva and Active Biotech remain committed to the development of NERVENTRA® (laquinimod) for multiple sclerosis following the negative opinion from the EMA's CHMP. www.activebiotech.com/press-releases-1? pressurl=http://cws.huginonline.com/A/1002/PR/201401/ 1756936.xml. (accessed 05 April 2017).

\section{Aharoni 2014}

Aharoni R. Immunomodulation neuroprotection and remyelination. The fundamental therapeutic effects of glatiramer acetate: a critical review. Journal of Autoimmunity 2014;54:81-92. [PUBMED: 24934599]

Broadley 2014

Broadley SA, Barnett MH, Boggild M, Brew BJ, Butzkueven $\mathrm{H}$, Heard R, et al. Therapeutic approaches to disease modifying therapy for multiple sclerosis in adults: an Australian and New Zealand perspective: part 3 treatment practicalities and recommendations. MS Neurology Group of the Australian and New Zealand Association of Neurologists. Journal of Clinical Neuroscience 2014;21(11): 1857-65. [PUBMED: 24993136]

\section{Chun 2010}

Chun J, Hartung HP. Mechanism of action of oral fingolimod (FTY720) in multiple sclerosis. Clinical Neuropharmacology 2010;33(2):91-101. [PUBMED: 20061941]

\section{Claussen 2012}

Claussen MC, Korn T. Immune mechanisms of new therapeutic strategies in MS: teriflunomide. Clinical Immunology 2012;142:49-56. [PUBMED: 21367665]

\section{Clerico 2008}

Clerico M, Faggiano F, Palace J, Rice G, Tintorè $M$, Durelli L. Recombinant interferon beta or glatiramer acetate for delaying conversion of the first demyelinating event to multiple sclerosis. Cochrane Database of Systematic Reviews 2008, Issue 2. [DOI: 10.1002/ 14651858.CD005278.pub3]

\section{Colombo 2014}

Colombo C, Mosconi P, Confalonieri P, Baroni I, Traversa $\mathrm{S}$, Hill SJ, et al. Web search behavior and information needs of people with multiple sclerosis: focus group study and analysis of online postings. Interactive Journal of Medical Research 2014;3(3):e12. [PUBMED: 25093374]

\section{Colombo 2016}

Colombo C, Filippini G, Synnot A, Hill S, Guglielmino R, Traversa S, et al. Development and assessment of a website presenting evidence-based information for people with multiple sclerosis: the IN-DEEP project. BMC Neurology 2016;16(1):30. [PUBMED: 26934873]

\section{EMA 2006}

European Medicines Agency. Committee for proprietary medicinal products European public assessment report: Tysabri. www.ema.europa.eu/ema/index.jsp?curl= pages/medicines/human/medicines/000603/wapp/ Post-authorisation/human 'wapp'000166.jsp\&mid= WC0b01ac058001d128 (accessed 05 April 2017).

\section{EMA 2011}

European Medicines Agency. Committee for proprietary medicinal products European public assessment report: Gilenya. www.ema.europa.eu/ema/index.jsp? curl=pages/medicines/human/medicines/002202/ human 'med'001433.jsp\&mid=WC0b01ac058001d124 (accessed 05 April 2017). 


\section{EMA 2013a}

European Medicines Agency. Committee for proprietary medicinal products European public assessment report: Aubagio. www.ema.europa.eu/ema/index.jsp? curl=pages $/$ medicines $/$ human/medicines $/ 002514 /$ human ' med' 001645.jsp\&mid=WC0b01ac058001d124 (accessed 05 April 2017).

\section{EMA 2013b}

European Medicines Agency. Committee for proprietary medicinal products European public assessment report: Lemtrada. www.ema.europa.eu/ema/index.jsp? curl=pages/medicines/human/medicines/003718/ human' ${ }^{\prime}$ ' 001678 .jsp\&mid=WC0b01ac058001d124 (accessed 05 April 2017).

\section{EMA 2014a}

European Medicines Agency. Committee for proprietary medicinal products European public assessment report: Tecfidera. www.ema.europa.eu/ema/index.jsp? curl=pages/medicines/human/medicines/002601/ human' med $001657 . j s p \&$ mid=WC0b01ac058001d124 (accessed 05 April 2017).

\section{EMA 2014b}

European Medicines Agency. Committee for proprietary medicinal products European public assessment report: Plegridy. www.ema.europa.eu/ema/index.jsp? curl=pages/medicines/human/medicines/002827/ human 'med' 001782.jsp\&mid=WC0b01ac058001d124 (accessed 05 April 2017).

\section{EMA 2014c}

European Medicines Agency. Refusal of the marketing authorisation for Nerventra (laquinimod). www.ema.europa.eu/docs/en 'GB/document library/ Summary 'of' opinion - ' Initial' authorisation/human/ 002546/WC500160120.pdf (accessed 05 April 2017).

EMA 2015a

European Medicines Agency. Guideline on clinical investigation of medicinal products for the treatment of multiple sclerosis. Committee for Medicinal Products for Human Use (CHMP). EMA/CHMP/771815/2011, Rev. 2. www.ema.europa.eu/docs/en GB/document library/ Scientific 'guideline/2015/03/WC500185161.pdf (accessed 05 April 2017).

\section{EMA 2015b}

European Medicines Agency. Refusal of the marketing authorization for Movectro (cladribine): outcome of re-examination. www.ema.europa.eu/docs/ en 'GB/document' library/Summary' of opinion 'Initial' authorisation/human/001197/WC500101072.pdf (accessed 05 April 2017).

\section{EMA 2016}

EMA. Marketing authorisation for the medicinal product Zinbryta. www.ema.europa.eu/docs/en 'GB/ document 'library/EPAR' - Product ' Information/human/ 003862/WC500210598.pdf (accessed 05 April 2017).
Faria 2015

Faria R, Hernandez Alava M, Manca A, Wailoo AJ. NICE DSU technical support document 17: the use of observational data to inform estimates of treatment effectiveness in technology appraisal: methods for comparative individual patient data. www.nicedsu.org.uk/TSD17\%20\%20DSU\%20Observational\%20data\%20FINAL.pdf (accessed 05 April 2017).

\section{FDA 2000}

U.S. Food, Drug Administration. Mitoxantrone (Novantrone) Product Approval Information - Licensing Action 2000. www.accessdata.fda.gov/drugsatfda docs/ nda/2000/21120.pdf' Novantrone Approv.pdf (accessed 05 April 2017).

\section{FDA 2006}

U.S. Food, Drug Administration. FDA approves resumed marketing of Tysabri under a special distribution program. www.fda.gov/ohrms/dockets/ac/06/briefing/ 2006-4208b1 $02 \cdot 01$ biogenbriefingmaterial.pdf (accessed 05 April 2017).

\section{FDA 2010}

U.S. Food, Drug Administration. Gilenya

(Fingolimod) Product Approval Information 2010. www.accessdata.fda.gov/drugsatfda docs/appletter/2010/ 022527s000ltr.pdf (accessed 05 April 2017).

\section{FDA 2012}

U.S. Food, Drug Administration. Aubagio (Teriflunomide) Product Approval Information 2012. www.accessdata.fda.gov/drugsatfda docs/appletter/2012/ 202992Orig1s000ltr.pdf (accessed 05 April 2017).

\section{FDA 2012a}

U.S. Food, Drug Administration. Avonex® (interferon beta-1a) intramuscular injection. Prescribing information. www.accessdata.fda.gov/drugsatfda docs/label/2012/ 103628s5191lbl.pdf (accessed 05 April 2017).

\section{FDA 2012b}

U.S. Food, Drug Administration. Betaseron ${ }^{\circledR}$ (interferon beta-1b). Prescribing information. www.accessdata.fda.gov/drugsatfda docs/label/2012/ 103471s5063s5067s5079s5088s5120s5124s5136s5138lbl.pdf (accessed 05 April 2017).

\section{FDA 2013}

U.S. Food, Drug Administration. Copaxone ${ }^{\circledR}$ (glatiramer acetate injection) solution for subcutaneous injection. www.accessdata.fda.gov/drugsatfda docs/label/2013/ 020622s087lbl.pdf (accessed 05 April 2017).

\section{FDA 2014a}

U.S. Food, Drug Administration. Alemtuzumab (Lemtrada) Product Approval Information. Licensing action 2014. www.accessdata.fda.gov/drugsatfda docs/ label/2014/103948s5139lbl.pdf (accessed 05 April 2017).

\section{FDA 2014b}

U.S. Food, Drug Administration. Peginterferon beta-1a (Plegridy) Product Approval Information. Licensing action 
2014. www.accessdata.fda.gov/drugsatfda docs/label/2014/ 125499lbl.pdf (accessed 05 April 2017).

\section{FDA 2016}

U.S. Food, Drug Administration. Zinbryta ${ }^{\mathrm{TM}}$ (daclizumab) injection, for subcutaneous use. Prescribing information. www.accessdata.fda.gov/drugsatfda docs/label/2016/ 761029s000lbl.pdf (accessed 13/04/2017).

\section{FDA 2017}

U.S. Food, Drug Administration. Ocrevus ${ }^{\mathrm{TM}}$ (ocrelizumab) injection, for intravenous use. Prescribing information. www.accessdata.fda.gov/drugsatfda docs/label/2017/ 761053lbl.pdf (accessed 13/04/2017).

\section{Filippi 2016}

Filippi M, Rocca MA, Ciccarelli O, De Stefano N, Evangelou N, Kappos L, et al. MRI criteria for the diagnosis of multiple sclerosis: MAGNIMS consensus guidelines. Lancet Neurology 2016;15(3):292-303. [DOI: 10.1016/ S1474-4422(15)00393-2]

Fox 2004

Fox E. Mechanism of action of mitoxantrone. Neurology 2004;12(12 Sppl 6):15-8. [PUBMED: 15623664]

\section{Freedman 2014}

Freedman MS, Comi G, De Stefano N, Barkhof F, Polman $\mathrm{CH}$, Uitdehaag BM, et al. Moving toward earlier treatment of multiple sclerosis: findings from a decade of clinical trials and implications for clinical practice. Multiple Sclerosis and Related Disorders 2014;3(2):147-55. [PUBMED: 25878002]

\section{Frischer 2009}

Frischer JM, Bramow S, Dal-Bianco A, Lucchinetti CF, Rauschka H, Schmidbauer M, et al. The relation between inflammation and neurodegeneration in multiple sclerosis brains. Brain 2009;132:1175-89. [PUBMED: 19339255]

\section{Goodin 2002}

Goodin DS, Frohman EM, Garmany GP Jr, Halper J, Likosky WH, Lublin FD, et al. Disease modifying therapies in multiple sclerosis: report of the therapeutics and technology assessment subcommittee of the American Academy of Neurology and the MS Council for Clinical Practice Guidelines. Neurology 2002;58(2):169-78. [PUBMED: 11805241]

\section{GRADE Working Group 2004}

GRADE Working Group. Grading quality of evidence and strength of recommendations. BMJ 2004;328(7454): 1490-4. [PUBMED: 15205295]

\section{Higgins 2003}

Higgins JP, Thompson SG, Deeks JJ, Altman DG. Measuring inconsistency in meta-analyses. BMJ 2003;327 (7414):557-60. [PUBMED: 12958120]

\section{Higgins 2008}

Higgins JP, White IR, Wood AM. Imputation methods for missing outcome data in meta-analysis of clinical trials. Clinical Trials 2008;5(3):225-39. [PUBMED: 18559412]

\section{Higgins 2011}

Higgins JPT, Altman DG, Sterne JAC (editors). Chapter 8: Assessing risk of bias in included studies. In: Higgins
JPT, Green S (editors). Cochrane Handbook for Systematic Reviews of Interventions Version 5.1.0 (updated March 2011). The Cochrane Collaboration, 2011. Available from handbook.cochrane.org.

\section{Hill 2012}

Hill S, Filippini G, Synnot A, Summers M, Beecher D, Colombo C, et al. Presenting evidence-based health information for people with multiple sclerosis: the INDEEP project protocol. BMC Medical Informatics and Decision Making 2012;12:20. [PUBMED: 22424304]

\section{Hu 2012}

Hu X, Miller L, Richman S, Hitchman S, Glick G, Liu S, et al. A novel PEGylated interferon beta-1a for multiple sclerosis: safety, pharmacology, and biology. Journal of Clinical Pharmacology 2012;52(6):798-808. [PUBMED: 21680782]

\section{Jansen 2013}

Jansen JP, Naci H. Is network meta-analysis as valid as standard pairwise meta-analysis? It all depends on the distribution of effect modifiers. BMC Medicine 2013;4(11): 1-8. [PUBMED: 23826681]

\section{Kappos 2011}

Kappos L, Calabresi PA, O'Connor P, Bar-Or A, Barkhof F, Yin $\mathrm{M}$, et al. Ocrelizumab in relapsing-remitting multiple sclerosis: a phase 2, randomised, placebo-controlled, multicentre trial. Lancet 2011;378(9805):1779-87. [PUBMED: 22047971]

\section{Kieseier 2011}

Kieseier BC. The mechanism of action of interferon- $\beta$ in relapsing multiple sclerosis. CNS Drugs 2011;25(6): 491-502. [PUBMED: 21649449]

\section{Kurtzke 1983}

Kurtzke J. Rating neurologic impairment in multiple sclerosis: an Expanded Disability Status Scale (EDSS). Neurology 1983;33(11):1444-52. [PUBMED: 6685237]

\section{Leist 2011}

Leist TP, Weissert R. Cladribine: mode of action and implications for treatment of multiple sclerosis. Clinical Neuropharmacology 2011;34(1):28-35. [PUBMED: 21242742]

\section{Linker 2011}

Linker RA, Lee DH, Ryan S, Van Dam AM, Conrad R, Bista P, et al. Fumaric acid esters exert neuroprotective effects in neuroinflammation via activation of the Nrf2 antioxidant pathway. Brain 2011;134(3):678-92. [PUBMED: 21354971]

\section{Lycke 2015}

Lycke J. Monoclonal antibody therapies for the treatment of relapsing-remitting multiple sclerosis: differentiating mechanisms and clinical outcomes. Therapeutic Advances in Neurological Disorders 2015;8(6):274-93. [PUBMED: 26600872]

\section{Millard 2011}

Millard M, Odde S, Neamati N. Integrin targeted therapeutics. Theranostics 2011;17(1):154-88. [PUBMED: 21547158] 


\section{Murphy 2010}

Murphy JA, Harris JA, Crannage AJ. Potential short-term use of oral cladribine in treatment of relapsing-remitting multiple sclerosis. Neuropsychiatric Disease and Treatment 2010;5(6):619-25. [PUBMED: 20957121]

\section{Naismith 2010}

Naismith R, Piccio L, Lyons J, Lauber J, Tutlam N, Parks B, et al. Rituximab add-on therapy for breakthrough relapsing multiple sclerosis: a 52-week phase II trial. Neurology 2010; 74(23):1860-7. [PUBMED: 20530322]

\section{NHS England 2014}

NHS England Clinical Reference Group for Neurosciences. Clinical commissioning policy: disease modifying therapies for patients with multiple sclerosis (MS). www.england.nhs.uk/wp-content/uploads/2013/10/d04-pb.pdf (accessed 13 April 2016).

Oh 2013

Oh J, O'Connor PW. An update of teriflunomide for treatment of multiple sclerosis. Therapeutics and Clinical Risk Management 2013;9:177-90. [PUBMED: 23761970]

\section{Pakpoor 2015}

Pakpoor J, Disanto G, Altmann DR, Pavitt S, Turner BP, Marta M, et al. No evidence for higher risk of cancer in patients with multiple sclerosis taking cladribine. Neurology Neuroimmunology \& Neuroinflammation 2015;2(6):e158. [PUBMED: 26468472]

Palace 2013

Palace J. Partnership and consent in MS treatment choice. Journal of the Neurological Sciences 2013;335:5-8. [PUBMED: 24090756]

\section{Polman 2011}

Polman C, Reingold S, Banwell B, Clanet M, Cohen J, Filippi M, et al. Diagnostic criteria for multiple sclerosis: 2010 revisions to the McDonald criteria. Annals of Neurology 2011;69(2):292-302. [PUBMED: 21387374]

\section{Poser 1983}

Poser CM, Paty DW, Scheinberg L, McDonald WI, Davis FA, Ebers GC, et al. New diagnostic criteria for multiple sclerosis: guidelines for research protocols. Annals of Neurology 1983;13:227-31. [PUBMED: 6847134]

\section{RevMan 2017 [Computer program]}

Nordic Cochrane Centre, The Cochrane Collaboration. Review Manager 5 (RevMan 5). Version 5.3. Copenhagen: Nordic Cochrane Centre, The Cochrane Collaboration, 2017.

\section{Salanti 2012}

Salanti G. Indirect and mixed-treatment comparison, network, or multiple-treatments meta-analysis: many names, many benefits, many concerns for the next generation evidence synthesis tool. Research Synthesis Methods 2012;3(2):80. [PUBMED: 26062083]

Scalfari 2013

Scalfari A, Neuhaus A, Daumer M, Deluca G, Muraro P, Ebers G. Early relapses, onset of progression, and late outcome in multiple sclerosis. JAMA Neurology 2013;70(2): 214-22. [PUBMED: 23407713]

Schmied 2003

Schmied M, Duda PW, Krieger JI, Trollmo C, Hafler DA. In vitro evidence that subcutaneous administration of glatiramer acetate induces hyporesponsive $\mathrm{T}$ cells in patients with multiple sclerosis. Clinical Immunology 2003;106(3): 163-74. [PUBMED: 12706402]

\section{Schmitz 2013}

Schmitz S, Adams R, Walsh C. Incorporating data from various trial designs into a mixed treatment comparison model. Statistics in Medicine 2013;32(17):2935-49. [PUBMED: 23440610]

\section{Schunemann 2011}

Schünemann HJ, Oxman AD, Vist GE, Higgins JPT, Deeks JJ, Glasziou P, et al. Chapter 12: Interpreting results and drawing conclusions. In: Higgins JPT, Green $S$ (editors), Cochrane Handbook for Systematic Reviews of Interventions Version 5.1.0 (updated March 2011). The Cochrane Collaboration, 2011. Available from handbook.cochrane.org.

\section{Scolding 2015}

Scolding N, Barnes D, Cader S, Chataway J, Chaudhuri A, Coles A, et al. Association of British Neurologists: revised (2015) guidelines for prescribing disease-modifying treatments in multiple sclerosis. Practical Neurology 2015; 15(4):273-9. [PUBMED: 26101071]

Singh 2011

Singh JA, Wells GA, Christensen R, Tanjong Ghogomu E, Maxwell L, MacDonald JK, et al. Adverse effects of biologics: a network meta-analysis and Cochrane overview. Cochrane Database of Systematic Reviews 2011, Issue 2. [DOI: 10.1002/14651858.CD008794]

\section{Smith 2010}

Smith B, Carson S, Fu R, McDonagh M, Dana T, Chan BKS, et al. Drug Class Review: Disease-modifying Drugs for Multiple Sclerosis: Final Update 1 Report. 2010 Aug. Portland (OR): Oregon Health \& Science University, 2010. [PUBMED: 21348046 ]

\section{Stangel 1999}

Stangel M, Toyka K, Gold R. Mechanisms of high-dose intravenous immunoglobulins in demyelinating diseases. Archives of Neurology 1999;56(6):661-3. [PUBMED: 10369303]

\section{Sterne 2016}

Sterne JA, Hernán MA, Reeves BC, Savovi

ć J, Berkman ND, et al. ROBINS-I: a tool for assessing risk of bias in non-randomised studies of interventions. BMJ (Clinical Research Ed.) 2016; Vol. 355:i4919. [PUBMED: 27733354]

\section{Synnot 2014}

Synnot AJ, Hill SJ, Garner KA, Summers MP, Filippini G, Osborne $\mathrm{RH}$, et al. Online health information seeking: how people with multiple sclerosis find, assess and integrate 
treatment information to manage their health. Health

Expectations 2016;19(3):727-37. [PUBMED: 25165024]

Tiede 2003

Tiede I, Fritz G, Strand S, Poppe D, Dvorsky R, Strand D, et al. CD28-dependent Rac1 activation is the molecular target of azathioprine in primary human CD4+ T lymphocytes. The Journal of Clinical Investigation 2003;111:1133-45. [PUBMED: 12697733]

\section{Tramacere 2015}

Tramacere I, Del Giovane C, Salanti G, D'Amico R, Filippini G. Immunomodulators and immunosuppressants for relapsing-remitting multiple sclerosis: a network metaanalysis. Cochrane Database of Systematic Reviews 2015, Issue 9. [DOI: 10.1002/14651858.CD011381]

\section{Varrin-Doyer 2014}

Varrin-Doyer M, Zamvil SS, Schulze-Topphoff U.

Laquinimod, an up-and-coming immunomodulatory agent for treatment of multiple sclerosis. Experimental Neurology 2014;262:66-71. [PUBMED: 24731945]

\section{Verde 2015}

Verde PE, Ohmann C. Combining randomized and nonrandomized evidence in clinical research: a review of methods and applications. Research Synthesis Methods 2015; 6(1):45-62. [PUBMED: 26035469]

\section{White 2008}

White IR, Higgins JPT, Wood AM. Allowing for uncertainty due to missing data in meta-analysis. 1. Two-stage methods. Statistics in Medicine 2008;27(5):711-27. [PUBMED: 17703496]

\section{Wilms 2010}

Wilms H, Sievers J, Rickert U, Rostami-Yazdi M, Mrowietz U, Lucius R. Dimethyl fumarate inhibits microglial and astrocytic inflammation by suppressing the synthesis of nitric oxide, IL-1beta, TNF-alpha and IL-6 in an in-vitro model of brain inflammation. Journal of Neuroinflammation 2010;7(30):2-8. [PUBMED: 20482831]

\section{Wingerchuk 2014}

Wingerchuk DM, Carter JL. Multiple sclerosis: current and emerging disease-modifying therapies and treatment strategies. Mayo Clinic Proceedings 2014;89(2):225-40. [PUBMED: 24485135]

\section{Wuest 2011}

Wuest SC, Edwan JH, Martin JF, Han S, Perry JS, Cartagena $\mathrm{CM}$, et al. A role for interleukin-2 trans-presentation in dendritic cell-mediated $\mathrm{T}$ cell activation in humans, as revealed by daclizumab therapy. Nature Medicine 2011;17 (5):604-9. [PUBMED: 21532597]

* Indicates the major publication for the study 


\section{CHARACTERISTICS OF STUDIES}

\section{Characteristics of included studies [ordered by study ID]}

\section{Achiron 2004}

\begin{tabular}{ll} 
Methods & $\begin{array}{l}\text { RCT, parallel-group. Recruitment period: March 1998-March 2003. Countries: } 1 \text { (Israel) } \\
\text {. Centres: } 1\end{array}$ \\
\hline Participants & $\begin{array}{l}\mathrm{N}=91 . \text { Women } 74 \% \text {. Age, mean (range): } 34 \text { years (15-50 years) } \\
\text { Participants with a first neurological episode suggesting MS in the previous } 3 \text { months. } \\
\text { They had positive brain MRI according to Fazekas criteria }\end{array}$ \\
\hline
\end{tabular}

Interventions

Immunoglobulins $0.4 \mathrm{~g} / \mathrm{kg}$ body weight intravenously daily for 5 consecutive days followed by additional booster doses of immunoglobulins $0.4 \mathrm{~g} / \mathrm{kg}$ body weight intravenously daily once every 6 weeks for a period of 12 months $(\mathrm{N}=45)$

Placebo ( $0.9 \%$ saline) intravenously monthly for 12 months $(\mathrm{N}=46)$

\begin{tabular}{ll}
\hline Outcomes & $\begin{array}{l}\text { Conversion to CDMS, i.e. number of participants who experienced a second attack } \\
\text { within } 12 \text { months }\end{array}$ \\
\hline
\end{tabular}

The study was supported by a research grant from Omrix Biopharmaceuticals, Tel-Aviv,
Israel, which also supplied the study drugs. The authors have no financial relationship to
Omrix Biopharmaceuticals. All authors had full access to all the data and had the right
to publish all the data. The data were analysed by an independent statistician (p 1519-
$20)$

\begin{tabular}{|c|c|c|}
\hline Bias & Authors' judgement & Support for judgement \\
\hline $\begin{array}{l}\text { Random sequence generation (selection } \\
\text { bias) }\end{array}$ & Low risk & $\begin{array}{l}\text { A block-stratified randomisation procedure } \\
\text { (p 1516) }\end{array}$ \\
\hline Allocation concealment (selection bias) & Unclear risk & $\begin{array}{l}\text { "According to block-stratified randomisa- } \\
\text { tion, participants were randomly assigned } \\
\text { to each of the two treatment groups" (p } \\
\text { 1516) }\end{array}$ \\
\hline Other major baseline imbalance & Unclear risk & $\begin{array}{l}\text { The study appears to be free of sources of } \\
\text { bias related to major baseline imbalance } \\
\text { (Table 1; p 1517) }\end{array}$ \\
\hline $\begin{array}{l}\text { Blinding of participants and personnel } \\
\text { (performance bias) } \\
\text { All outcomes }\end{array}$ & Low risk & $\begin{array}{l}\text { "At the pharmacy, containers and tubing } \\
\text { of IVIg or saline were wrapped in sealed } \\
\text { opaque bags. The active treatment and } \\
\text { placebo were administered intravenously in } \\
\text { identical settings and regime" (p 1516) }\end{array}$ \\
\hline
\end{tabular}

Treatment with disease-modifying drugs for people with a first clinical attack suggestive of multiple sclerosis (Review) 


\section{Achiron 2004 (Continued)}

\begin{tabular}{|c|c|c|}
\hline $\begin{array}{l}\text { Blinding of outcome assessment (detection } \\
\text { bias) } \\
\text { All outcomes }\end{array}$ & Low risk & $\begin{array}{l}\text { "Each patient was evaluated by an exam- } \\
\text { ining neurologist who was unaware of the } \\
\text { patient's treatment assignment. Changes } \\
\text { on neurological examination to determine } \\
\text { whether a new relapse had occurred were } \\
\text { based on the neurological examination per- } \\
\text { formed by two evaluating neurologists both } \\
\text { unaware of treatment assignment" (p 1516) }\end{array}$ \\
\hline
\end{tabular}

Incomplete outcome data (attrition bias) Low risk All outcomes

Selective reporting (reporting bias)
High risk
One participant in the treated group and zero participants in the placebo group were lost to follow-up (Fig. 1, p 1516)

Disability-worsening that was included as a secondary outcome was not reported in the results

\section{ACISS 2010}

Methods Cohort study. Austrian MS participating centres: 29. Participant recruitment started in September 2003 and terminated in December 2005. Final participant follow-up visits in December 2007

Participants $\quad \mathrm{N}=296$. Women 72\%. Age, mean (sd): 32.5 (9.5) years. Participants with newly diagnosed CIS. The diagnosis of a CIS was based on the presence of signs and symptoms compatible with MS without evidence for any other CNS disorder which might have caused them (Miller 2008). Monofocal presentation 80\% (optic neuritis 29\%; spinal cord syndrome 27\%; brain stem 25\%; other 19\%). Multifocal presentation: 16\%. EDSS , median (range): 2.0 (0-6). Brain MRI, abnormal: $94 \%$ of participants. Oligoclonal antibodies in cerebrospinal fluid, positive: $82 \%$ of participants

Interventions Treatments for 163 participants who completed 2 years of observation were:

$\mathrm{N}=49$ treated with DMTs within 3 months of CIS onset (early treatment). INF- $ß$ 1a intramuscular: 76\%; INFßla subcutaneous and INF- $\beta$ 1b subcutaneous: $12 \%$ each; glatiramer acetate: $16 \%$; others: $4 \%$

$\mathrm{N}=59$ treated with DMTs between 3-24 months of follow-up (delayed treatment). IFNs: 76\%; glatiramer acetate 20\%; others: $4 \%$

$\mathrm{N}=55$ never treated up to 24 months of follow-up

Outcomes Proportion of participants who converted to CDMS. Number of relapses over 2 years. EDSS (median and range). Quality of life assessed globally with a VAS, which ranged from 0 (worst) to 100 (best). It was recorded at baseline and through the follow-up by the participant and the treating physician independently 
Methods

Participants
RCT, parallel-group. Recruitment period: February 2002-June 2003. Countries: $18 \mathrm{Eu}$ ropean countries, Israel and Canada. Centres: 98

\begin{tabular}{|c|c|}
\hline & $\begin{array}{l}\text { first neurological event suggestive of MS within } 2 \text { months after onset of the first event. } \\
\text { Presentation: monofocal } 52 \% \text { (optic neuritis } 17 \% \text {; spinal cord syndrome } 16 \% \text {; brain } \\
\text { stem or cerebellar syndrome } 12 \% \text {; other cerebral } 7 \% \text { ), or multifocal } 48 \% \text {. They had at } \\
\text { least two clinically silent lesions on their T2-weighted brain MRI scan with a size of at } \\
\text { least } 3 \mathrm{~mm} \text {, at least one of which being ovoid, periventricular, or infratentorial }\end{array}$ \\
\hline Interventions & $\begin{array}{l}\text { Interferon beta- } 1 \mathrm{~b} \text { (Betaseron) } 250 \mu \mathrm{g} \text { subcutaneous every other day for } 24 \text { months }(\mathrm{N}= \\
305) \\
\text { Placebo subcutaneous every other day for } 24 \text { months }(\mathrm{N}=182) \\
\text { Corticosteroid treatment of first relapse: } 71 \% \\
\text { Participants who converted to CDMS during the double-blind period were offered in- } \\
\text { terferon beta-1b } 250 \mu \text { subcutaneously every other day for up to } 5 \text { years from randomi- } \\
\text { sation. (BENEFIT } 2007 \text { ( } 3 \text { years FU) }(\mathrm{p} 390)\end{array}$ \\
\hline Outcomes & $\begin{array}{l}\text { Primary: time to conversion to CDMS represented by Kaplan-Meier estimates of the } \\
\text { cumulative percentage of participants with CDMS, defined by: 1) a relapse with clinical } \\
\text { evidence of at least one CNS lesion, and if the first presentation was monofocal distinct } \\
\text { from the lesion responsible for the CIS presentation, or } 2 \text { ) sustained progression by } 1.5 \\
\text { points on the EDSS reaching a total EDSS score of } 2.5 \text { and confirmed at a consecutive } \\
\text { visit } 3 \text { months later (slightly modified Poser criteria). The validity of CDMS diagnoses } \\
\text { was confirmed by a central committee }\end{array}$ \\
\hline
\end{tabular}

Funded by Schering AG. Four co-authors of Schering AG. Restriction description: any manuscript/abstract related to the study had to be submitted for review to the sponsor at least 90 days prior to publication (clinicalTrials.gov)

\section{Risk of bias}

\begin{tabular}{|c|c|c|}
\hline Bias & Authors' judgement & Support for judgement \\
\hline $\begin{array}{l}\text { Random sequence generation (selection } \\
\text { bias) }\end{array}$ & Low risk & $\begin{array}{l}\text { "A minimization procedure with an ele- } \\
\text { ment of chance was applied to minimize } \\
\text { imbalance of treatment groups for (se- } \\
\text { lected) factors with potential impact on the } \\
\text { risk of developing definite MS: steroid use } \\
\text { during the first clinical event; onset of the } \\
\text { first event as monofocal vs multifocal by } \\
\text { central assessment; number of T2 lesions } \\
\text { on the screening MRI" ( } p \text { 1243) }\end{array}$ \\
\hline Allocation concealment (selection bias) & Low risk & $\begin{array}{l}\text { Central randomisation in a } 5: 3 \text { ratio ( } p \\
1243 \text { ) }\end{array}$ \\
\hline
\end{tabular}


BENEFIT 2006 (Continued)

Other major baseline imbalance

Low risk
The study appears to be free of sources of bias related to major baseline imbalance (table $1 ; \mathrm{p}$ 1244)

Blinding of participants and personnel High risk (performance bias)

All outcomes

Blinding of outcome assessment (detection Unclear risk bias)

All outcomes

All outcomes

"After CDMS confirmation, all evaluations foreseen per protocol for the month 24/end-of-study visit were performed. At this end-of-study visit-without breaking the randomisation code-participants were given the option of participating in the follow-up study with open-label interferon beta- $1 b$ treatment" ( $p$ 1243). High risk of un-blinding after shifting to open-label active treatment during the randomised study

"Participants were instructed to cover injection sites during the examination by the masked evaluation neurologist". The diagnosis of CDMS had to be confirmed by a central committee whose masking was not reported ( $\mathrm{p}$ 1243)

Proportions and reasons of incomplete outcome data did not differ substantially across intervention groups. $437(89.7 \%)$ of the 487 randomised participants completed the study $(271(88.8 \%)$ of 305 allocated to IFNB- $1 \mathrm{~b}$ and $166(91.2 \%)$ of $182 \mathrm{al}-$ located to placebo). 34 (11.2\%) IFNB-1b participants did not complete the study: 13 did not receive IFNB-1b and were not followed; 8 adverse event; 3 lost to follow-up; 9 withdrawal by subject; 1 adverse event, then subject's withdrawal. $16(8.8 \%)$ placebo did not complete the study: 6 did not receive placebo and were not followed; 2 lost to follow-up; 7 withdrawal by subject; 1 fulfilled local definition and McDonald criteria

Selective reporting (reporting bias) Low risk
The study protocol was not available but it is clear that the published reports included all expected outcomes, including those that were pre-specified 
BENEFIT 2007 (3 years FU)

\begin{tabular}{ll} 
Methods & $\begin{array}{l}\text { OLE study of the BENEFIT } 2006 \text { (placebo-controlled phase of } 24 \text { months). Centres: } \\
97 \text { of the original } 98 \text { BENEFIT study sites }\end{array}$ \\
\hline Participants & $\mathrm{N}=418$. Women $71 \%$. Age, median: 30 years \\
\hline Interventions & $\begin{array}{l}\mathrm{N}=261 / 305 \text { originally randomised to Interferon beta- } 1 \mathrm{~b} 250 \mu \mathrm{g} \text { subcutaneous every } \\
\text { other day (early-treatment group). Active treatment exposure: } 36 \text { months } \\
\mathrm{N}=157 / 182 \text { originally randomised to placebo (delayed-treatment group). Active treat- } \\
\text { ment exposure: } 12 \text { months }\end{array}$ \\
\hline Outcomes & $\begin{array}{l}\text { Time to CDMS and time to confirmed disability progression measured by EDSS scale } \\
\text { at } 36 \text { months. Annualised relapse rate }\end{array}$ \\
\hline Notes & $\begin{array}{l}\text { Multivariate Cox regressions for time to CDMS and time to McDonald MS (steroid } \\
\text { use during the first clinical event, onset of disease (monofocal vs multifocal), age at } \\
\text { screening, sex, and number of T2 lesions and gadolinium-enhanced lesions at screening; } \\
\text { time to confirmed EDSS progression was adjusted (as preplanned) for T2-lesion volume } \\
\text { at screening) }\end{array}$
\end{tabular}

\section{Risk of bias}

\begin{tabular}{|c|c|c|}
\hline Bias & Authors' judgement & Support for judgement \\
\hline $\begin{array}{l}\text { Random sequence generation (selection } \\
\text { bias) }\end{array}$ & High risk & No random assignment to the OLE groups \\
\hline Allocation concealment (selection bias) & High risk & $\begin{array}{l}\text { No allocation concealment to the OLE } \\
\text { groups }\end{array}$ \\
\hline Other major baseline imbalance & Low risk & $\begin{array}{l}\text { Clinical characteristics were similar be- } \\
\text { tween the two groups }\end{array}$ \\
\hline $\begin{array}{l}\text { Blinding of participants and personnel } \\
\text { (performance bias) } \\
\text { All outcomes }\end{array}$ & High risk & Unblinding \\
\hline $\begin{array}{l}\text { Blinding of outcome assessment (detection } \\
\text { bias) } \\
\text { All outcomes }\end{array}$ & High risk & Unblinding \\
\hline $\begin{array}{l}\text { Incomplete outcome data (attrition bias) } \\
\text { All outcomes }\end{array}$ & Low risk & $\begin{array}{l}18 \% \text { and } 21 \% \text { of early and delayed treat- } \\
\text { ment groups, respectively, dropped out. } \\
\text { Proportions and reasons of missing partici- } \\
\text { pants did not differ substantially across in- } \\
\text { tervention groups }\end{array}$ \\
\hline Selective reporting (reporting bias) & High risk & Serious adverse events not reported \\
\hline
\end{tabular}

Treatment with disease-modifying drugs for people with a first clinical attack suggestive of multiple sclerosis (Review) 
BENEFIT 2009 (5 years FU)

\begin{tabular}{ll} 
Methods & $\begin{array}{l}\text { OLE study of the BENEFIT } 2006 \text { (placebo-controlled phase of } 24 \text { months). Centres: } \\
97 \text { of the original } 98 \text { BENEFIT study sites }\end{array}$ \\
\hline Participants & $\mathrm{N}=418$. Women $71 \%$. Age, median: 30 years \\
\hline Interventions & $\begin{array}{l}\mathrm{N}=261 / 305 \text { originally randomised to Interferon beta- } 1 \mathrm{~b} 250 \mu \mathrm{g} \text { subcutaneous every } \\
\text { other day (early-treatment group). Active treatment exposure: } 60 \text { months } \\
\mathrm{N}=157 / 182 \text { originally randomised to placebo (delayed-treatment group). Active treat- } \\
\text { ment exposure: } 36 \text { months }\end{array}$ \\
\hline Outcomes & $\begin{array}{l}\text { Time to CDMS and time to confirmed disability progression measured by EDSS scale } \\
\text { at } 60 \text { months. Annualised relapse rate and proportions with relapses }\end{array}$ \\
\hline Notes & $\begin{array}{l}\text { Adjusted Cox proportional hazards regression for time to conversion (steroid use during } \\
\text { the first clinical event, onset of disease (monofocal vs multifocal), age, sex, and number } \\
\text { of T2 lesions and gadolinium-enhancing lesions at screening) }\end{array}$
\end{tabular}

\section{Risk of bias}

\begin{tabular}{|c|c|c|}
\hline Bias & Authors' judgement & Support for judgement \\
\hline $\begin{array}{l}\text { Random sequence generation (selection } \\
\text { bias) }\end{array}$ & High risk & No random assignment to the OLE groups \\
\hline Allocation concealment (selection bias) & High risk & $\begin{array}{l}\text { No allocation concealment to the OLE } \\
\text { groups }\end{array}$ \\
\hline Other major baseline imbalance & Unclear risk & Insufficient information \\
\hline $\begin{array}{l}\text { Blinding of participants and personnel } \\
\text { (performance bias) } \\
\text { All outcomes }\end{array}$ & High risk & Unblinding \\
\hline $\begin{array}{l}\text { Blinding of outcome assessment (detection } \\
\text { bias) } \\
\text { All outcomes }\end{array}$ & High risk & Unblinding \\
\hline $\begin{array}{l}\text { Incomplete outcome data (attrition bias) } \\
\text { All outcomes }\end{array}$ & High risk & $\begin{array}{l}23 \% \text { and } 32 \% \text { of early and delayed treat- } \\
\text { ment groups, respectively, dropped out. } \\
\text { Proportions and reasons for missing par- } \\
\text { ticipants differed substantially across inter- } \\
\text { vention groups }\end{array}$ \\
\hline Selective reporting (reporting bias) & High risk & $\begin{array}{l}\text { Treatment discontinuation for adverse } \\
\text { events not reported }\end{array}$ \\
\hline
\end{tabular}

Treatment with disease-modifying drugs for people with a first clinical attack suggestive of multiple sclerosis (Review) 
BENEFIT 2014 (8.7 years FU)

\begin{tabular}{ll} 
Methods & $\begin{array}{l}\text { OLE study of the BENEFIT } 2006 \text { (placebo-controlled phase of } 24 \text { months). Centres: } \\
72 \text { of the original } 98 \text { BENEFIT study sites }\end{array}$ \\
\hline Participants & $\begin{array}{l}\mathrm{N}=284 \text { recruited from } 72 \text { of the } 97 \text { initial centres in the BENEFIT RCT. Women } 71 \% . \\
\text { Age, median: } 30 \text { years }\end{array}$ \\
\hline Interventions & $\begin{array}{l}\mathrm{N}=178 / 305 \text { originally randomised to Interferon beta- } 1 \mathrm{~b} 250 \mu \mathrm{g} \text { subcutaneous every } \\
\text { other day (early-treatment group). Active treatment exposure: } 60 \text { months } \\
\mathrm{N}=106 / 182 \text { originally randomised to placebo (delayed-treatment group). Active treat- } \\
\text { ment exposure: } 36 \text { months }\end{array}$ \\
\hline Outcomes & $\begin{array}{l}\text { Time to CDMS and time to confirmed disability progression measured by EDSS scale } \\
\text { at } 8.7 \text { years. Annualised relapse rate }\end{array}$ \\
\hline Notes & $\begin{array}{l}\text { Proportional hazards regression (covariates: randomised treatment, steroid use during } \\
\text { the first clinical event, type of disease onset and categorised number of T2 lesions on } \\
\text { BENEFITscreening MRI) }\end{array}$
\end{tabular}

\section{Risk of bias}

\begin{tabular}{|c|c|c|}
\hline Bias & Authors' judgement & Support for judgement \\
\hline $\begin{array}{l}\text { Random sequence generation (selection } \\
\text { bias) }\end{array}$ & High risk & No random assignment to the OLE groups \\
\hline Allocation concealment (selection bias) & High risk & $\begin{array}{l}\text { No allocation concealment to the OLE } \\
\text { groups }\end{array}$ \\
\hline Other major baseline imbalance & Unclear risk & Insufficient information \\
\hline $\begin{array}{l}\text { Blinding of participants and personnel } \\
\text { (performance bias) } \\
\text { All outcomes }\end{array}$ & High risk & Unblinding \\
\hline $\begin{array}{l}\text { Blinding of outcome assessment (detection } \\
\text { bias) } \\
\text { All outcomes }\end{array}$ & High risk & Unblinding \\
\hline $\begin{array}{l}\text { Incomplete outcome data (attrition bias) } \\
\text { All outcomes }\end{array}$ & High risk & $\begin{array}{l}48.5 \% \text { and } 44.5 \% \text { of early and delayed } \\
\text { treatment groups, respectively, dropped } \\
\text { out. Proportions and reasons for missing } \\
\text { participants differed substantially across in- } \\
\text { tervention groups }\end{array}$ \\
\hline Selective reporting (reporting bias) & High risk & $\begin{array}{l}\text { Treatment discontinuation for adverse } \\
\text { events not reported }\end{array}$ \\
\hline
\end{tabular}


BENEFIT 2016 (11 years FU)

\begin{tabular}{ll} 
Methods & $\begin{array}{l}\text { Following the OLE study, a prospective, comprehensive, 11-year, cross-sectional reassess- } \\
\text { ment of the BENEFIT } 2006 \text { (placebo-controlled phase of } 24 \text { months). Centres: } 66 \text { of } \\
\text { the original } 98 \text { BENEFIT study sites }\end{array}$ \\
\hline Participants & $\begin{array}{l}\mathrm{N}=278 \text { recruited from } 66 \text { of the } 97 \text { initial centres in the BENEFIT RCT. Women } 70 \% . \\
\text { Age, median: } 30 \text { years }\end{array}$ \\
\hline Interventions & $\begin{array}{l}\mathrm{N}=167 / 305 \text { originally randomised to Interferon beta-1b } 250 \mu \text { subcutaneous every } \\
\text { other day (early-treatment group). Active treatment exposure: } 60 \text { months }\end{array}$ \\
\hline $\begin{array}{l}\mathrm{N}=111 / 182 \text { originally randomised to placebo (delayed-treatment group). Active treat- } \\
\text { ment exposure: } 36 \text { months }\end{array}$ \\
\hline Outcomes & $\begin{array}{l}\text { Time to CDMS and time to confirmed disability progression measured by EDSS scale } \\
\text { at } 11 \text { years. Annualised relapse rate }\end{array}$ \\
\hline Notes & $\begin{array}{l}\text { Proportional hazards regression for time-to-event outcomes and generalised linear regres- } \\
\text { sion models. Steroid use during first event (yes or no), multifocal or monofocal onset of } \\
\text { disease, and number of T2 lesions at screening (2-4, 5-8, or } \geq 9) \text { included as the standard } \\
\text { set of covariates. An extended set of covariates that included number of gadolinium- } \\
\text { enhancing (Gd1) lesions at screening, age, and sex in addition to the standard covariates } \\
\text { was used for analysis of time to CDMS, time to first relapse, and ARR }\end{array}$ \\
\hline
\end{tabular}

\section{Risk of bias}

\begin{tabular}{l|l|l}
\hline Bias & Authors' judgement & Support for judgement \\
\hline $\begin{array}{l}\text { Random sequence generation (selection } \\
\text { bias) }\end{array}$ & High risk & No random assignment to the OLE groups \\
\hline $\begin{array}{l}\text { Allocation concealment (selection bias) } \\
\text { Other major baseline imbalance }\end{array}$ & High risk & No allocation concealment to the OLE \\
\hline $\begin{array}{l}\text { Blinding of participants and personnel } \\
\text { (performance bias) } \\
\text { All outcomes }\end{array}$ & High risk & Insufficient information \\
\hline $\begin{array}{l}\text { Blinding of outcome assessment (detection } \\
\text { bias) } \\
\text { All outcomes }\end{array}$ & High risk & Unblinding \\
\hline
\end{tabular}

Incomplete outcome data (attrition bias) High risk All outcomes
$45 \%$ and $39 \%$ of early and delayed treatment groups, respectively, dropped out. Proportions and reasons for missing participants differed substantially across intervention groups 
BENEFIT 2016 (11 years FU) (Continued)

Selective reporting (reporting bias) High risk

Treatment discontinuation for adverse events not reported

CHAMPS 2000

\begin{tabular}{ll} 
Methods & $\begin{array}{l}\text { RCT, parallel-group. Recruitment period: April 1996-March 2000. Countries: } 2 \text { (USA } \\
\text { and Canada). Centres: } 50\end{array}$ \\
\hline Participants & $\begin{array}{l}\mathrm{N}=383 . \text { Women } 75 \% \text {. Age, mean (range): } 33 \text { years (18-50 years). Participants with a } \\
\text { first isolated, well-defined neurologic event no more than } 27 \text { days before randomisation. } \\
\text { Monofocal presentation: } 70 \% \text { (optic neuritis } 50 \% \text {; spinal cord syndrome } 22 \% \text {; brain } \\
\text { stem or cerebellar syndrome } 28 \%) . \text { They had } 2 \text { or more clinically silent lesions of the } \\
\text { brain that were at least } 3 \mathrm{~mm} \text { in diameter on MRI scans (at least } 1 \text { lesion had to be } \\
\text { periventricular or ovoid) }\end{array}$
\end{tabular}

Interventions

Interferon beta-1a (Avonex) $30 \mu \mathrm{g}$ intramuscular once a week for 18 months $(\mathrm{N}=193)$

Placebo intramuscular once a week for 18 months $(\mathrm{N}=190)$

All participants (100\%) received corticosteroid treatment (18 days)

Acetaminophen (paracetamol) $650 \mathrm{mg}$ before and after each injection during the first 6 months of treatment

Outcomes

Primary: conversion to CDMS as defined by: 1) a new clinical abnormality consistent with the participant's report of neurological or visual symptom distinct from that of the initial episode at study entry or: 2) worsening by 1.5 points on the EDSS confirmed at a consecutive visit 3 months later (slightly modified Poser criteria)

Notes

Funded by Biogen. Stopped after 18-month interim analysis

Risk of bias

\begin{tabular}{l|l} 
Bias Authors' judgement & Support for judgement
\end{tabular}

Random sequence generation (selection Low risk bias)

"To assign participants randomly in approximately equal numbers to the two treatment groups, we used a minimization procedure to minimize imbalance of treatment groups for (selected) factors the number of lesions on T2-weighted MRI scans and the type of initial clinical event" (p 899)

\begin{tabular}{l|ll}
\hline Allocation concealment (selection bias) & Unclear risk & No information \\
\hline Other major baseline imbalance & Low risk & $\begin{array}{l}\text { The study appears to be free of sources of } \\
\text { bias related to major baseline imbalance }\end{array}$ \\
\hline $\begin{array}{l}\text { Blinding of participants and personnel } \\
\text { (performance bias) } \\
\text { All outcomes }\end{array}$ & Unclear risk & $\begin{array}{l}\text { Unclear risk of unblinding because it is un- } \\
\text { clear if participants could have shifted to ac- } \\
\text { tive treatment during the randomised study }\end{array}$
\end{tabular}

Treatment with disease-modifying drugs for people with a first clinical attack suggestive of multiple sclerosis (Review)

Copyright () 2017 The Cochrane Collaboration. Published by John Wiley \& Sons, Ltd. 
CHAMPS 2000 (Continued)

\begin{tabular}{|c|c|c|}
\hline $\begin{array}{l}\text { Blinding of outcome assessment (detection } \\
\text { bias) } \\
\text { All outcomes }\end{array}$ & Low risk & $\begin{array}{l}\text { "Each patient was examined by a treat- } \\
\text { ing and an examining neurologist, both of } \\
\text { whom were unaware of the patient's treat- } \\
\text { ment assignment (p 899). Clinical out- } \\
\text { comes were confirmed by a central end- } \\
\text { point committee whose members were un- } \\
\text { aware of the participants' treatment assign- } \\
\text { ments" (p 899) }\end{array}$ \\
\hline
\end{tabular}

Incomplete outcome data (attrition bias) High risk

All outcomes

Truncated. The study period was planned to be 3 years. It was stopped early after 18-month interim analysis of efficacy. 177 participants ( $46 \%$ of the randomised) $(80$ treated and 97 placebo) had completed the study. At 3 years, 30 withdrawals +83 interrupted $=113(58.5 \%)$ in interferon group; 27 withdrawals +66 interrupted $=93(48$. 9\%) in placebo group. (Fig. 1; p 902)

Selective reporting (reporting bias) Low risk

The study protocol was not available but the published reports included all expected outcomes, including those that were prespecified

CHAMPS 2006 (5 years FU)

Methods

OLE study of the CHAMPS 2000 (placebo-controlled phase of 36 months) Centres: 32 of the original 50 CHAMPS study sites

Participants

$\mathrm{N}=203$ recruited from 32 of the 50 initial centres in the CHAMPS trial. Women 77\% (early treatment), $74 \%$ delayed treatment. Age, mean: 35 years

Interventions

$\mathrm{N}=100 / 193$ originally randomised to interferon beta- $1 \mathrm{a}$ (Avonex) $30 \mu \mathrm{g}$ intramuscular once a week (early-treatment group). Active treatment exposure: 60 months $\mathrm{N}=103 / 190$ originally randomised to placebo (delayed-treatment group). Active treatment exposure: 24 months

Outcomes

Time to CDMS and time to confirmed disability progression measured by EDSS scale at 60 months. Annualised relapse rate

Notes

Multivariate model was used to adjust for recipient age, clinical centre, baseline brain MRI T2 lesion volume (log transformation), and the number of Gd lesions at baseline. Effect modification related to these factors was assessed with interaction terms in the model. Possible violations of the proportional hazards assumption were checked using time-dependent variables

Treatment with disease-modifying drugs for people with a first clinical attack suggestive of multiple sclerosis (Review) 
CHAMPS 2006 (5 years FU) (Continued)

\section{Risk of bias}

\begin{tabular}{|c|c|c|}
\hline Bias & Authors' judgement & Support for judgement \\
\hline $\begin{array}{l}\text { Random sequence generation (selection } \\
\text { bias) }\end{array}$ & High risk & No random assignment to the OLE groups \\
\hline Allocation concealment (selection bias) & High risk & $\begin{array}{l}\text { No allocation concealment to the OLE } \\
\text { groups }\end{array}$ \\
\hline Other major baseline imbalance & Low risk & $\begin{array}{l}\text { Demographic and clinical characteristics } \\
\text { were similar between the } 2 \text { groups }\end{array}$ \\
\hline $\begin{array}{l}\text { Blinding of participants and personnel } \\
\text { (performance bias) } \\
\text { All outcomes }\end{array}$ & High risk & Unblinding \\
\hline $\begin{array}{l}\text { Blinding of outcome assessment (detection } \\
\text { bias) } \\
\text { All outcomes }\end{array}$ & High risk & Unblinding \\
\hline $\begin{array}{l}\text { Incomplete outcome data (attrition bias) } \\
\text { All outcomes }\end{array}$ & High risk & $\begin{array}{l}50 \% \text { and } 51 \% \text { of early and delayed treat- } \\
\text { ment groups, respectively, dropped out. } \\
\text { Proportions and reasons for missing par- } \\
\text { ticipants differed substantially across inter- } \\
\text { vention groups }\end{array}$ \\
\hline Selective reporting (reporting bias) & High risk & $\begin{array}{l}\text { Treatment discontinuation for adverse } \\
\text { events and serious adverse events not re- } \\
\text { ported }\end{array}$ \\
\hline
\end{tabular}

CHAMPS 2012 (10 years FU)

$\begin{array}{ll}\text { Methods } & \text { OLE study of the CHAMPS } 2000 \text { (placebo-controlled phase of } 36 \text { months). Centres: } \\ & 24 \text { of the original } 50 \text { CHAMPS study sites }\end{array}$

24 of the original 50 CHAMPS study sites

Participants

$\mathrm{N}=155$ recruited from 24 of the 50 initial centres in the CHAMPS trial. Women $74 \%$ (early treatment), $72 \%$ delayed treatment. Age, mean: 35 years

Interventions

$\mathrm{N}=81 / 193$ originally randomised to interferon beta-1a (Avonex) $30 \mu \mathrm{g}$ intramuscular once a week (early-treatment group). Active treatment exposure: 120 months $\mathrm{N}=74 / 190$ originally randomised to placebo (delayed-treatment group). Active treatment exposure: 84 months

Outcomes

Time to CDMS and time to confirmed disability progression measured by EDSS scale at 60 months. Annualised relapse rate 
CHAMPS 2012 (10 years FU) (Continued)

\begin{tabular}{|c|c|c|}
\hline Notes & \multicolumn{2}{|c|}{$\begin{array}{l}\text { Multivariate model was used to adjust for recipient age, clinical centre, baseline brain } \\
\text { MRI T2 lesion volume (log transformation), and the number of Gd lesions at baseline. } \\
\text { Effect modification related to these factors was assessed with interaction terms in the } \\
\text { model. Possible violations of the proportional hazards assumption were checked using } \\
\text { time-dependent variables }\end{array}$} \\
\hline \multicolumn{3}{|l|}{ Risk of bias } \\
\hline Bias & Authors' judgement & Support for judgement \\
\hline $\begin{array}{l}\text { Random sequence generation (selection } \\
\text { bias) }\end{array}$ & High risk & No random assignment to the OLE groups \\
\hline Allocation concealment (selection bias) & High risk & $\begin{array}{l}\text { No allocation concealment to the OLE } \\
\text { groups }\end{array}$ \\
\hline Other major baseline imbalance & Unclear risk & $\begin{array}{l}\text { Insufficient information about clinical } \\
\text { characteristics of participants }\end{array}$ \\
\hline $\begin{array}{l}\text { Blinding of participants and personnel } \\
\text { (performance bias) } \\
\text { All outcomes }\end{array}$ & High risk & Unblinding \\
\hline $\begin{array}{l}\text { Blinding of outcome assessment (detection } \\
\text { bias) } \\
\text { All outcomes }\end{array}$ & High risk & Unblinding \\
\hline $\begin{array}{l}\text { Incomplete outcome data (attrition bias) } \\
\text { All outcomes }\end{array}$ & High risk & $\begin{array}{l}65 \% \text { and } 69 \% \text { of early and delayed treat- } \\
\text { ment groups, respectively, dropped out. } \\
\text { Proportions and reasons for missing par- } \\
\text { ticipants differed substantially across inter- } \\
\text { vention groups }\end{array}$ \\
\hline Selective reporting (reporting bias) & High risk & $\begin{array}{l}\text { Treatment discontinuation for adverse } \\
\text { events not reported }\end{array}$ \\
\hline
\end{tabular}

\section{ETOMS 2001}

Methods

Participants
RCT, parallel-group. Recruitment period: August 1995-July 1997. 14 countries in Europe. Centres: 57

$\mathrm{N}=309$. Women $64 \%$. Age, mean (range): 28 years (18-40 years)

Participants with a first neurological episode suggesting multiple sclerosis in the previous 3 months. Monofocal (61\%) or multifocal presentation. They had positive brain MRI for at least 4 white-matter lesions on the T2-weighted scans, or presence of at least 3 white-matter lesions, if at least one was infratentorial or enhancing after gadolinium 
ETOMS 2001 (Continued)

\begin{tabular}{|c|c|c|}
\hline Interventions & \multicolumn{2}{|c|}{$\begin{array}{l}\text { Interferon beta-1a (Rebif) } 22 \mu \mathrm{g} \text { subcutaneous once a week for } 24 \text { months }(\mathrm{N}=154) \\
\text { Placebo subcutaneous once a week for } 24 \text { months }(\mathrm{N}=155) \\
\text { Steroid use at first clinical demyelinating event: } 70 \% \\
\text { After the conversion to CDMS, the investigator discussed with the participant the pos- } \\
\text { sibility of starting open-label treatment with interferon beta-1a once weekly until the } \\
\text { completion of the trial (p 1577) }\end{array}$} \\
\hline Outcomes & \multicolumn{2}{|c|}{ Primary: conversion to CDMS defined according to Poser diagnostic criteria } \\
\hline Notes & \multicolumn{2}{|c|}{ Funded by Serono. COI of authors not reported } \\
\hline \multicolumn{3}{|l|}{ Risk of bias } \\
\hline Bias & Authors' judgement & Support for judgement \\
\hline $\begin{array}{l}\text { Random sequence generation (selection } \\
\text { bias) }\end{array}$ & Low risk & $\begin{array}{l}\text { "The treatment was assigned according to } \\
\text { a computer-generated randomisation list } \\
\text { stratified by centre" ( } \mathrm{p} \text { 1577) }\end{array}$ \\
\hline Allocation concealment (selection bias) & Unclear risk & No information \\
\hline Other major baseline imbalance & Low risk & $\begin{array}{l}\text { The study appears to be free of sources of } \\
\text { bias related to major baseline imbalance }\end{array}$ \\
\hline $\begin{array}{l}\text { Blinding of participants and personnel } \\
\text { (performance bias) } \\
\text { All outcomes }\end{array}$ & High risk & $\begin{array}{l}\text { "After the occurrence of the second exac- } \\
\text { erbation, as stipulated in the protocol, the } \\
\text { investigator discussed with the patient the } \\
\text { possibility of starting open-label treatment } \\
\text { with interferon beta-1a once weekly until } \\
\text { the completion of the trial". (p 1577) High } \\
\text { risk of unblinding after shifting to open-la- } \\
\text { bel active treatment during the randomised } \\
\text { study }\end{array}$ \\
\hline $\begin{array}{l}\text { Blinding of outcome assessment (detection } \\
\text { bias) } \\
\text { All outcomes }\end{array}$ & Unclear risk & $\begin{array}{l}\text { "At each study site, a treating physician was } \\
\text { responsible for the overall management of } \\
\text { the patient, including safety monitoring. } \\
\text { An evaluating physician was responsible } \\
\text { for all scheduled neurological examinations } \\
\text { and exacerbation follow-up. Two members } \\
\text { of the steering committee reviewed the doc- } \\
\text { umentation of all exacerbations and, by } \\
\text { consensus, classified them as confirmed or } \\
\text { unconfirmed" ( } p \text { 1577) }\end{array}$ \\
\hline
\end{tabular}

Incomplete outcome data (attrition bias) Low risk All outcomes
Proportions and reasons of incomplete outcome data did not differ substantially across intervention groups. 141 (91.6\%) of 154 
ETOMS 2001 (Continued)

participants in Interferon beta-1a and 137 (88.4\%) of 155 participants in the placebo group completed the study

Selective reporting (reporting bias) Low risk

The study protocol is available and all of the study's pre-specified (primary and secondary) outcomes have been reported

\section{GERONIMUS 2013}

Methods Prospective cohort study. Regione Emilia Romagna, Italy. MS participating centres: 22. Recruitment of participants from December 2004-June 2007. Censoring date: 31 March 2010

Participants $\quad \mathrm{N}=168$. Women 69\%. Age, mean (sd):33.0 (8.0) years. Participants with first symptom suggestive of an inflammatory demyelinating disorder of the central nervous system in the preceding 6 months. Monofocal presentation $73 \%$ (optic neuritis 29\%; brain stem/cerebellar 21\%; cerebral or spinal 23\%). Multifocal presentation: 27\%. EDSS, median (range): 1.0 (0-6.5). Participants with MRI positive for $\geq 3$ Barkhof criteria: $60 \%$ of participants. Oligoclonal antibodies in cerebrospinal fluid, positive: $68 \%$ of participants

Interventions $\quad \mathrm{N}=31(18 \%)$ and $\mathrm{N}=51(30 \%)$ of participants were treated with disease-modifying drugs before or after conversion to CDMS. $\mathrm{N}=86$ not treated

$\mathrm{N}=67$ interferon; $\mathrm{N}=9$ glatiramer acetate; $\mathrm{N}=3$ intravenous immunoglobulin; $\mathrm{N}=2$ azathioprine; $\mathrm{N}=1$ mitoxantrone

$\mathrm{N}=18$ participants underwent at least one other treatment: natalizumab (10); glatiramer acetate (5); mitoxantrone (3); azathioprine (2); plasma exchange (1)

Outcomes CDMS according to Poser criteria. Follow-up 2 and 4 years

Notes Multivariate analysis was done using the Cox proportional-hazard regression model. Functional systems at onset were categorised as afferent (visual or sensitive or both), efferent (any of the others) or combined (afferent and efferent) ; Barkhof criteria were dichotomised as C3 of 4 (positive) versus B2 of 4 (negative). All the variables statistically significant in the univariate analysis for conversion to MS according to either McDonald criteria or CDMS criteria were simultaneously entered in the multivariate model, except the number of T2 lesions and GD positive lesions that are already included in Barkhof criteria. This study was supported with an unconditional grant by Biogen Idec

Motamed 2007

Methods

Participants
RCT. Recruitment period: October 2002-March 2005. Country: Iran. One centre

$\mathrm{N}=25$. Women 68\%. Age, mean (range): 25 years (17-39 years)

Participants with a first, isolated optic neuritis (32\%), spinal cord (28\%), brain stem $(24 \%)$ or cerebellar (16\%) syndrome, and which was confirmed on ophthalmologic or neurologic examination

Mean EDSS: $1.74(\mathrm{SD}=0.76)$

MRI scan judged to be positive according to McDonald criteria (revision of 2005) 


\section{Motamed 2007 (Continued)}

\begin{tabular}{|c|c|c|}
\hline Interventions & \multicolumn{2}{|c|}{$\begin{array}{l}N=11: \text { interferon beta-1a (Rebif) } 22 \mu \mathrm{g} \text { subcutaneous } 3 \text { times a week for } 21 \text { months } \\
N=14: \text { no disease-modifying treatment }\end{array}$} \\
\hline Outcomes & \multicolumn{2}{|c|}{$\begin{array}{l}\text { Worsening of disability measured by Kurtzke Expanded Disability Status Scale (EDSS) } \\
\text { and numbers of new relapses during } 21 \text { months of follow-up }\end{array}$} \\
\hline Notes & \multicolumn{2}{|c|}{ Sponsor not reported. Potential conflicts of interest of authors not reported } \\
\hline \multicolumn{3}{|l|}{ Risk of bias } \\
\hline Bias & Authors' judgement & Support for judgement \\
\hline $\begin{array}{l}\text { Random sequence generation (selection } \\
\text { bias) }\end{array}$ & Unclear risk & No information \\
\hline Allocation concealment (selection bias) & Unclear risk & No information \\
\hline Other major baseline imbalance & Unclear risk & $\begin{array}{l}\text { Baseline MRI findings imbalance. (Table 1; } \\
\text { p 346) }\end{array}$ \\
\hline $\begin{array}{l}\text { Blinding of participants and personnel } \\
\text { (performance bias) } \\
\text { All outcomes }\end{array}$ & High risk & Absence of blinding. ( $\mathrm{p} 348$ ) \\
\hline $\begin{array}{l}\text { Blinding of outcome assessment (detection } \\
\text { bias) } \\
\text { All outcomes }\end{array}$ & High risk & Absence of blinding. ( $\mathrm{p} 348$ ) \\
\hline $\begin{array}{l}\text { Incomplete outcome data (attrition bias) } \\
\text { All outcomes }\end{array}$ & Unclear risk & No information \\
\hline Selective reporting (reporting bias) & Unclear risk & No information \\
\hline
\end{tabular}

MSBASIS 2016

Methods Prospective cohort study (the MSBase Incident Study - MSBasis) from an international MSBase Registry. MSBasis started in November 2004. Centres: 50. Countries: 22

Participants $\quad \mathrm{N}=3296$. Women 70.5\%. Age, median (IQR): 31.6 (25.3-39.3) years. Registry participants with a CIS with symptom onset less than 12 months from the enrolment date. Clinical presentation: optic pathways 22\%; supratentorial 20. 5\%; brainstem 21.5\%; spinal cord syndrome 26\%). EDSS, median (IQR): 2.0 (1-2.5). Abnormal T1 and T2 MRI scans were recorded in $47 \%$ and $96 \%$ of participants, respectively. Oligoclonal antibodies in cerebrospinal fluid, positive: $32 \%$ of participants

Interventions $\quad \mathrm{N}=910(28 \%)$ participants were treated with intramuscular IFN $\beta$-1a (42.7\%), subcutaneous IFN $\beta$-1a (33.8\%), IFN $\beta$-1b (18.4\%), or glatiramer acetate (13.7\%)

$\mathrm{N}=2386(72 \%)$ were not exposed to disease-modifying drugs during follow-up 


\section{MSBASIS 2016 (Continued)}

Outcomes Primary outcome: time to CDMS, i.e. individualised risk of clinical conversion to CDMS at 12 months. CDMS defined as examination evidence of a symptomatic second neurological episode attributable to demyelination of more than 24 h' duration and more than 4 weeks from the initial attack (Poser criteria). $N=5378.70$ person-years contributed to outcome data

Notes All models presented were adjusted for country to control for any residual inter-country heterogeneity, for baseline and time-varying factors

The MSBasis study was supported by Merck Serono, between 2004 and 2009

\section{ORACLE 2014}

Methods RCT, parallel-group. Recruitment period: October 2008-October 2010. Countries: 34 (Argentina (2), Austria (2), Belgium (4), Bosnia and Herzegovina (1), Bulgaria (9), Canada (1), Croatia (2), Czech Republic (6), Estonia (2), Finland (4), France (3), Georgia (3), Germany (2), India (6), Italy (19), Korea (5), Lebanon (1), Macedonia (1), Norway (2), Poland (9), Portugal (4), Romania (4), Russia (25), Serbia (3), Singapore (1), Spain (2), Sweden (3), Taiwan (3), Thailand (1), Turkey (2), Ukraine (3), United Arab Emirates (1), UK (1), USA (23). Centres: 160

Participants $\mathrm{N}=617$. Women 65\%. Age, mean (range): 32 years (18-55 years). Presentation: monofocal 52\%; multifocal 48\%. Participants with a first clinical demyelinating event within 75 days before screening. They had an abnormal brain MRI consisting of at least two clinically silent T2-weighted MRI lesions, at least one of which was ovoid, periventricular, or infratentorial, of at least $3 \mathrm{~mm}$ in diameter

Interventions

Cladribine cumulative dose: $3.5 \mathrm{mg} / \mathrm{kg}$ body weight oral for 22 months $(\mathrm{N}=206)$

Cladribine cumulative dose: $5.25 \mathrm{mg} / \mathrm{kg}$ body weight oral for 22 months $(\mathrm{N}=205)$

Placebo oral tablets (undefined) oral for 22 months $(\mathrm{N}=206)$

Corticosteroid treatment of first relapse: $66 \%$

Participants who converted to CDMS during the double-blind period entered the openlabel maintenance period and were offered open-label treatment with subcutaneous interferon beta-1a, $44 \mu \mathrm{g} 3$ times weekly. participants who did not convert to CDMS were eligible to enter the long-term follow-up without study drug until conversion to MS according to the $2005 \mathrm{McDonald}$ criteria, when they were treated with open-label cladribine $3.5 \mathrm{mg} / \mathrm{kg}$ under the original design, or with subcutaneous interferon beta1a $44 \mu \mathrm{g}$ three times weekly after the protocol amendment due to the sponsor's decision to terminate development of oral cladribine. Participants converting to CDMS during long-term follow-up received interferon beta-1a $44 \mu \mathrm{g} 3$ times weekly. (p 258)

Outcomes

Primary: time to CDMS conversion represented by Kaplan-Meier estimates of the cumulative percentage of participants with CDMS (time frame: baseline up to month 22) defined according to Poser criteria, i.e. the occurrence of a second attack or a sustained increase in the expanded disability status scale (EDSS) score

Secondary: 1) time to develop MS conversion according to the revised McDonald Criteria (2005) represented by Kaplan-Meier estimates of the cumulative percentage of participants with McDonald MS (time frame: baseline up to month 22); 2) number of participants with adverse events and serious adverse events (time frame: baseline up to month 22) 
ORACLE 2014 (Continued)

Fotes
manded by Merck Serono SA Geneva, a subsidiary of Merck KGaA, Darmstadt, Ger-
study was designed by members of the steering committee and the sponsor. Data were
collected, analysed, and interpreted by the sponsor. All authors had access to the data
and contributed to data analysis and interpretation (p 261)

Risk of bias

\begin{tabular}{|c|c|c|}
\hline Bias & Authors' judgement & Support for judgement \\
\hline $\begin{array}{l}\text { Random sequence generation (selection } \\
\text { bias) }\end{array}$ & Low risk & $\begin{array}{l}\text { "Randomisation was done using a central } \\
\text { web-based randomisation system and was } \\
\text { stratified by geographic region". (p 258) }\end{array}$ \\
\hline Allocation concealment (selection bias) & Low risk & $\begin{array}{l}\text { A central web-based randomisation system. } \\
\text { (p 258) }\end{array}$ \\
\hline Other major baseline imbalance & Low risk & $\begin{array}{l}\text { The study appears to be free of sources of } \\
\text { bias related to major baseline imbalance }\end{array}$ \\
\hline $\begin{array}{l}\text { Blinding of participants and personnel } \\
\text { (performance bias) } \\
\text { All outcomes }\end{array}$ & High risk & $\begin{array}{l}\text { "Participants who converted to CDMS } \\
\text { during the double-blind period entered the } \\
\text { open-label maintenance period and were } \\
\text { offered open-label treatment with subcuta- } \\
\text { neous interferon beta- } 1 \mathrm{a}, 44 \mu \mathrm{g} \text { three times } \\
\text { weekly". (p 258) High risk of unblinding } \\
\text { after shifting to open-label active treatment } \\
\text { during the randomised study }\end{array}$ \\
\hline
\end{tabular}

Blinding of outcome assessment (detection Low risk bias)

All outcomes
"Masking was maintained using a twophysician model (both doctors were masked). The treating physician supervised study medication administration, and recorded and treated adverse events and MS relapses. The evaluating physician assessed all neurological findings and relapses, and was additionally masked to patient laboratory data. For every patient, conversion to CDMS required confirmation and approval by a sponsor-appointed, treatmentblinded study adjudication committee". (p 258)

Incomplete outcome data (attrition bias) High risk All outcomes
Truncated. The study period was planned to be 22 months. It was stopped early following the sponsor's decision to stop the cladribine programme (Supplementary web-appendix). 211 (34\%) of 614 ran- 


\begin{tabular}{|l|l|l}
\hline & $\begin{array}{l}\text { domised participants (104 Cladribine 5. } \\
25 \mathrm{mg} / \mathrm{kg} ; 131 \text { Cladribine } 3.5 \mathrm{mg} / \mathrm{kg} \text {; and } \\
104 \text { placebo) completed the study (Fig. 3; } \\
\mathrm{p} 262) \text {. The number excludes participants } \\
\text { who converted to CDMS during the dou- } \\
\text { ble-blind period, and therefore left the dou- } \\
\text { ble-blind period to enter the open-label } \\
\text { maintenance }\end{array}$ \\
\hline Selective reporting (reporting bias) & High risk & $\begin{array}{l}\text { In the original protocol, an analysis of dis- } \\
\text { ability-worsening was to be done in partic- } \\
\text { ipants who had converted to CDMS but, } \\
\text { owing to the early trial termination, the } \\
\text { sponsor decided before database lock, and } \\
\text { with an amended statistical analysis plan, } \\
\text { not to analyse time to disability-worsening. } \\
\text { (p 260) }\end{array}$ \\
\hline
\end{tabular}

Pakdaman 2007

Methods

Participants

Interventions

Outcomes

Notes
RCT, parallel-group. Recruitment period: February 2002-August 2005. Country: Iran. Centres: 4

$\mathrm{N}=217$. Women 68\%. Age, range: $19-50$ years. Participants with a first optic neuritis (48\%), spinal cord syndrome (24\%), brain stem or cerebellar syndrome $(22 \%)$ in the previous 3 months confirmed by neurologic examination. They had an abnormal brain MRI consisting of 2 or more clinically silent lesions that were at least $3 \mathrm{~mm}$ in diameter and at least 1 had to be periventricular or ovoid

Interferon beta-1a (Avonex) $30 \mu \mathrm{g}$ intramuscular once a week for 36 months ( $\mathrm{N}=104$ included in analysis)

Placebo (unspecified) for 36 months ( $\mathrm{N}=98$ included in analysis)

\begin{tabular}{ll}
\hline Outcomes & $\begin{array}{l}\text { Primary: time to conversion to CDMS as defined by the occurrence of a second exac- } \\
\text { erbation that was attributed to a part of central nervous system that differed from the } \\
\text { initial episode at study entry } \\
\text { Secondary: time to second exacerbation }\end{array}$ \\
\hline Notes & Sponsor not reported. Potential conflicts of interest of authors not reported \\
\hline
\end{tabular}

Risk of bias

\begin{tabular}{lll}
\hline Bias & Authors' judgement & Support for judgement \\
\hline $\begin{array}{l}\text { Random sequence generation (selection } \\
\text { bias) }\end{array}$ & Unclear risk & No information \\
\hline Allocation concealment (selection bias) & Unclear risk & No information
\end{tabular}

Treatment with disease-modifying drugs for people with a first clinical attack suggestive of multiple sclerosis (Review) 
Pakdaman 2007 (Continued)

Other major baseline imbalance Low risk

The study appears to be free of sources of bias related to major baseline imbalance (Table 1; p 430)

Blinding of participants and personnel Unclear risk

Insufficient information. Only "double (performance bias)

blind trial" is reported

All outcomes

Blinding of outcome assessment (detection Unclear risk

Insufficient information

bias)

All outcomes

Incomplete outcome data (attrition bias) Unclear risk

All outcomes

Of the 217 participants randomised, 202

(93\%) completed the study; 104 received interferon beta $1 \mathrm{a}$ and 98 received placebo. Data on participants in whom CDMS did not occur were censored on the date they were last seen by the neurologist. (p 430)

Selective reporting (reporting bias) High risk

Selective under-reporting of data: conversion to CDMS was reported but with inadequate detail for the data

\section{PRECISE 2009}

Methods

RCT, parallel-group. Recruitment period: January 2004-January 2006. 16 countries worldwide, in 80 centres from the USA, Europe, Argentina, Australia, and New Zealand

Participants

$\mathrm{N}=481$. Women 67\%. Age, mean (range): 31 years (18-45 years). Monofocal presentation: $100 \%$. Participants with one unifocal neurological event within 90 days after onset. They had positive brain MRI for at least 2 cerebral lesions on the T2-weighted images of at least $6 \mathrm{~mm}$ in diameter

Interventions

Glatiramer acetate (Copaxone) $20 \mu \mathrm{g}$ subcutaneous once a day for 36 months $(\mathrm{N}=243$ ) Placebo subcutaneous once a day for 36 months $(\mathrm{N}=238)$

Steroid use at first clinical demyelinating event: $64 \%$

Ibuprofen (400 mg) or paracetamol (acetaminophen) $(1000 \mathrm{mg}$ ) prophylactically with each injection during the first 3 months of treatment

All participants switched to active treatment with glatiramer acetate upon conversion to CDMS. (p 1506)

Outcomes

Primary: time to conversion to CDMS defined by: 1) a second event suggestive of MS lasting at least $48 \mathrm{~h}$ duration or: 2) worsening by 1.5 points on the EDSS confirmed at a consecutive visit 3 months later (slightly modified Poser criteria)

Notes

Funded by TEVA. The sponsor was involved in the study design, conduct, monitoring, data analysis, and writing of the report. The corresponding author had full access to all the data and had final responsibility for the decision to submit for publication ( $p$ 1507)

Treatment with disease-modifying drugs for people with a first clinical attack suggestive of multiple sclerosis (Review)

Copyright @ 2017 The Cochrane Collaboration. Published by John Wiley \& Sons, Ltd. 
PRECISE 2009 (Continued)

Restriction: should the investigator wish to publish the results of this study, he/she agrees to provide Teva with a manuscript for review 60 days prior to submission for publication. Teva retains the right to delete confidential information and to object to suggest publication and/or its timing (at the Company's sole discretion)

If Teva chooses to publish this study a copy will be provided to the investigator at least 30 days prior to the expected date of submission to the intended publisher (trial.gov)

\section{Risk of bias}

\begin{tabular}{|c|c|c|}
\hline Bias & Authors' judgement & Support for judgement \\
\hline $\begin{array}{l}\text { Random sequence generation (selection } \\
\text { bias) }\end{array}$ & Low risk & $\begin{array}{l}\text { "The randomisation scheme was produced } \\
\text { by the sponsor of the study with a } 1: 1 \text { as- } \\
\text { signment ratio. A SAS-based blocks with } \\
\text { block size of } 4 \text {, stratified by centre was } \\
\text { used". (p 1504) }\end{array}$ \\
\hline Allocation concealment (selection bias) & Unclear risk & No information \\
\hline Other major baseline imbalance & Low risk & $\begin{array}{l}\text { The study appears to be free of sources of } \\
\text { bias related to major baseline imbalance. } \\
\text { (table 2; p 1506) }\end{array}$ \\
\hline
\end{tabular}

Blinding of participants and personnel High risk (performance bias)

All outcomes
The criterion to enter the prospectively planned open label study phase was either a second relapse or the end of the double-blind phase, whichever came first. High risk of unblinding after shifting to open-label active treatment during the randomised study

Blinding of outcome assessment (detection Unclear risk bias)

All outcomes

Incomplete outcome data (attrition bias) High risk All outcomes
Unclear risk for blinding of clinical outcome assessment. "Treating and examining neurologists at the sites were masked to MRI results during the study. The unmasked statistician presented unmasked results to the Data Monitoring Committee, as per their request" ( $p$ 1504)

Truncated. The study period was planned to be 3 years. Based on the results of a planned interim analysis of efficacy and on the recommendations of the data monitoring committee (unmasked), the trial was stopped early and all participants were switched to glatiramer acetate. At the time of the interim analysis, $230(47.8 \%)$ of 481 randomised participants completed the study. $98(40.3 \%)$ of 243 treated par- 
PRECISE 2009 (Continued)

\begin{tabular}{|c|c|c|}
\hline & & $\begin{array}{l}\text { ticipants and } 132(55.5 \%) \text { of } 238 \text { placebo } \\
\text { completed the study. Proportion and rea- } \\
\text { sons of incomplete data differed between } \\
\text { the groups. } 39(16.0 \%) \text { of } 243 \text { participants } \\
\text { in the glatiramer group and } 23(8.8 \%) \\
\text { of } 238 \text { in the placebo group discontinued } \\
\text { treatment early (table } 1 \text {, p } 1505) \text { and the } \\
\text { proportion of termination because of ad- } \\
\text { verse events differed significantly between } \\
\text { the two treatment groups }\end{array}$ \\
\hline Selective reporting (reporting bias) & Low risk & $\begin{array}{l}\text { The study protocol was available and all of } \\
\text { the study's pre-specified primary outcomes } \\
\text { were reported }\end{array}$ \\
\hline
\end{tabular}

PRECISE 2013 (5 years FU)

Methods

Participants

Interventions

Notes
OLE study of the PRECISE 2009 (placebo-controlled phase of 36 months). Centres: 80 of the original 80 PRECISE study sites

$\mathrm{N}=409$. Women $69 \%$ and $65 \%$ in the early and delayed groups, respectively. Age, median: 30 years

$\mathrm{N}=198 / 243$ originally randomised to glatiramer acetate (early-treatment group). Active treatment exposure: 60 months

$\mathrm{N}=211 / 238$ originally randomised to placebo (delayed-treatment group). Active treatment exposure: 24 months

Time to CDMS and time to confirmed disability progression measured by EDSS scale at 60 months. Annualised relapse rate. Proportion of participants with relapses or disability progression

Risk of conversion to CDMS from a Cox's proportional hazards model was assessed for early-and delayed-treatment subgroups defined by demographics, characteristics of CIS (gender, age, presenting syndrome, steroid treatment for the initial attack) and MRI findings (disease dissemination and activity), at baseline

\section{Risk of bias}

\begin{tabular}{l|ll} 
Bias & Authors' judgement & Support for judgement \\
\hline $\begin{array}{l}\text { Random sequence generation (selection } \\
\text { bias) }\end{array}$ & High risk & No random assignment to the OLE groups \\
\hline $\begin{array}{l}\text { Allocation concealment (selection bias) } \\
\text { High risk }\end{array}$ & No allocation concealment to the OLE \\
groups
\end{tabular}


PRECISE 2013 (5 years FU) (Continued)

\begin{tabular}{l|l|l} 
Other major baseline imbalance & Unclear risk & $\begin{array}{l}\text { Clinical characteristics were similar be- } \\
\text { tween the two groups }\end{array}$ \\
\hline $\begin{array}{l}\text { Blinding of participants and personnel } \\
\text { (performance bias) } \\
\text { All outcomes }\end{array}$ & High risk & Unblinding \\
\hline $\begin{array}{l}\text { Blinding of outcome assessment (detection } \\
\text { bias) } \\
\text { All outcomes }\end{array}$ & High risk & Unblinding \\
\hline
\end{tabular}

Incomplete outcome data (attrition bias) High risk All outcomes
$33 \%$ and $47 \%$ of early and delayed treatment groups, respectively, dropped out. Proportions and reasons for missing participants differed substantially across intervention groups

Selective reporting (reporting bias) Low risk
Prespecified outcome were reported including adverse events and serious adverse events

\section{REFLEX 2012}

Methods

Participants

Interventions
RCT, parallel-group. Recruitment period: November 2006-August 2010. 28 countries in Europe and Canada. Centres: 78

$\mathrm{N}=517$. Women $64 \%$. Age, mean (range): 31 years (18-50 years). Participants with a single event suggestive of MS within 60 days before study entry. Presentation: monofocal $54 \%$; multifocal $46 \%$. They had at least two clinically silent lesions of $3 \mathrm{~mm}$ or more on T2-weighted brain MRI scan, at least one of which was ovoid, periventricular, or infratentorial

Interferon beta-1a (Rebif ) $44 \mu \mathrm{g}$ subcutaneous 3 times a week for 24 months $(\mathrm{N}=171)$ Interferon beta-1a (Rebif) $44 \mu \mathrm{g}$ subcutaneous once a week and placebo subcutaneous 2 times a week for 24 months $(\mathrm{N}=175)$

Placebo subcutaneous 3 times a week for 24 months $(\mathrm{N}=171)$

Steroid use at first clinical demyelinating event: $71 \%$

Ibuprofen $(400 \mathrm{mg})$ or paracetamol (acetaminophen) $(1000 \mathrm{mg})$ prophylactically with each injection during the first 3 months of treatment

On conversion to CDMS, participants were switched to open-label subcutaneous interferon beta- 1 a at $44 \mu \mathrm{g} 3$ times a week until the end of the 24 months

Outcomes

Primary: time to conversion to MS according to the McDonald Criteria (2005) to 24 months

Secondary: time to conversion to CDMS defined by either a second attack or a 3-month sustained increase ( $\geq$ to 1.5 points) in EDSS score (slightly modified Poser criteria) 


\begin{tabular}{ll} 
Notes & $\begin{array}{l}\text { Funded by Merck Serono. The study was designed by members of the steering committee } \\
\text { and the sponsor. The sponsor collected the data, did the analysis, and was involved in the } \\
\text { interpretation of the data. The data were available to all authors, and they contributed } \\
\text { to the analysis and interpretation of the data. The steering committee was responsible } \\
\text { for the final decision to submit this report for publication } \\
\text { Restriction: sponsor has the right to publish any results communication in connection } \\
\text { with the study. The PI shall submit any communications including study results to the } \\
\text { sponsor for review } 30 \text { working days prior to communication submission. The sponsor } \\
\text { can request the PI to modify or delete any sponsor's proprietary information. If the PI } \\
\text { refuses the modification, the submission shall be postponed for } 60 \text { days from PI refusal, } \\
\text { to provide the sponsor the opportunity to file a patent or seek legal remedies (trial.gov) }\end{array}$ \\
\hline
\end{tabular}

\section{Risk of bias}

\begin{tabular}{|c|c|c|}
\hline Bias & Authors' judgement & Support for judgement \\
\hline $\begin{array}{l}\text { Random sequence generation (selection } \\
\text { bias) }\end{array}$ & Low risk & $\begin{array}{l}\text { Central randomisation. "Randomisation } \\
\text { was stratified according to baseline factors: } \\
\text { age ( }<30 \text { years vs } \geq 30 \text { years), steroid use } \\
\text { for first event (yes vs no), classification of } \\
\text { first event (monofocal vs multifocal), and } \\
\text { at least one MRI gadolinium-enhancing le- } \\
\text { sion (yes vs no)". ( p 34) }\end{array}$ \\
\hline
\end{tabular}

Allocation concealment (selection bias) Low risk
"The study centre dialled a centralised interactive voice response system to randomly assign participants in a 1:1:1 ratio" (p 34) . "A treatment kit number, corresponding to the randomisation group, was allocated centrally to each patient for use only by that individual”. (p 34)
Other major baseline imbalance Low risk

Blinding of participants and personnel High risk (performance bias)

All outcomes
The study appears to be free of sources of bias related to major baseline imbalance. (table 1; p 36)

"On conversion to CDMS, participants were switched to open-label subcutaneous interferon beta-1a at $44 \mu \mathrm{g}$ three times a week until the end of the 24 months". (p 34) High risk of unblinding after shifting to open-label active treatment during the randomised study

Blinding of outcome assessment (detection Low risk bias)

All outcomes
"A two-physician (treating and assessing) model was used to assist with study masking. The treating physician was responsible for supervision of study drug admin- 
REFLEX 2012 (Continued)

istration and for recording adverse events and safety assessments. The assessing physician was not involved in the care of study participants and was exclusively responsible for all neurological assessments, beginning with the pre-study assessment. Injection sites were covered before a patient saw the assessing physician to maintain masking”. (p 34)

Incomplete outcome data (attrition bias) Low risk All outcomes

$448(87 \%)$ of the 517 randomised participants had completed the study: $146(85 \%)$ of 171 participants in interferon beta-1a 44 $\mu \mathrm{g} 3$ times a week; 156 (89\%) of 175 participants in interferon beta-1a $44 \mu \mathrm{g}$ once a week; 146 (85\%) of 171 in placebo. Proportion and reasons of withdrawn from study did not differ between the groups: 26 (15.2\%) of 171 participants in interferon beta-1a $44 \mu \mathrm{g} 3$ times a week; $20(11.4 \%)$ of 175 participants in interferon beta-1a 44 $\mu \mathrm{g}$ once a week; and 26 (15.2) of 171 in placebo

Selective reporting (reporting bias) Low risk

The study protocol was available and all of the study's pre-specified (primary and secondary) outcomes were reported

REFLEX 2016 (3 and 5 years FU)

Methods

OLE study of the REFLEX 2012 (placebo-controlled phase of 24 months). Centres: 70 of the original 78 REFLEX study sites

Participants

$\mathrm{N}=402$. Women $61 \%, 62 \%$ and $62 \%$ in the 3 groups, respectively. Age, mean: 31.4 (SD 8.3) years

Interventions

$\mathrm{N}=127 / 171$ originally randomised to sc IFN $\beta$-1a $44 \mathrm{mg}$ tiw (early-treatment group). Active treatment exposure: 60 months

$\mathrm{N}=142 / 175$ originally randomised to sc IFN $\beta$-1a $44 \mu \mathrm{g}$ qw (early-treatment group). Active treatment exposure: 60 months

$\mathrm{N}=133 / 171$ in the delayed-treatment arm (originally randomised to placebo). Active treatment exposure: 36 months

Outcomes

Time to CDMS conversion (defined in REFLEX 2012) from first randomisation to month 36; time to CDMS to month 60 (secondary end point). Proportion of participants remaining relapse-free; time to confirmed disability-worsening (increase of EDSS $\geq 1$.

0 point, confirmed during a visit 6 months later) and EDSS change from baseline

Treatment with disease-modifying drugs for people with a first clinical attack suggestive of multiple sclerosis (Review)

Copyright @ 2017 The Cochrane Collaboration. Published by John Wiley \& Sons, Ltd. 
REFLEX 2016 (3 and 5 years FU) (Continued)

$\begin{array}{ll}\text { Notes } & \begin{array}{l}\text { Probabilities of CDMS conversion, McDonald MS conversion and EDSS progression } \\ \text { over time were determined for each treatment group in the form of cumulative incidence } \\ \text { curves estimated using the non-parametric Kaplan-Meier method }\end{array}\end{array}$

\section{Risk of bias}

\begin{tabular}{|c|c|c|}
\hline Bias & Authors' judgement & Support for judgement \\
\hline $\begin{array}{l}\text { Random sequence generation (selection } \\
\text { bias) }\end{array}$ & High risk & No random assignment to theOLE groups \\
\hline Allocation concealment (selection bias) & High risk & $\begin{array}{l}\text { No allocation concealment to the OLE } \\
\text { groups }\end{array}$ \\
\hline Other major baseline imbalance & Unclear risk & $\begin{array}{l}\text { Insufficient information about clinical } \\
\text { characteristics of participants }\end{array}$ \\
\hline $\begin{array}{l}\text { Blinding of participants and personnel } \\
\text { (performance bias) } \\
\text { All outcomes }\end{array}$ & High risk & Unblinding \\
\hline $\begin{array}{l}\text { Blinding of outcome assessment (detection } \\
\text { bias) } \\
\text { All outcomes }\end{array}$ & High risk & Unblinding \\
\hline $\begin{array}{l}\text { Incomplete outcome data (attrition bias) } \\
\text { All outcomes }\end{array}$ & High risk & $\begin{array}{l}30 \%, 25 \% \text {, and } 29 \% \text { dropped out re- } \\
\text { spectively in early and delayed treatments } \\
\text { groups with different reasons. Not re- } \\
\text { ported reasons for discontinuation across } \\
\text { the groups }\end{array}$ \\
\hline Selective reporting (reporting bias) & Low risk & All expected outcomes were reported \\
\hline
\end{tabular}

Tintore 2015

Methods Prospective cohort study. Study started in January 1995 and the database was locked on 15 March 2013

Participants $\quad \mathrm{N}=1015$. Women 68\%. Age, mean (SD): 31.1(8.2) years. Monocentric. Participants with CIS that was suggestive of CNS demyelination and was not attributable to other diseases, with symptom onset within 3 months of the first clinical evaluation. Clinical topography at onset: optic neuritis 37\%; spinal cord syndrome 26\%; brain stem 27\%; other 11\%. EDSS , median (range): 2.0 (0-6). Brain MRI available for $94 \%$ of participants and abnormal in $69 \%$ of them. Oligoclonal antibodies in cerebrospinal fluid available for $79 \%$ of participants and positive in $57 \%$ of them $\mathrm{N}=1058$ enrolled

- $\mathrm{N}=43(4 \%)$ excluded for various reasons: previous attack $(\mathrm{N}=7)$, age over $50(\mathrm{~N}=4)$, exceeded entry window $(\mathrm{N}$

$=12)$, and alternative diagnosis $(\mathrm{N}=20)$

- $\mathrm{N}=1015$ included in analysis

- $\mathrm{N}=7(0.7 \%)$ died during follow-up: car accident $(\mathrm{N}=1)$, myocardial infarction $(\mathrm{N}=1)$, pancreatic cancer $(\mathrm{N}=$ $1)$, meningitis as a complication of septoplasty $(\mathrm{N}=1)$, septic shock in a participant with severe disability $(\mathrm{N}=1)$, 
Tintore 2015 (Continued)

cardiogenic shock of unknown origin $(\mathrm{N}=1)$ and acute leukemia in a participant who received mitoxantrone $(\mathrm{N}=$ 1)

Interventions $\quad \mathrm{N}=388(38.3 \%)$ of participants were on DMT at least once during follow-up (IFNs or glatiramer acetate)

$\mathrm{N}=174(45 \%)$ of participants were on DMTs prior to conversion to clinical definite MS (early treatment)

$\mathrm{N}=214(55 \%)$ of participants were on DMTs after conversion to CDMS (delayed treatment)

$\mathrm{N}=376(97 \%)$ of participants were on DMTs prior to reaching an EDSS score of 3.0

$\mathrm{N}=281(75.3 \%)$ of 375 participants with 3-4 Barkhof criteria at baseline received DMT, 143 (51\%) of those prior CDMS (early treatment), and 273 (97\%) prior to EDSS score of 3.0

The mean time to DMT was significantly shorter in the participants with CIS from 2002-2007 compared with those from 1995-2001 (15.2 months $\mathrm{SD}=21$ versus 41.5 months, $\mathrm{SD}=38, \mathrm{P}<0.001)$

Outcomes CDMS and disability-worsening (reaching EDSS score 3.0). Clinical follow-up duration, mean (SD) (range): 81 (57) (0.3-220) months

The participants were evaluated on a regular basis (every 3-6 months or annually depending on each participant's characteristics). The participants who did not attend two consecutive follow-up visits were defined as 'lost to followup'

Notes

Multivariate Cox proportional hazards regression analyses for the time to conversion to CDMS or McDonald. Covariates including age, gender, clinical topography, oligoclonal bands, MRI criteria (Barkhof criteria and the number of lesions) and DMT onset prior to the diagnosis of CDMS or McDonald 2005 multiple sclerosis criteria, depending on the outcome, were considered. Possible interactions between age, gender, topographic characteristics, the presence of oligoclonal bands, the number of lesions and DMT were also evaluated. DMT was used in these models as a time-dependent variable to take into account the date of treatment onset

This work is independent of all the funding bodies, which have played no part in any of its stages

\section{TOPIC 2014}

Methods RCT, parallel-group. Recruitment period: February 2008-August 2012. 20 countries in Europe, USA, Canada, and Australia. Centres: 112

Participants

$\mathrm{N}=618$. Women $68 \%$. Age, mean (range): 32 years (18-55 years). Presentation: monofocal 59\%; multifocal $41 \%$. Participants with a first acute or subacute optic neuritis, spinal cord syndrome, brain stem or cerebellar syndrome occurring within 3 months before randomisation. They had an abnormal brain MRI consisting of at least two T2weighted MRI lesions of at least $3 \mathrm{~mm}$ in diameter

Interventions

Teriflunomide $14 \mathrm{mg}$ oral capsule once daily for up to 25 months $(\mathrm{N}=216)$

Teriflunomide $7 \mathrm{mg}$ oral capsule once daily for up to 25 months $(\mathrm{N}=205)$

Placebo oral capsule once daily for 25 months $(\mathrm{N}=197)$

Previous systemic corticosteroid treatment: $14 \%$

Outcomes

Primary: conversion to CDMS as defined by the occurrence of a second relapse (Poser diagnostic criteria)

Secondary: time to relapse

Notes

Funder Sanofi, Genzyme. Data were obtained by the investigators and were analysed by the sponsor. Interpretation of the data was done by the sponsor and the authors. All

Treatment with disease-modifying drugs for people with a first clinical attack suggestive of multiple sclerosis (Review)

Copyright @ 2017 The Cochrane Collaboration. Published by John Wiley \& Sons, Ltd. 
TOPIC 2014

authors had full access to, and take responsibility for, the veracity of study data TOPIC was stopped on Aug 10, 2012, because the 2010 revisions of the MCDonald diagnostic criteria enabled an earlier diagnosis of multiple sclerosis, in some cases at first clinical event. Re-evaluation of the power calculation based on updated information from the teriflunomide clinical programme, especially from the TOWER study, indicated that sufficient power to detect a reduction in risk of relapse had already been achieved

\section{Risk of bias}

\begin{tabular}{|c|c|c|}
\hline Bias & Authors' judgement & Support for judgement \\
\hline $\begin{array}{l}\text { Random sequence generation (selection } \\
\text { bias) }\end{array}$ & Low risk & $\begin{array}{l}\text { "Randomisation was done centrally, by an } \\
\text { interactive voice recognition system that } \\
\text { generated an allocation sequence using } \\
\text { a permuted-block randomisation schedule } \\
\text { (block size of six) with stratification by } \\
\text { baseline monofocal or multifocal status". (p } \\
978)\end{array}$ \\
\hline Allocation concealment (selection bias) & Low risk & $\begin{array}{l}\text { "An independent company (ClinPhone, } \\
\text { Perceptive Informatics, Nottingham, UK) } \\
\text { ran and maintained the interactive voice } \\
\text { recognition system for the duration of the } \\
\text { study, under the responsibility of the study } \\
\text { funder. After a screening phase (up to } 4 \\
\text { weeks), investigators called the interactive } \\
\text { voice recognition system to receive a ran- } \\
\text { dom, masked treatment assignment for } \\
\text { each patient". (p 978) }\end{array}$ \\
\hline
\end{tabular}

Other major baseline imbalance Low risk

The study appears to be free of sources of bias related to major baseline imbalance. (table 1; p 980)

Blinding of participants and personnel High risk (performance bias)

Participants who had a relapse which deAll outcomes fined CDMS, and had been treated for at least 24 weeks, could also enter the OLE study. (p 978) High risk of unblinding after shifting to open-label active treatment during the randomised study

Blinding of outcome assessment (detection Unclear risk bias)

All outcomes
"A treating neurologist at each site assessed participant eligibility, supervised study drug administration, and did the safety assessments. An independent examining neurologist was responsible for all functional system and EDSS assessments. Relapses indicating CDMS were confirmed by the treating neurologist based on the ex- 
TOPIC 2014

amining neurologist's EDSS assessment" ( $\mathrm{p}$ 979)

Incomplete outcome data (attrition bias) High risk

All outcomes

Selective reporting (reporting bias)
Low risk
At least $41 \%$ and $45 \%$ in the treated groups and $40 \%$ in the placebo group were lost to follow-up (Fig. 2; p 980)

The study protocol is not available, however the published reports included all expected outcomes

CDMS: clinically definite multiple sclerosis; CIS: clinically isolated syndrome; CNS: central nervous system; DMT: disease-modifying treatment; EDSS: Expanded Disability Status Scale; h: hour; IFN: interferon; MRI: magnetic resonance imaging; MS: multiple sclerosis; N: number; OLE: open-label extension; VAS: visual analogue scale

Characteristics of excluded studies [ordered by study ID]

\begin{tabular}{|c|c|}
\hline Study & Reason for exclusion \\
\hline BENEFIT 2007 & $\begin{array}{l}\text { Subanalysis of BENEFIT } 2006 \text { to evaluate prognostic effect of MRI at baseline on conversion } \\
\text { to CDMS }\end{array}$ \\
\hline BENEFIT 2008 & $\begin{array}{l}\text { Subanalysis of BENEFIT } 2006 \text { trial to evaluate predictive effect of treatment in subgroups of } \\
\text { participants }\end{array}$ \\
\hline BENEFIT 2011 & $\begin{array}{l}\text { Subanalysis of BENEFIT } 2006 \text { trial to evaluate the frequency and consequences of neutralizing } \\
\text { antibodies in subgroups of participants }\end{array}$ \\
\hline BENEFIT 2012 & $\begin{array}{l}\text { Subanalysis of BENEFIT } 2006 \text { trial and open label extension ( } 5 \text { years) study to evaluate cognitive } \\
\text { performance in subgroups of participants }\end{array}$ \\
\hline BENEFIT 2014a & Subanalysis of BENEFIT 2006 trial to evaluate effect of Vitamin-D on conversion to CDMS \\
\hline BENEFIT 2014b & $\begin{array}{l}\text { Reanalysis of BENEFIT } 2006 \text { trial and OLE ( } 5 \text { years) study (BENEFIT } 2009 \text { ( } 5 \text { years FU)) to } \\
\text { evaluate predictive effect of treatment on persisting T1 hypointensities on MRI }\end{array}$ \\
\hline CHAMPIONS 2015 & $\begin{array}{l}\text { Reanalysis of CHAMPS } 2000 \text { trial and OLE ( } 10 \text { years) study (CHAMPS } 2012 \text { (10 years FU)) } \\
\text { to compare the } 10 \text {-year disease progression between subgroups of participants with different } \\
\text { baseline MRI characteristics (low and higher T2 lesion counts) }\end{array}$ \\
\hline CHAMPS 2001 & Subanalysis of CHAMPS 2000 trial in participants with a first clinical attack of optic neuritis \\
\hline CHAMPS 2002a & Subanalysis of CHAMPS 2000 trial in participants allocated to placebo group \\
\hline
\end{tabular}

Treatment with disease-modifying drugs for people with a first clinical attack suggestive of multiple sclerosis (Review) 


\begin{tabular}{l|l}
\hline CHAMPS 2002b & $\begin{array}{l}\text { Subanalysis of CHAMPS } 2000 \text { trial to evaluate predictive effect of baseline characteristics on } \\
\text { conversion to CDMS }\end{array}$ \\
\hline CHAMPS 2002c & $\begin{array}{l}\text { Subanalysis of CHAMPS } 2000 \text { trial to evaluate prognostic effect of MRI at baseline on conversion } \\
\text { to CDMS }\end{array}$ \\
\hline CHAMPS 2003 & $\begin{array}{l}\text { Subanalysis of CHAMPS } 2000 \text { trial to evaluate predictive effect of treatment in subgroups of } \\
\text { high risk participants }\end{array}$ \\
\hline CHAMPS 2009 & $\begin{array}{l}\text { Reanalysis of CHAMPS } 2000 \text { trial to evaluate predictive effect of treatment in subgroups of } \\
\text { participants with different baseline risk of disease progression }\end{array}$ \\
\hline
\end{tabular}

Curkendall 2011

Outcomes were not measured. A retrospective study using insurance claims data (2000-2008) of participants with a first clinical attack suggestive of MS. The objective of the study was to assess health care utilisation and expenditures associated with treating participants early with diseasemodifying drugs rather than delaying until participants met the full diagnostic criteria of MS

ETOMS 2003

Subanalysis of ETOMS 2001 trial to evaluate prognostic effect of MRI at baseline on conversion to CDMS

Filippi 2004

Subanalysis of ETOMS 2001 trial to evaluate prognostic effect of MRI at baseline on conversion to CDMS

Kuhle 2015

Cohort study. No treatment with disease-modifying drugs

Lazzaro 2009

An open cohorts epidemiological model based on demographics of participants enrolled in the BENEFIT 2006 trial. The model arbitrarily started with 2000 CIS participants diagnosed according to Mc Donald criteria, i.e. MS

Meyniel 2012

Prospective cohort study. $\mathrm{N}=125(10 \%)$ participants initially treated with disease-modifying drugs at the first clinical attack suggestive of MS were not reported separately from participants (1094; 88\%) who converted to relapsing-remitting MS at the time of their first disease-modifying drugs commencement

Moraal 2009

Reanalysis of CHAMPS 2000 trial to assess the prognostic value of baseline MRI for conversion to CDMS over 3 years and the predictive effect of the intervention

Mowry 2009

Prospective cohort study. $\mathrm{N}=9(9 \%)$ participants who began disease-modifying drugs within 1 year of their first clinical attack suggestive of MS were not reported separately from participants (96; 91\%) who converted to relapsing-remitting MS at the time of their first disease-modifying drugs commencement

MSBASIS 2015

Prospective cohort study, a sub-study of the MSBase Registry (an international online database on MS). $N=252$ (19\%) participants who began disease-modifying drugs at their first clinical attack suggestive of MS were not reported separately from participants (1087; 81\%) who converted to relapsing-remitting MS at the time of their first disease-modifying drugs commencement

Treatment with disease-modifying drugs for people with a first clinical attack suggestive of multiple sclerosis (Review) 
REFLEX 2014a

REFLEX 2014b

SWISS COHORT STUDY 2013

Cohort Study. N = $54(10 \%)$ participants initially treated with disease-modifying drugs at their first clinical attack suggestive of MS were not reported separately from participants (492; 90\%) who converted to relapsing-remitting MS at the time of their first disease-modifying drugs commencement

\section{SWISS COHORT STUDY 2016 Cohort study. Outcomes were not measured}

CDMS: clinically definite multiple sclerosis; CIS: clinically isolated syndrome; MRI: magnetic resonance imaging; MS: multiple sclerosis; OLE: open-label extension

\section{Characteristics of ongoing studies [ordered by study ID]}

\section{NCT01013350}

Trial name or title Prospective observational long-term safety registry of multiple sclerosis patients who have participated in cladribine clinical trials (PREMIERE)

\begin{tabular}{|c|c|}
\hline Methods & Observational study \\
\hline Participants & $\begin{array}{l}\text { Estimated enrolment: } 1190 \text {. Subjects with MS and had already participated in sponsor oral cladribine clinical } \\
\text { development trials }\end{array}$ \\
\hline Interventions & Cladribine \\
\hline Outcomes & $\begin{array}{l}\text { - Number of participants with serious adverse drug reactions (SADRs) } \\
\text { - Time to resolution of lymphopenia, among registry participants with persistent lymphopenia } \\
\text { - Number of participants with all adverse events (adverse events) } \\
\text { Time frame: up to the end of the registry, which is planned for } 2018 \text {, or } 8 \text { years after the participant's first } \\
\text { enrolment into a cladribine clinical trial, whichever occurs first }\end{array}$ \\
\hline Starting date & November 2009 \\
\hline Contact information & US Medical Information \\
\hline Notes & ClinicalTrials.gov identifier: NCT01013350 \\
\hline
\end{tabular}


Trial name or title

\begin{tabular}{ll}
\hline Methods & Prospective cohort \\
\hline Participants & $\begin{array}{l}\text { Estimated enrolment: } 200 \text { participants with CIS within the last } 6 \text { months or diagnosis of MS within the last } \\
2 \text { years }\end{array}$ \\
\hline Interventions & Immunomodulatory therapy \\
\hline Outcomes & Primary: time (in days) until relapse during the observation period of 4 years \\
\hline Starting date & January 2011 \\
\hline Contact information & Prof. Friedemann Paul friedemann.paul@charite.de; Dr. Klemens Ruprecht klemens.ruprecht@charite.de \\
\hline Notes & ClinicalTrials.gov identifier: NCT01371071 \\
\hline
\end{tabular}

CIS: clinically isolated syndrome; MS: multiple sclerosis 
DATA ANDANALYSES

Comparison 1. Active intervention versus placebo

\begin{tabular}{|c|c|c|c|c|}
\hline Outcome or subgroup title & $\begin{array}{l}\text { No. of } \\
\text { studies }\end{array}$ & $\begin{array}{c}\text { No. of } \\
\text { participants }\end{array}$ & Statistical method & Effect size \\
\hline $\begin{array}{l}1 \text { Occurrence of at least one serious } \\
\text { adverse event over } 24 \text { months }\end{array}$ & 7 & 3385 & Odds Ratio (M-H, Random, 95\% CI) & $0.78[0.60,1.03]$ \\
\hline $\begin{array}{l}1.1 \text { Interferon beta- } 1 \mathrm{~b} \\
\text { (Betaseron) versus placebo }\end{array}$ & 1 & 468 & Odds Ratio (M-H, Random, 95\% CI) & $1.00[0.48,2.11]$ \\
\hline $\begin{array}{l}1.2 \text { Interferon beta-1a } \\
\text { (Avonex) versus placebo }\end{array}$ & 1 & 383 & Odds Ratio (M-H, Random, 95\% CI) & $0.60[0.28,1.27]$ \\
\hline $\begin{array}{l}1.3 \text { Interferon beta-1a (Rebif) } \\
\text { versus placebo }\end{array}$ & 2 & 823 & Odds Ratio (M-H, Random, 95\% CI) & $0.72[0.35,1.46]$ \\
\hline $\begin{array}{l}1.4 \text { Glatiramer acetate versus } \\
\text { placebo }\end{array}$ & 1 & 481 & Odds Ratio (M-H, Random, 95\% CI) & $0.55[0.25,1.17]$ \\
\hline $\begin{array}{l}1.5 \text { Teriflunomide versus } \\
\text { placebo }\end{array}$ & 1 & 614 & Odds Ratio (M-H, Random, 95\% CI) & $1.06[0.59,1.89]$ \\
\hline 1.6 Cladribine versus placebo & 1 & 616 & Odds Ratio (M-H, Random, 95\% CI) & $0.77[0.43,1.37]$ \\
\hline $\begin{array}{l}2 \text { Occurrence of at least one serious } \\
\text { adverse event over } 36 \text { months }\end{array}$ & 1 & & Odds Ratio (M-H, Random, 95\% CI) & Subtotals only \\
\hline $\begin{array}{l}2.1 \text { Interferon beta-1a } \\
\text { (Avonex) versus placebo }\end{array}$ & 1 & 202 & Odds Ratio (M-H, Random, 95\% CI) & $1.23[0.44,3.45]$ \\
\hline $\begin{array}{l}3 \text { Withdrawing from the study or } \\
\text { discontinuing the drug due to } \\
\text { adverse events over } 24 \text { months }\end{array}$ & 5 & 2693 & Odds Ratio (M-H, Random, 95\% CI) & $2.43[0.91,6.49]$ \\
\hline $\begin{array}{l}3.1 \text { Interferon beta-1b } \\
\text { (Betaseron) versus placebo }\end{array}$ & 1 & 468 & Odds Ratio (M-H, Random, 95\% CI) & $21.54[2.92,159.08]$ \\
\hline $\begin{array}{l}3.2 \text { Interferon beta-1a (Rebif) } \\
\text { versus placebo }\end{array}$ & 1 & 514 & Odds Ratio (M-H, Random, 95\% CI) & $0.73[0.26,2.10]$ \\
\hline $\begin{array}{l}3.3 \text { Glatiramer acetate versus } \\
\text { placebo }\end{array}$ & 1 & 481 & Odds Ratio (M-H, Random, 95\% CI) & $3.58[1.16,11.03]$ \\
\hline $\begin{array}{l}3.4 \text { Teriflunomide versus } \\
\text { placebo }\end{array}$ & 1 & 614 & Odds Ratio (M-H, Random, 95\% CI) & $1.02[0.58,1.81]$ \\
\hline 3.5 Cladribine versus placebo & 1 & 616 & Odds Ratio (M-H, Random, 95\% CI) & $4.13[1.44,11.87]$ \\
\hline $\begin{array}{l}4 \text { Withdrawing from the study or } \\
\text { discontinuing the drug due to } \\
\text { adverse events over } 12 \text { months }\end{array}$ & 1 & & Odds Ratio (M-H, Random, 95\% CI) & Subtotals only \\
\hline $\begin{array}{l}4.1 \text { Interferon beta-1a } \\
\text { (Avonex) versus placebo }\end{array}$ & 1 & 383 & Odds Ratio (M-H, Random, 95\% CI) & $0.14[0.02,1.12]$ \\
\hline $\begin{array}{l}5 \text { Time to conversion to CDMS } \\
\text { over } 24 \text { months }\end{array}$ & 9 & & Hazard Ratio (Random, 95\% CI) & $0.53[0.47,0.60]$ \\
\hline $\begin{array}{l}5.1 \text { Interferon beta-1b } \\
\text { (Betaseron) versus placebo }\end{array}$ & 1 & & Hazard Ratio (Random, 95\% CI) & $0.50[0.36,0.69]$ \\
\hline $\begin{array}{l}5.2 \text { Interferon beta-1a } \\
\text { (Avonex) versus placebo }\end{array}$ & 1 & & Hazard Ratio (Random, 95\% CI) & $0.56[0.38,0.83]$ \\
\hline $\begin{array}{l}5.3 \text { Interferon beta-1a (Rebif) } \\
\text { versus placebo }\end{array}$ & 2 & & Hazard Ratio (Random, 95\% CI) & $0.57[0.43,0.77]$ \\
\hline
\end{tabular}

Treatment with disease-modifying drugs for people with a first clinical attack suggestive of multiple sclerosis (Review)

Copyright $\odot 2017$ The Cochrane Collaboration. Published by John Wiley \& Sons, Ltd. 


\begin{tabular}{|c|c|c|c|c|}
\hline $\begin{array}{l}5.4 \text { Glatiramer acetate versus } \\
\text { placebo }\end{array}$ & 1 & & Hazard Ratio (Random, 95\% CI) & $0.55[0.40,0.76]$ \\
\hline $\begin{array}{l}5.5 \text { Teriflunomide versus } \\
\text { placebo }\end{array}$ & 1 & & Hazard Ratio (Random, 95\% CI) & $0.57[0.38,0.86]$ \\
\hline 5.6 Cladribine versus placebo & 1 & & Hazard Ratio (Random, 95\% CI) & $0.38[0.25,0.58]$ \\
\hline $\begin{array}{l}5.7 \text { Any DMD vs no } \\
\text { treatment }\end{array}$ & 2 & & Hazard Ratio (Random, 95\% CI) & $0.48[0.30,0.78]$ \\
\hline $\begin{array}{l}\text { Time to conversion to CDMS } \\
\text { over } 12 \text { months }\end{array}$ & 1 & & Hazard Ratio (Random, 95\% CI) & Subtotals only \\
\hline $\begin{array}{l}6.1 \text { Immunoglobulins versus } \\
\text { placebo }\end{array}$ & 1 & & Hazard Ratio (Random, 95\% CI) & $0.36[0.15,0.86]$ \\
\hline $\begin{array}{l}\text { Withdrawing from the study or } \\
\text { discontinuing the drug for any } \\
\text { reason over } 24 \text { months }\end{array}$ & 6 & 2931 & Odds Ratio (M-H, Random, 95\% CI) & $1.00[0.61,1.62]$ \\
\hline $\begin{array}{l}7.1 \text { Interferon beta-1b } \\
\text { (Betaseron) versus placebo }\end{array}$ & 1 & 487 & Odds Ratio (M-H, Random, 95\% CI) & $1.50[0.95,2.35]$ \\
\hline $\begin{array}{l}7.2 \text { Interferon beta-1a } \\
\text { (Avonex) versus placebo }\end{array}$ & 1 & 383 & Odds Ratio (M-H, Random, 95\% CI) & $1.09[0.65,1.81]$ \\
\hline $\begin{array}{l}7.3 \text { Interferon beta-1a (Rebif) } \\
\text { versus placebo }\end{array}$ & 2 & 826 & Odds Ratio (M-H, Random, 95\% CI) & $0.52[0.18,1.44]$ \\
\hline $\begin{array}{l}7.4 \text { Teriflunomide versus } \\
\text { placebo }\end{array}$ & 1 & 618 & Odds Ratio (M-H, Random, 95\% CI) & $0.87[0.59,1.27]$ \\
\hline 7.5 Cladribine versus placebo & 1 & 617 & Odds Ratio (M-H, Random, 95\% CI) & $2.30[1.49,3.56]$ \\
\hline $\begin{array}{l}\text { Withdrawing from the study or } \\
\text { discontinuing the drug for any } \\
\text { reason over } 12 \text { months }\end{array}$ & 1 & & Odds Ratio (M-H, Random, 95\% CI) & Subtotals only \\
\hline $\begin{array}{l}8.1 \text { Immunoglobulins versus } \\
\text { placebo }\end{array}$ & 1 & 91 & Odds Ratio (M-H, Random, 95\% CI) & $2.15[0.37,12.35]$ \\
\hline
\end{tabular}

\section{Comparison 2. Early versus delayed treatment}

\begin{tabular}{|c|c|c|c|c|}
\hline Outcome or subgroup title & $\begin{array}{l}\text { No. of } \\
\text { studies }\end{array}$ & $\begin{array}{c}\text { No. of } \\
\text { participants }\end{array}$ & Statistical method & Effect size \\
\hline $\begin{array}{l}1 \text { Time to conversion to CDMS at } \\
\text { different follow-up years }\end{array}$ & 10 & & Hazard Ratio (Random, 95\% CI) & Subtotals only \\
\hline $1.12-4$ years' follow-up & 5 & & Hazard Ratio (Random, 95\% CI) & $0.62[0.48,0.81]$ \\
\hline 1.25 years' follow-up & 4 & & Hazard Ratio (Random, 95\% CI) & $0.62[0.53,0.73]$ \\
\hline $1.38 .7-10$ years' follow-up & 2 & & Hazard Ratio (Random, 95\% CI) & $0.65[0.54,0.79]$ \\
\hline
\end{tabular}


Analysis I.I. Comparison I Active intervention versus placebo, Outcome I Occurrence of at least one serious adverse event over 24 months.

Review: Treatment with disease-modifying drugs for people with a first clinical attack suggestive of multiple sclerosis

Comparison: I Active intervention versus placebo

Outcome: I Occurrence of at least one serious adverse event over 24 months

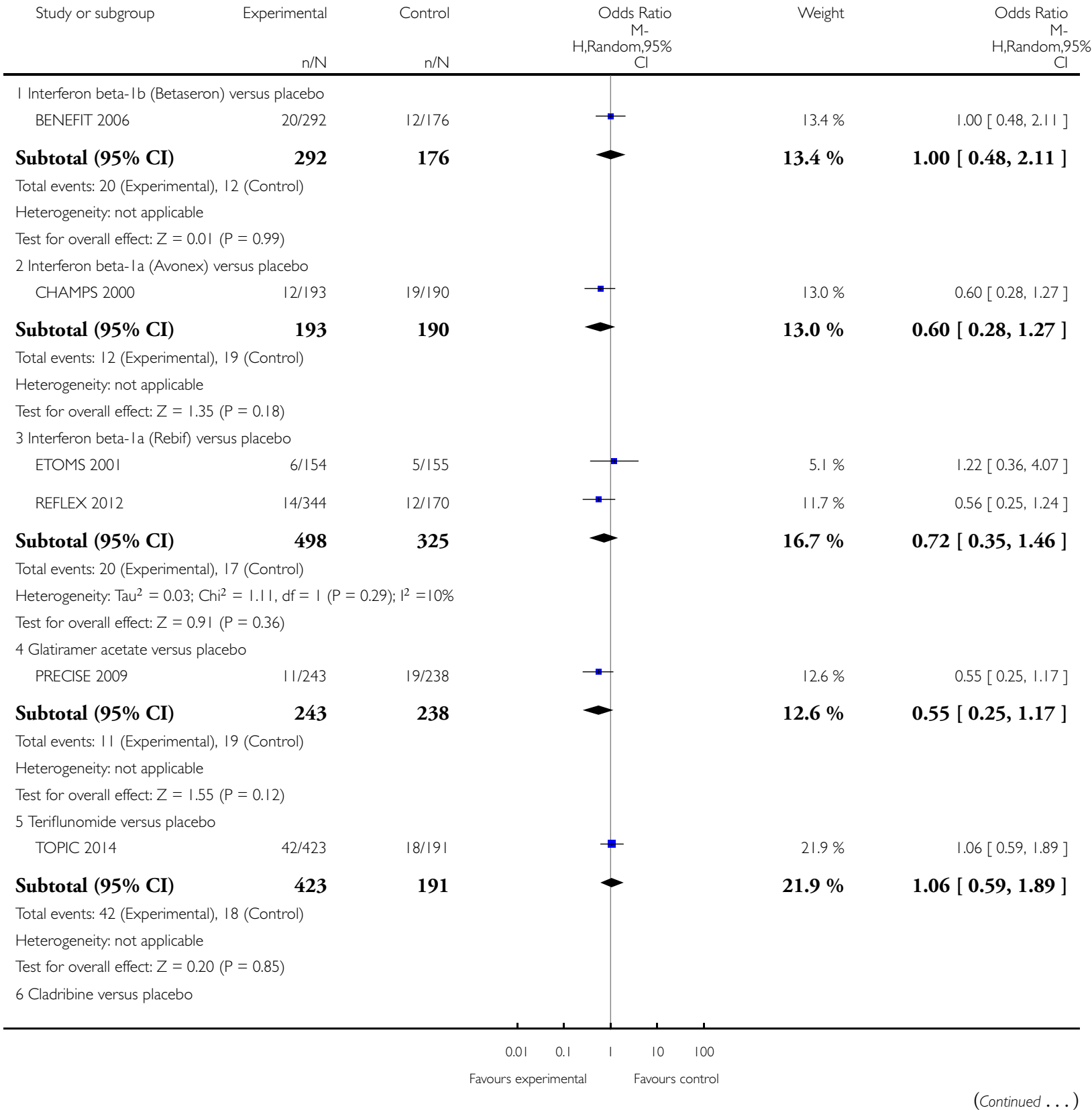




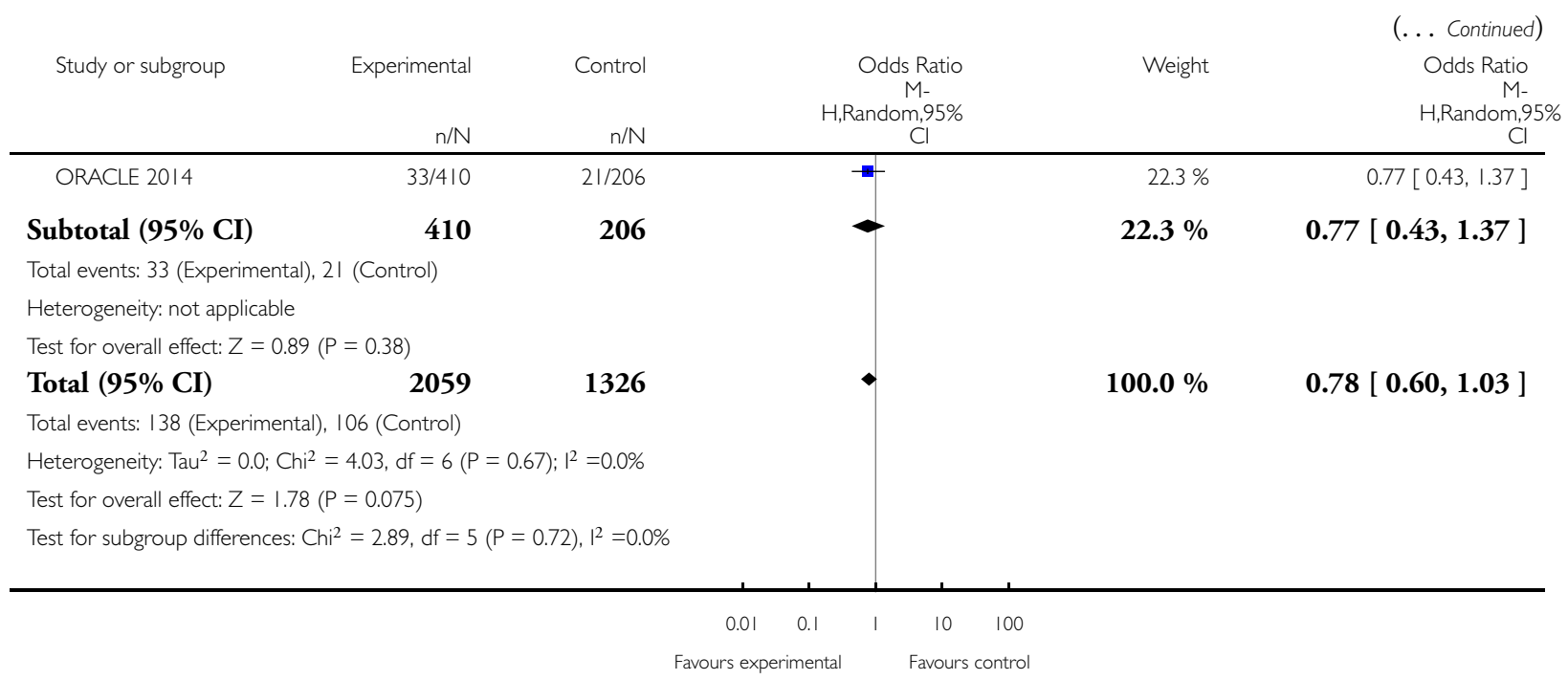

\section{Analysis I.2. Comparison I Active intervention versus placebo, Outcome 2 Occurrence of at least one} serious adverse event over 36 months.

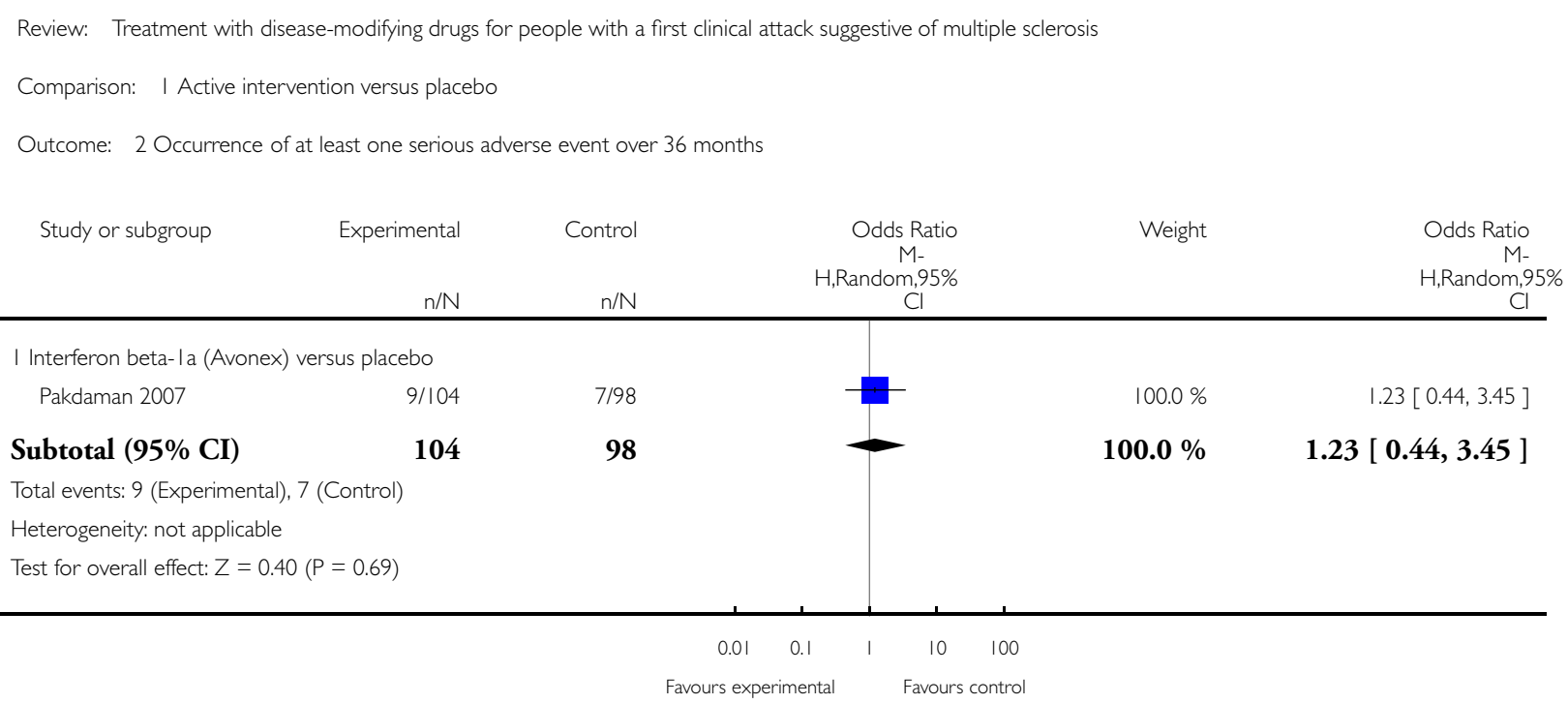


Analysis I.3. Comparison I Active intervention versus placebo, Outcome 3 Withdrawing from the study or discontinuing the drug due to adverse events over 24 months.

Review: Treatment with disease-modifying drugs for people with a first clinical attack suggestive of multiple sclerosis

Comparison: I Active intervention versus placebo

Outcome: 3 Withdrawing from the study or discontinuing the drug due to adverse events over 24 months

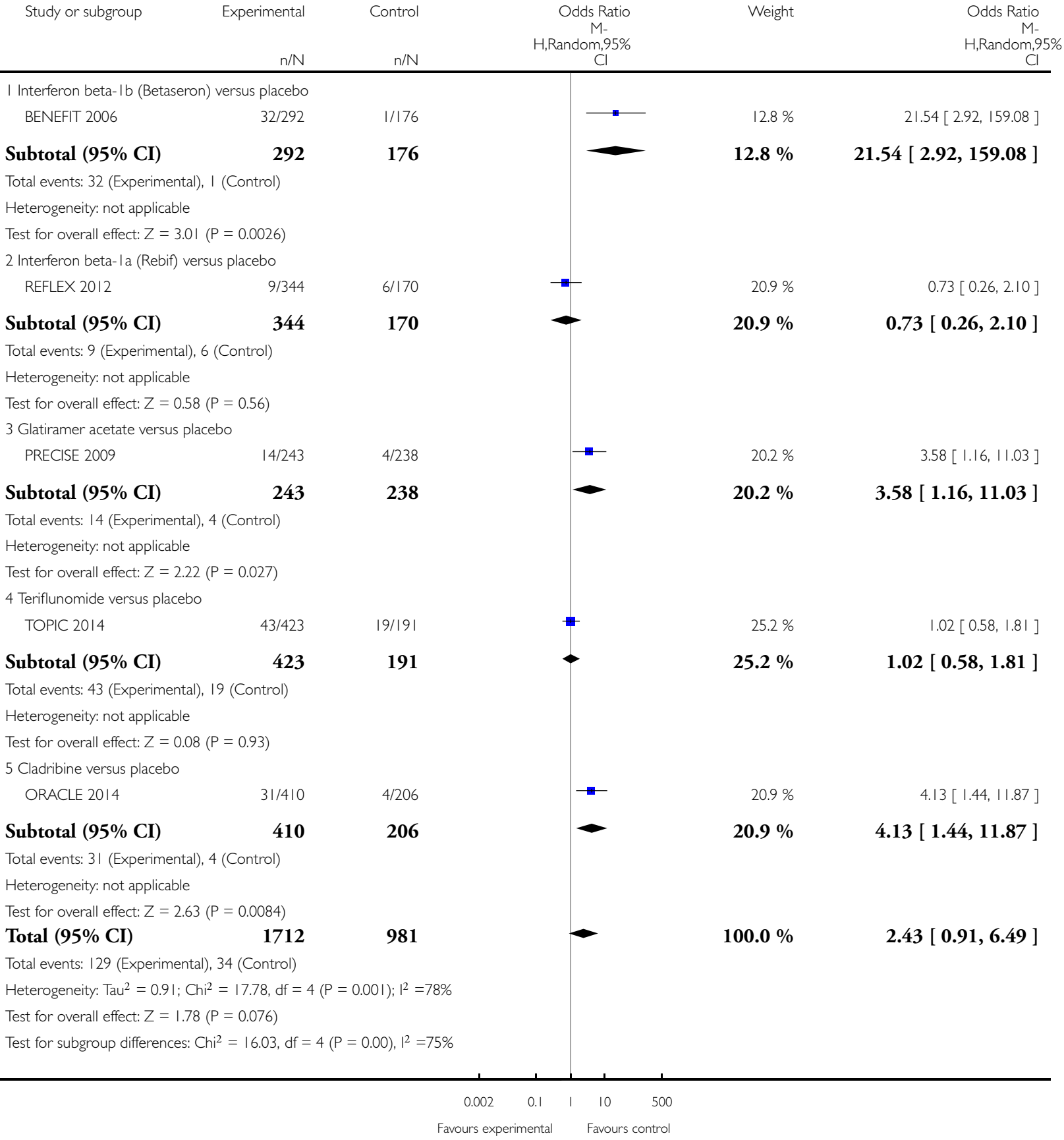

Treatment with disease-modifying drugs for people with a first clinical attack suggestive of multiple sclerosis (Review) 
Analysis I.4. Comparison I Active intervention versus placebo, Outcome 4 Withdrawing from the study or discontinuing the drug due to adverse events over 12 months.

\begin{tabular}{|c|c|c|c|c|c|}
\hline \multicolumn{6}{|c|}{ Comparison: I Active intervention versus placebo } \\
\hline \multicolumn{6}{|c|}{ Outcome: 4 Withdrawing from the study or discontinuing the drug due to adverse events over 12 months } \\
\hline Study or subgroup & Experimental & $\begin{array}{r}\text { Control } \\
n / N\end{array}$ & $\begin{array}{c}\text { Odds Ratio } \\
\text { M- } \\
\text { H,Random,95\% } \\
\mathrm{Cl} \\
\end{array}$ & Weight & $\begin{array}{c}\text { Odds Ratio } \\
\text { M- } \\
\text { H,Random,95\% } \\
\text { Cl }\end{array}$ \\
\hline \multicolumn{6}{|c|}{ I Interferon beta-la (Avonex) versus placebo } \\
\hline CHAMPS 2000 & $1 / 193$ & $7 / 190$ & & $100.0 \%$ & $0.14[0.02,1.12]$ \\
\hline Subtotal $(95 \% \mathrm{CI})$ & 193 & 190 & & $100.0 \%$ & $0.14[0.02,1.12]$ \\
\hline \multicolumn{6}{|c|}{ Total events: I (Experimental), 7 (Control) } \\
\hline \multicolumn{6}{|c|}{ Heterogeneity: not applicable } \\
\hline \multicolumn{6}{|c|}{ Test for overall effect: $Z=1.86(P=0.063)$} \\
\hline
\end{tabular}


Analysis I.5. Comparison I Active intervention versus placebo, Outcome 5 Time to conversion to CDMS over 24 months.

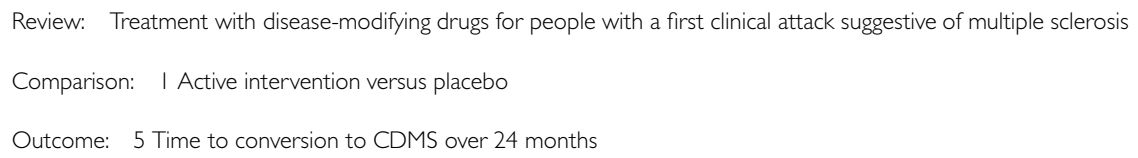

\section{Subtotal (95\% CI)}

Heterogeneity: not applicable

Test for overall effect: $Z=4.14$ ( $P=0.000035)$

2 Interferon beta- Ia (Avonex) versus placebo

$$
\text { CHAMPS } 2000
$$

Subtotal (95\% CI)

Heterogeneity: not applicable

Test for overall effect: $Z=2.93(P=0.0034)$

3 Interferon beta- Ia (Rebif) versus placebo

$$
\begin{array}{lc}
\text { ETOMS 200I } & -0.4308(0.1876) \\
\text { REFLEX } 2012 & -0.734(0.2231)
\end{array}
$$

Subtotal (95\% CI)

$$
\begin{aligned}
& \text { Heterogeneity: } \mathrm{Tau}^{2}=0.00 ; \mathrm{Chi}^{2}=1.08, \mathrm{df}=\mathrm{I}(\mathrm{P}=0.30) ; \mathrm{I}^{2}=8 \% \\
& \text { Test for overall effect: } \mathrm{Z}=3.73(\mathrm{P}=0.00019) \\
& 4 \text { Glatiramer acetate versus placebo } \\
& \quad \text { PRECISE } 2009 \quad-0.5978(0.1625)
\end{aligned}
$$

Subtotal (95\% CI)

Heterogeneity: not applicable

Test for overall effect: $Z=3.68(P=0.00023)$

5 Teriflunomide versus placebo

$$
\text { TOPIC } 2014 \quad-0.5621(0.2069)
$$

\section{Subtotal (95\% CI)}

Heterogeneity: not applicable

Test for overall effect: $Z=2.72(P=0.0066)$

6 Cladribine versus placebo

$$
\text { ORACLE } 2014 \quad-0.9676(0.2136)
$$

\section{Subtotal (95\% CI)}

Heterogeneity: not applicable

Test for overall effect: $Z=4.53(P<0.0000$ I $)$

7 Any DMD vs no treatment

\section{$12.9 \%$}

$12.9 \%$

$9.3 \%$

$9.3 \%$

$10.3 \%$

$7.3 \%$

$17.6 \%$

$13.7 \%$

$13.7 \%$

$8.5 \%$

$8.5 \%$

$8.0 \%$

$8.0 \%$
$0.50[0.36,0.69]$

$0.50[0.36,0.69$ ]

$0.56[0.38,0.83]$

0.56 [ 0.38, 0.83 ]

$0.65[0.45,0.94]$

$0.48[0.31,0.74]$

$0.57[0.43,0.77$ ]

$0.55[0.40,0.76$ ]

0.55 [ $0.40,0.76$ ]

$0.57[0.38,0.86]$

0.57 [ 0.38, 0.86 ]

$0.38[0.25,0.58]$

$0.38[0.25,0.58$ ] 


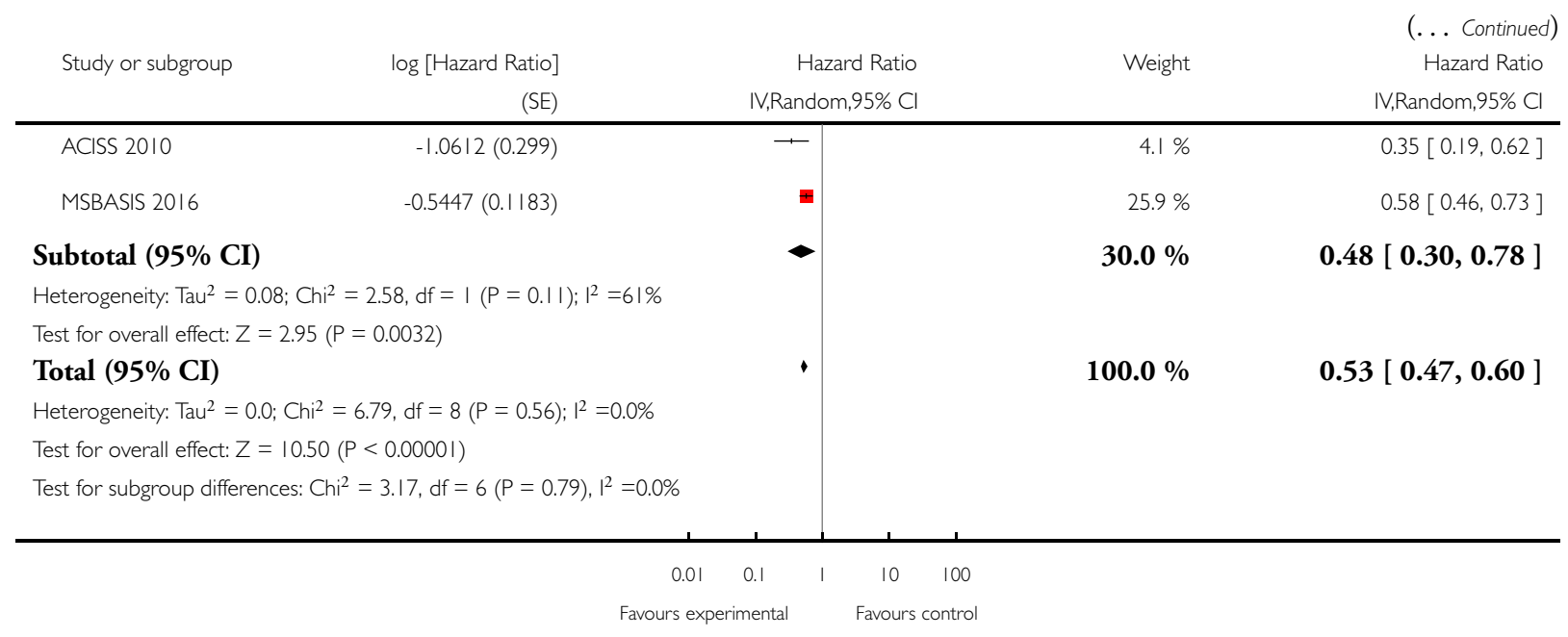

Analysis I.6. Comparison I Active intervention versus placebo, Outcome 6 Time to conversion to CDMS over 12 months.

Review: Treatment with disease-modifying drugs for people with a first clinical attack suggestive of multiple sclerosis

Comparison: I Active intervention versus placebo

Outcome: 6 Time to conversion to CDMS over 12 months

Study or subgroup $\quad \log [$ Hazard Ratio] Hazard Ratio Hazard Ratio

(SE) IV,Random,95\% Cl IV,Random,95\% Cl

I Immunoglobulins versus placebo

Achiron 2004

$-1.0217(0.4467)$

$100.0 \%$

$0.36[0.15,0.86]$

Subtotal (95\% CI)

$100.0 \%$

$0.36[0.15,0.86]$

Heterogeneity: not applicable

Test for overall effect: $Z=2.29(P=0.022)$

$\begin{array}{llllll}0.01 & 0.1 & 1 & 10 & 100\end{array}$

Favours experimental

Favours contro 


\section{Analysis I.7. Comparison I Active intervention versus placebo, Outcome 7 Withdrawing from the study or} discontinuing the drug for any reason over 24 months.

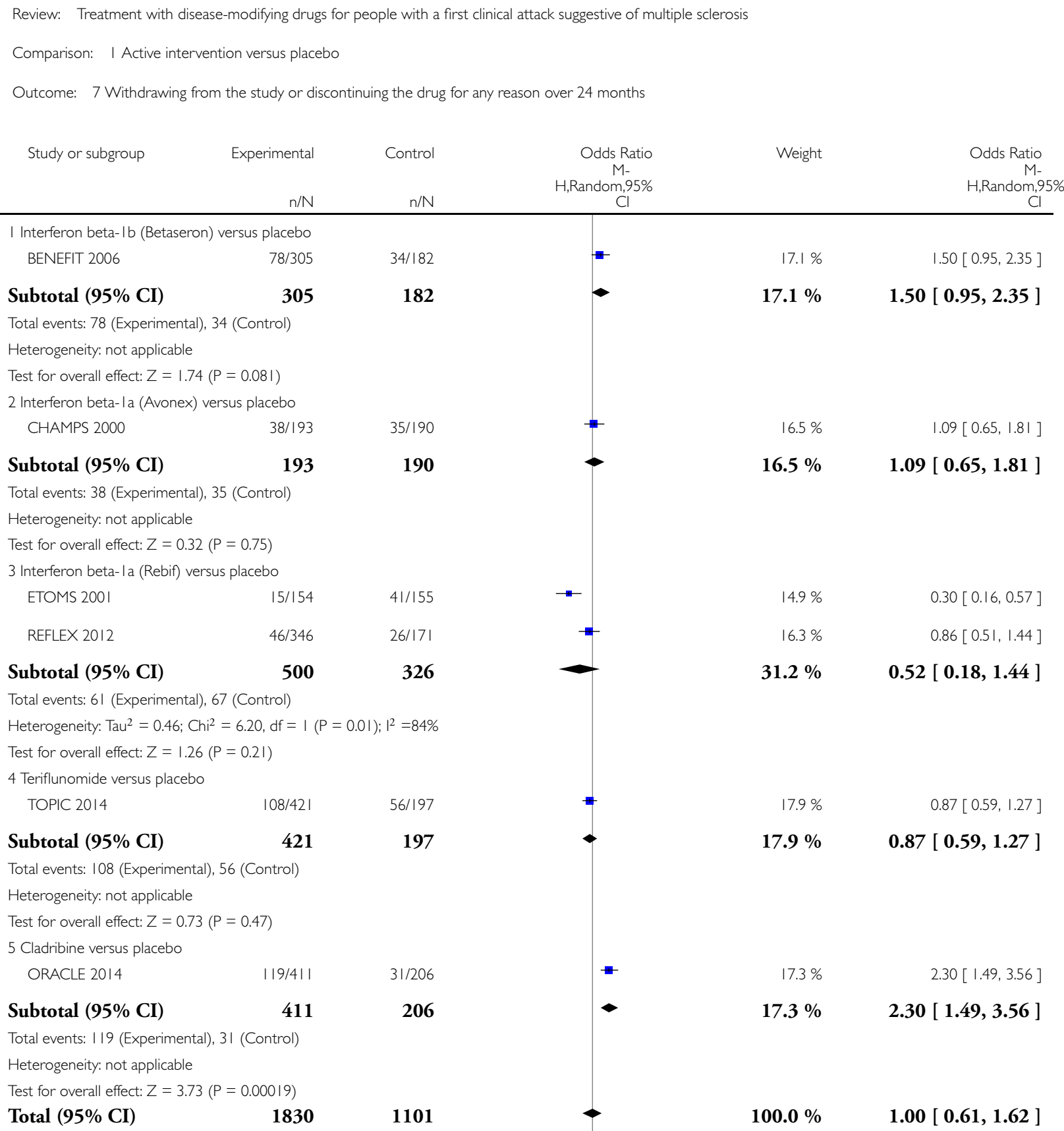

\begin{tabular}{l|l}
$34 / 182$ & $-17.1 \%$
\end{tabular}

Total events: 38 (Experimental), 35 (Control)

Heterogeneity: not applicable

Test for overall effect: $Z=0.32(P=0.75)$

3 Interferon beta- la (Rebif) versus placebo

ETOMS 200

REFLEX 2012

Total events: $6 \mathrm{I}$ (Experimental), 67 (Control)

Heterogeneity: $\mathrm{Tau}^{2}=0.46 ; \mathrm{Chi}^{2}=6.20, \mathrm{df}=1(P=0.01) ; \mathrm{I}^{2}=84 \%$

Test for overall effect: $Z=1.26(P=0.21)$

4 Teriflunomide versus placebo

$$
\text { TOPIC } 2014 \quad \text { 108/421 56/197 }
$$

$421 \quad 197$

Subtotal $\mathbf{( 9 5 \% ~ C I ) ~}$

Total events: 108 (Experimental), 56 (Control)

Heterogeneity: not applicable

Test for overall effect: $Z=0.73(P=0.47)$

5 Cladribine versus placebo

ORACLE $2014 \quad$ |19/4| 31/206

Total events: I 19 (Experimental), 3I (Control)

Heterogeneity: not applicable

Test for overall effect: $Z=3.73(P=0.00019)$

Total (95\% CI)

$16.5 \%$

$16.5 \%$

$1.09[0.65,1.81]$

$1.09[0.65,1.81]$

$14.9 \%$

$16.3 \%$

$0.30[0.16,0.57]$

$0.86[0.51,1.44]$

$31.2 \%$

0.52 [ 0.18, 1.44 ]

$17.9 \%$

$0.87[0.59,1.27]$

$17.9 \%$

0.87 [ 0.59, 1.27 ]

$17.3 \%$

$2.30[1.49,3.56]$

$-\quad 17.3 \%$

$2.30[1.49,3.56$ ] 


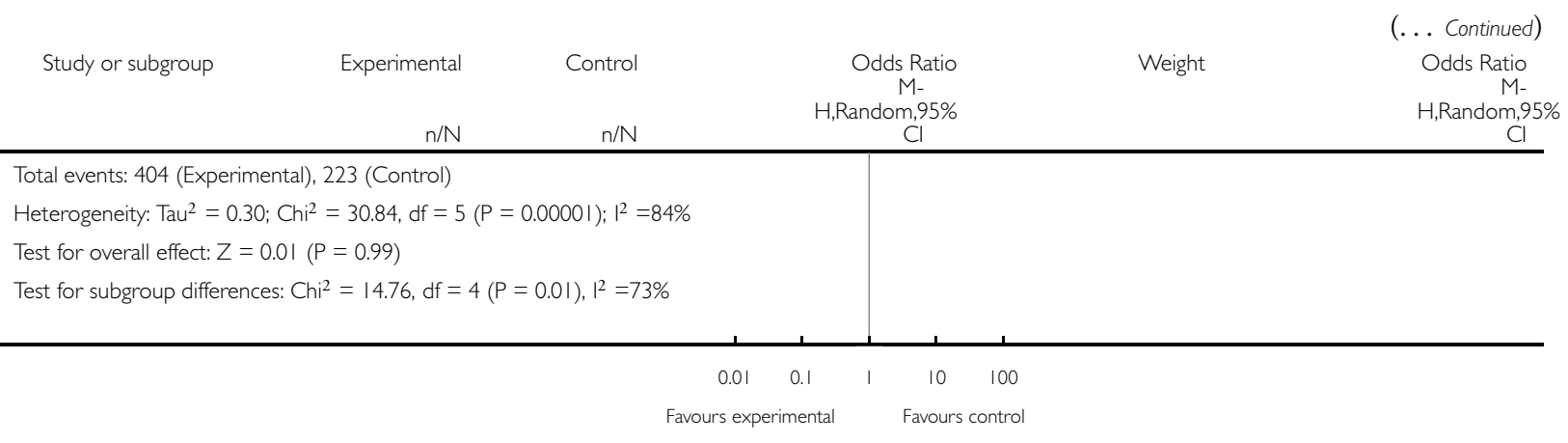

\section{Analysis I.8. Comparison I Active intervention versus placebo, Outcome 8 Withdrawing from the study or discontinuing the drug for any reason over 12 months.}

Review: Treatment with disease-modifying drugs for people with a first clinical attack suggestive of multiple sclerosis

Comparison: I Active intervention versus placebo

Outcome: 8 Withdrawing from the study or discontinuing the drug for any reason over 12 months

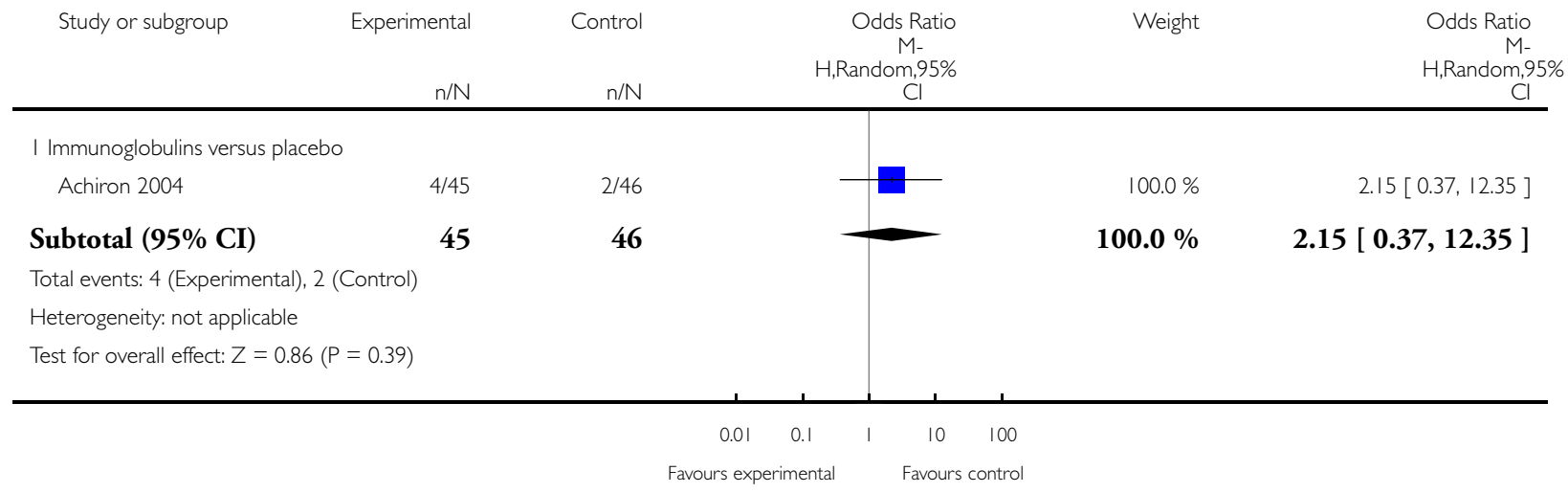




\section{Analysis 2.1. Comparison 2 Early versus delayed treatment, Outcome I Time to conversion to CDMS at} different follow-up years.

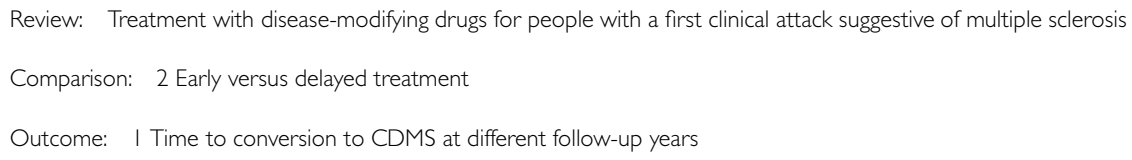

$\begin{array}{lc}\begin{array}{ll}\text { I } 2 \text {-4 years' follow-up } \\ \text { ACISS } 2010\end{array} & -0.4757(0.24) \\ \text { BENEFIT } 2007 \text { (3 years FU) } & -0.5276(0.1497) \\ \text { GERONIMUS 20I3 } & -1.0217(0.3537) \\ \text { REFLEX 2016 (3 and } 5 \text { years FU) } & -0.5888(0.1933) \\ \text { Tintore } 2015 & -0.1054(0.1468)\end{array}$

Subtotal (95\% CI)

Heterogeneity: Tau $^{2}=0.05 ; \mathrm{Chi}^{2}=8.82, \mathrm{df}=4(\mathrm{P}=0.07) ; \mathrm{I}^{2}=55 \%$

Test for overall effect: $Z=3.58(P=0.00034)$

25 years' follow-up

BENEFIT 2009 (5 years FU)

CHAMPS 2006 (5 years FU)

$-0.5621(0.2069)$

PRECISE 2013 (5 years FU)

$-0.5276(0.1497)$

REFLEX 2016 (3 and 5 years FU)

$-0.3813(0.18)$

Subtotal (95\% CI)

Heterogeneity: Tau $^{2}=0.0 ; \mathrm{Chi}^{2}=0.58, \mathrm{df}=3(\mathrm{P}=0.90) ;\left.\right|^{2}=0.0 \%$

Test for overall effect: $Z=5.90(P<0.00001)$

3 8.7- 10 years' follow-up

$$
\begin{array}{ll}
\text { BENEFIT } 2014(8.7 \text { years FU) } & -0.3857(0.1272) \\
\text { CHAMPS } 2012(10 \text { years FU) } & -0.4943(0.1552)
\end{array}
$$

Subtotal $(\mathbf{9 5 \%} \mathrm{CI})$

Heterogeneity: $\mathrm{Tau}^{2}=0.0 ; \mathrm{Chi}^{2}=0.29, \mathrm{df}=\mathrm{I}(\mathrm{P}=0.59) ; \mathrm{I}^{2}=0.0 \%$

Test for overall effect: $Z=4.36(P=0.000013)$

Test for subgroup differences: $\mathrm{Chi}^{2}=0.17, \mathrm{df}=2(\mathrm{P}=0.92), \mathrm{I}^{2}=0.0 \%$

$\begin{array}{lll}-16.9 \% & 0.62[0.39,0.99] \\ & 25.7 \% & 0.59[0.44,0.79] \\ & 10.2 \% & 0.36[0.18,0.72] \\ & 21.1 \% & 0.55[0.38,0.81] \\ & 26.1 \% & 0.90[0.67,1.20]\end{array}$

$100.0 \%$

$0.62[0.48,0.81]$

$34.5 \%$

$0.63[0.48,0.83]$

$15.5 \%$

$0.57[0.38,0.86]$

$29.6 \%$

$0.59[0.44,0.79]$

$20.5 \%$

$0.68[0.48,0.97]$

$100.0 \%$

$0.62[0.53,0.73$ ]

$59.8 \%$

$0.68[0.53,0.87]$

$40.2 \%$

$0.61[0.45,0.83]$

$100.0 \%$

$0.65[0.54,0.79$ ]

$\begin{array}{lllllll}0.1 & 0.2 & 0.5 & 1 & 2 & 5 & 10\end{array}$

Favours early Favours delayed 
ADDITIONAL TABLES

Table 1. Summary of characteristics of included studies

\begin{tabular}{|c|c|c|c|c|}
\hline Type of intervention & Route & $\begin{array}{l}\text { RCTs } \\
\mathrm{N}=10\end{array}$ & $\begin{array}{l}\text { OLEs } \\
\mathbf{N}=\mathbf{8}\end{array}$ & $\begin{array}{l}\text { Cohort studies } \\
\mathrm{N}=4\end{array}$ \\
\hline $\begin{array}{l}\text { Interferon beta- } 1 \mathrm{~b} \text { sc } \\
(\text { Betaseron } \AA)\end{array}$ & sc & 1 & $\begin{array}{l}4 \text { OLEs at a maximum follow-up of } 3 \text {, } \\
5,8.7 \text {, and } 11 \text { years }\end{array}$ & 0 \\
\hline $\begin{array}{l}\text { Interferon } \quad \text { beta-1a } \\
(\text { Avonex } \AA)\end{array}$ & $\mathrm{im}$ & 2 & $\begin{array}{l}2 \text { OLEs at a maximum follow-up of } 5 \\
\text { and } 10 \text { years }\end{array}$ & 0 \\
\hline $\begin{array}{l}\text { Interferon } \quad \text { beta-1a } \\
\text { (Rebif®) }\end{array}$ & sc & 3 & $\begin{array}{l}1 \text { OLE at a maximum follow-up of } 3 \\
\text { and } 5 \text { years }\end{array}$ & 0 \\
\hline Glatiramer acetate sc & sc & 1 & $\begin{array}{l}1 \text { OLE at a maximum follow-up of } 5 \\
\text { years }\end{array}$ & 0 \\
\hline Cladribine os & os & 1 & 0 & 0 \\
\hline Teriflunomide os & os & 1 & 0 & 0 \\
\hline Immunoglobulins iv & iv & 1 & 0 & 0 \\
\hline disease-modifying drugs & - & 0 & 0 & follow-up from 2 to 6 years \\
\hline
\end{tabular}

Table 2. Risk of bias in included cohort studies (ROBINS-I)

\begin{tabular}{l|l|l}
\hline ACISS 2010 & Authors' judgment & Support for judgement \\
\hline Confounding & Serious & $\begin{array}{l}\text { All known important domains were not appropriately controlled } \\
\text { for }\end{array}$ \\
\hline Selection of participants into the study & Low & $\begin{array}{l}\text { All participants who would have been eligible for the target trial } \\
\text { were likely included in the study and for each participant start of } \\
\text { follow up and start of intervention likely coincided }\end{array}$ \\
\hline Classification of interventions & Low & $\begin{array}{l}\text { Intervention status was well defined and intervention definition } \\
\text { was based on information collected at the time of intervention }\end{array}$ \\
\hline Deviations from intended interventions & NI & $\begin{array}{l}\text { No information was reported on whether there was deviation from } \\
\text { the intended intervention }\end{array}$ \\
\hline
\end{tabular}


Table 2. Risk of bias in included cohort studies (ROBINS-I) (Continued)

\begin{tabular}{l|l|l}
\hline Missing data & Critical & $\begin{array}{l}\text { There were critical differences between early, delayed or no treat- } \\
\text { ment in participants with missing data and an appropriate analysis } \\
\text { to address missing data was not done }\end{array}$ \\
\hline Measurement of outcomes & Serious & $\begin{array}{l}\text { The outcome measures were subjective and assessed by assessors } \\
\text { aware of the intervention received by study participants. This judg- } \\
\text { ment is applicable to all the three outcomes reported in the article }\end{array}$ \\
\hline Selection of the reported result & Low & $\begin{array}{l}\text { There was evidence that reported results corresponded to all in- } \\
\text { tended outcomes and analyses }\end{array}$ \\
\hline Overall bias & Critical & Study judged to be at critical risk of bias in one domain \\
\hline
\end{tabular}

GERONIMUS 2013

\begin{tabular}{|c|c|c|}
\hline Bias & Authors' judgment & Support for judgement \\
\hline Confounding & Moderate & $\begin{array}{l}\text { Confounding expected, all known important confounding do- } \\
\text { mains appropriately measured and controlled for, and reliability } \\
\text { and validity of measurement of important domains were sufficient, } \\
\text { such that we do not expect serious residual confounding }\end{array}$ \\
\hline Selection of participants into the study & Low & $\begin{array}{l}\text { All participants who would have been eligible for the target trial } \\
\text { were likely included in the study and for each participant start of } \\
\text { follow up and start of intervention likely coincided }\end{array}$ \\
\hline Classification of interventions & Serious & Intervention status was not well defined \\
\hline Deviations from intended interventions & NI & $\begin{array}{l}\text { No information was reported on whether there was deviation from } \\
\text { the intended intervention }\end{array}$ \\
\hline Missing data & Low & Data were reasonably complete \\
\hline Measurement of outcomes & Serious & $\begin{array}{l}\text { CDMS was assessed by assessors aware of the intervention received } \\
\text { by study participants }\end{array}$ \\
\hline Selection of the reported result & Low & $\begin{array}{l}\text { There was evidence that reported results corresponded to all in- } \\
\text { tended outcomes and analyses }\end{array}$ \\
\hline Overall bias & Serious & $\begin{array}{l}\text { Study judged to be at serious risk of bias in two domains, but not } \\
\text { at critical risk of bias in any domain }\end{array}$ \\
\hline
\end{tabular}

MSBASIS 2016

Treatment with disease-modifying drugs for people with a first clinical attack suggestive of multiple sclerosis (Review) 
Table 2. Risk of bias in included cohort studies (ROBINS-I)

(Continued)

\begin{tabular}{|c|c|c|}
\hline Bias & Authors' judgment & Support for judgement \\
\hline Confounding & Serious & Important domains were not appropriately controlled for \\
\hline Selection of participants into the study & Critical & $\begin{array}{l}\text { Selection into the study was very strongly related to intervention } \\
\text { and outcome and this could not be adjusted for in analyses }\end{array}$ \\
\hline Classification of interventions & Serious & Intervention status was not well defined \\
\hline Deviations from intended interventions & NI & $\begin{array}{l}\text { No information was reported on whether there was deviation from } \\
\text { the intended intervention }\end{array}$ \\
\hline Missing data & NI & No information was reported on missing data \\
\hline Measurement of outcomes & Serious & $\begin{array}{l}\text { The outcome measures were subjective and they were assessed by } \\
\text { assessors aware of the intervention received by study participants. } \\
\text { Follow-up duration not reported }\end{array}$ \\
\hline Selection of the reported result & Low & $\begin{array}{l}\text { There was evidence that reported results corresponded to all in- } \\
\text { tended outcomes and analyses }\end{array}$ \\
\hline Overall bias & Critical & Study judged to be at critical risk of bias in one domain \\
\hline
\end{tabular}

Tintore 2015

\begin{tabular}{ll|l}
\hline Bias & Authors judgment & Support for judgement \\
\hline Confounding & Serious & Important domains were not appropriately controlled for \\
\hline Selection of participants into the study & Low & $\begin{array}{l}\text { All participants who would have been eligible for the target trial } \\
\text { were likely included in the study and for each participant start of } \\
\text { follow up and start of intervention likely coincided }\end{array}$ \\
\hline Classification of interventions & Serious & Intervention status was not well defined \\
\hline Deviations from intended interventions & NI & $\begin{array}{l}\text { No information was reported on whether there was deviation from } \\
\text { the intended intervention }\end{array}$ \\
\hline Missing data & Serious & $\begin{array}{l}\text { Reasons for missing data differed substantially across interventions, } \\
\text { and the analysis is unlikely to have removed the risk of bias arising } \\
\text { from the missing data }\end{array}$ \\
\hline Measurement of outcomes & Serious & $\begin{array}{l}\text { The outcome measures were subjective and assessed by assessors } \\
\text { aware of the intervention received by study participants. This judg- } \\
\text { ment is applicable to all outcomes reported in the article }\end{array}$
\end{tabular}

Treatment with disease-modifying drugs for people with a first clinical attack suggestive of multiple sclerosis (Review) 
Table 2. Risk of bias in included cohort studies (ROBINS-I) (Continued)

\begin{tabular}{|c|c|c|}
\hline Selection of the reported result & Low & $\begin{array}{l}\text { There was evidence that reported results corresponded to all in- } \\
\text { tended outcomes and analyses }\end{array}$ \\
\hline Overall bias & Serious & $\begin{array}{l}\text { Study judged to be at serious risk of bias in four domains, but not } \\
\text { at critical risk of bias in any domain }\end{array}$ \\
\hline
\end{tabular}

ROBINS-I is a tool to evaluate Risk Of Bias In Non-randomised Studies - of Interventions (Sterne 2016)

Table 3. Assessment of adverse events monitoring, definition and reporting of serious adverse events

\begin{tabular}{|c|c|c|}
\hline Study & $\begin{array}{l}\text { Did the researchers actively monitor for } \\
\text { adverse events or did they simply provide } \\
\text { spontaneous reporting of adverse events that } \\
\text { arose? }\end{array}$ & $\begin{array}{l}\text { Did the authors define serious adverse } \\
\text { events according to an accepted interna- } \\
\text { tional classification and report the number } \\
\text { of serious adverse events? }\end{array}$ \\
\hline Achiron 2004 & No information & No information \\
\hline ACISS 2010 & No information & No information \\
\hline BENEFIT 2006 & $\begin{array}{l}\text { Yes, active monitoring. "Regular visits were } \\
\text { scheduled for safety assessments at months } 3 \text {, } \\
6,9,12,18 \text {, and } 24 \text { ". (page } 1243 \text { ) }\end{array}$ & No information \\
\hline BENEFIT 2007 (3 years FU) & No information & No information \\
\hline BENEFIT 2009 ( 5 years FU) & No information & No information \\
\hline BENEFIT 2014 (8.7 years FU) & No information & No information \\
\hline BENEFIT 2016 (11 years FU) & No information & No information \\
\hline CHAMPS 2000 & $\begin{array}{l}\text { No active monitoring. "Each center was in- } \\
\text { structed to report all adverse events during the } \\
\text { first six months of treatment, but thereafter to } \\
\text { report only serious adverse events". (page 899) }\end{array}$ & No information \\
\hline CHAMPS 2006 (5 years FU) & No information & No information \\
\hline CHAMPS 2012 (10 years FU) & No information & No information \\
\hline ETOMS 2001 & $\begin{array}{l}\text { Yes, active monitoring. "Safety was assessed at } \\
1,6,12,18,24 \text { months". (page 1577) }\end{array}$ & $\begin{array}{l}\text { Yes to both questions. "Serious adverse events } \\
\text { were defined according to the guidelines of the } \\
\text { International Conference on Harmonisation". } \\
\text { (page 1580) }\end{array}$ \\
\hline GERONIMUS 2013 & No information & No information \\
\hline
\end{tabular}

Treatment with disease-modifying drugs for people with a first clinical attack suggestive of multiple sclerosis (Review) 


\begin{tabular}{|c|c|c|}
\hline Motamed 2007 & $\begin{array}{l}\text { Yes, active monitoring. "Safety assessments } \\
\text { were performed at the end of months } 1,2,3 \text {, } \\
9,15 \text {, and } 21 \text { by a neurologist". (page } 345 \text { ) }\end{array}$ & No information \\
\hline MSBASIS 2016 & No information & No information \\
\hline ORACLE 2014 & $\begin{array}{l}\text { Yes, active monitoring. "Adverse events and } \\
\text { laboratory findings were recorded at study } \\
\text { visits and at regularly scheduled interim vis- } \\
\text { its" (page 259). "International Conference on } \\
\text { Harmonisation of Technical Requirements for } \\
\text { Registration of Pharmaceuticals for Human } \\
\text { Use". (page 258) }\end{array}$ & $\begin{array}{l}\text { Yes to both questions. "International Confer- } \\
\text { ence on Harmonisation of Technical Require- } \\
\text { ments for Registration of Pharmaceuticals for } \\
\text { Human Use". (page 258) }\end{array}$ \\
\hline Pakdaman 2007 & No information & No information \\
\hline PRECISE 2009 & $\begin{array}{l}\text { Unclear whether the researchers actively mon- } \\
\text { itored for adverse events or they simply pro- } \\
\text { vided spontaneous reporting of adverse events }\end{array}$ & No information \\
\hline PRECISE 2013 (5 years FU) & $\begin{array}{l}\text { Unclear whether the researchers actively mon- } \\
\text { itored for adverse events or they simply pro- } \\
\text { vided spontaneous reporting of adverse events }\end{array}$ & No information \\
\hline REFLEX 2012 & $\begin{array}{l}\text { Yes, active monitoring. "Active monitoring by } \\
\text { personnel was ensured via various testing". } \\
\text { (page 34). "Adverse events were coded with the } \\
\text { Medical Dictionary for Regulatory Activities } \\
\text { (MedDRA) and analysed according to the pre- } \\
\text { ferred terms". (page 35) }\end{array}$ & $\begin{array}{l}\text { Yes to both questions. "Adverse events were } \\
\text { coded with the Medical Dictionary for Regu- } \\
\text { latory Activities (MedDRA) and analysed ac- } \\
\text { cording to the preferred terms". (page 35) }\end{array}$ \\
\hline REFLEX 2016 (3 and 5 years FU) & $\begin{array}{l}\text { Unclear. "Adverse events (adverse events) were } \\
\text { monitored at months } 25 \text { and } 27 \text { and then every } \\
3 \text { months to the study end". (page 2) }\end{array}$ & No information \\
\hline Tintore 2015 & No information & No information \\
\hline TOPIC 2014 & $\begin{array}{l}\text { Unclear. "Adverse events were reported by } \\
\text { study participants or investigators throughout } \\
\text { the study; investigators recorded all such events } \\
\text { on case report forms". (page 979) }\end{array}$ & No information \\
\hline
\end{tabular}


Table 4. Outcome data from cohort studies

\begin{tabular}{|c|c|c|c|}
\hline ACISS 2010 & $\begin{array}{l}\text { Early DMDs treatment }(\mathrm{N}= \\
\text { 49) }\end{array}$ & $\begin{array}{l}\text { Delayed DMDs treatment }(\mathrm{N} \\
=57)\end{array}$ & $\begin{array}{l}\text { No treatment } \\
(\mathrm{N}=52)\end{array}$ \\
\hline $\begin{array}{l}\text { EDSS score over } 24 \text { months' } \\
\text { follow-up } \\
\text { Mean (SD) } \\
\text { Median (range) } \\
\text { Kruskal-Wallis H-Test P value } \\
<0.001\end{array}$ & $\begin{array}{l}1.2(0.9) \\
1.5(0-3)\end{array}$ & $\begin{array}{l}1.6(1.2) \\
1.5(0-6)\end{array}$ & $\begin{array}{l}0.8(0.8) \\
1.0(0-3)\end{array}$ \\
\hline$P$ value versus no treatment & 0.016 & $<0.001$ & NA \\
\hline $\begin{array}{l}\mathrm{P} \text { value early versus delayed } \\
\text { treatment (Wilcoxon matched } \\
\text { pair test) }\end{array}$ & 0.055 & NA & NA \\
\hline $\begin{array}{l}\text { Relapses } \\
\text { Mean (SD) } \\
\text { Median (range) } \\
\text { Kruskal-Wallis H-Test P value } \\
<0.001\end{array}$ & $\begin{array}{l}0.5(0.8) \\
0.0(0-4)\end{array}$ & $\begin{array}{l}1.0(1.1) \\
1.0(0-4)\end{array}$ & $\begin{array}{l}0.2(0.5) \\
0.0(0-3)\end{array}$ \\
\hline$P$ value versus no treatment & 0.059 & $<0.001$ & NA \\
\hline $\begin{array}{l}\mathrm{P} \text { value early versus delayed } \\
\text { treatment (Wilcoxon matched } \\
\text { pair test) }\end{array}$ & 0.01 & NA & NA \\
\hline
\end{tabular}

Tintore 2015

Risk of attaining an EDSS score of 3.0 with early DMDs compared with delayed DMDs treatment Adjusted hazard ratio: 0.5 (95\% CI 0.3 to 0.9$)$

Unadjusted hazard ratio: 1.1 (95\% CI 0.7 to 1.9$)$

DMDs: disease-modifying drugs. EDSS: expanded disability status scale; NA: not applicable; SD: standard deviation

Table 5. Time until the delayed treatment in open-label extension studies

\begin{tabular}{l|l}
\hline Study & Time until the delayed treatment after randomisation \\
\hline BENEFIT 2006 & Mean (SD): $1.5(0.73)$ years \\
\hline CHAMPS 2000 & Median (interquartile range): 30 (24-35) months \\
\hline
\end{tabular}

PRECISE 2009 Median (range): 29 (0.5 -38) months

Treatment with disease-modifying drugs for people with a first clinical attack suggestive of multiple sclerosis (Review) 
Table 5. Time until the delayed treatment in open-label extension studies (Continued)

REFLEX 2012 Data not reported

Table 6. Safety outcome data from open-label extension studies

\begin{tabular}{|c|c|c|c|c|}
\hline & Interferon beta- $1 b$ & $\begin{array}{l}\text { Intramuscular inter- } \\
\text { feron beta 1-a (Avonex) }\end{array}$ & $\begin{array}{l}\text { Subcutaneous interferon } \\
\text { beta 1-a (Rebif) }\end{array}$ & Glatiramer acetate \\
\hline Participants & 487 & 383 & 517 & 481 \\
\hline $\begin{array}{l}\text { Serious adverse events - } \\
\text { number of participants }\end{array}$ & 123 & 65 & 49 & 60 \\
\hline $\begin{array}{l}\text { Discontinued treatment } \\
\text { for any adverse events }\end{array}$ & Not reported & Not reported & 20 & 71 \\
\hline $\begin{array}{l}\text { Discontinued treatment } \\
\text { or were lost to follow-up } \\
\text { for any reason }\end{array}$ & 204 & Not reported & 146 & 192 \\
\hline Years of follow-up & 8.7 & 10 & 5 & 5 \\
\hline
\end{tabular}

\section{A P P E N D I C E S}

\section{Appendix I. Keywords}

clinically isolated syndrome* OR first demyelinating event* OR first demyelinating episode OR first demyelinating attack OR First event OR first episode OR first clinical episode OR single clinical episodes OR first demyelinating event* OR clinically isolated syndrome*

\section{Appendix 2. MEDLINE}

$((()(((()((()(()($ “clinically isolated syndrome*”[Title/Abstract]) OR cis“[Title/Abstract]) OR ”first demyelinating

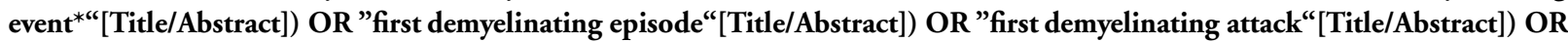
First event[Title/Abstract]) OR "first episode“[Title/Abstract] OR "first clinical episode“[Title/Abstract] OR "single clinical episodes“[Title/Abstract])))))) OR first demyelinating event*[Text Word]) OR clinically isolated syndrome*[Text Word]))

AND

((((((()(((Multiple Sclerosis“[Mesh:noexp]) OR (”Multiple Sclerosis/diagnosis“[Mesh:noexp] OR ”Multiple Sclerosis/therapy“[Mesh:noexp]))) OR ("multiple sclerosis“[Title/Abstract]) OR ”optic neuritis“[Title/Abstract]) OR ”optic neuritis“[Title/ Abstract]))) OR ”early multiple sclerosis“[Title/Abstract]) OR "early stage multiple sclerosis“[Title/Abstract] OR conversion to multiple sclerosis[Title/Abstract]))) OR early stage multiple sclerosis[Text Word]) OR conversion to multiple sclerosis[Text Word])

Treatment with disease-modifying drugs for people with a first clinical attack suggestive of multiple sclerosis (Review) 


\section{Appendix 3. Embase}

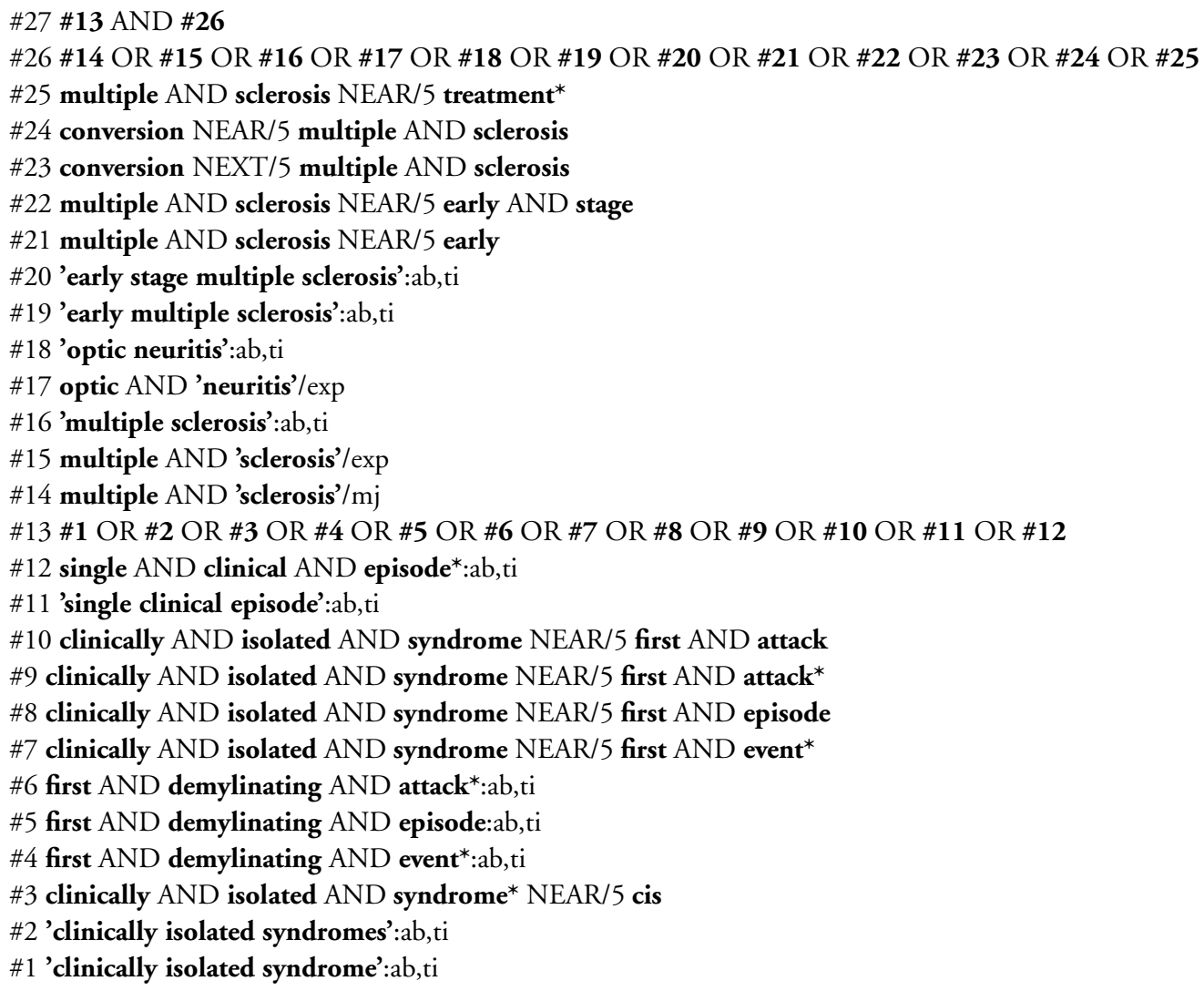

\section{CONTRIBUTIONSOFAUTHORS}

Concept development - GF, MC, OB, SF, AS

Title registration - GF

Drafting of protocol - GF, IT

Editing of protocol - GF, MC, OB, SF, AS

Data abstraction - GF, CDG, MC, OB, MM, FP, IT, AS, GS

Data analysis - CDG, GS

Drafting the review - GF, CDG, GS

Editing and revising the review - GF, CDG, MC, OB, MM, FP, SF, IT, AS, GS 


\section{DECLARATIONSOF INTEREST}

GF - none. As Co-ordinating Editor, Dr. Filippini was excluded from the editorial process to ensure separation of the review author from the editorial process. This included all editorial decisions and related activities (e.g. sign-off for publication).

CDG - received financial support for conducting the review process from a grant financed by Swiss MS Register. This had no bearing on, and did not influence, what has been written in the submitted work.

MC - received personal compensation from Merck, Biogen, Novartis and Sanofi-Genzyme for serving on advisory boards and for providing expert testimony as well as for travel/ accommodation/meeting expenses. Dr. Clerico's institution received some grants for research projects from Merck.

OB - received salary from Cognizant Technology Solutions for epidemiological consultation for Pharma companies.

MM - speaker honoraria from Merck Serono and Novartis; received financial support for travel/accommodation/meeting expenses from Biogen Idec, Novartis, Genzyme and Teva. This had no bearing on, and did not influence, what has been written in the submitted work.

FP - none

SF - received honoraria for consultancy, educational activities and/or lectures from Allergan, Bayer, Biogen, Genzyme, Merck, Novartis, Sanofi and Teva.

IT - none

AS - none

GS - none

\section{SOURCES OF SUPPORT}

\section{Internal sources}

- Foundation Neurological Institute Carlo Besta, Milan, Italy.

Support from the Institute to the Editorial Base of Cochrane Multiple Sclerosis and Rare Diseases of the CNS

\section{External sources}

- Cochrane Review Support Programme, UK.

Funding support for this priority review.

- Grant from the Swiss MS Society, Switzerland.

Cinzia Del Giovane received a grant that supported the review.

\section{DIFFERENCES BETWEEN PROTOCOLAND REVIEW}

- Objectives. We expanded the research questions including:

$\circ$ is early treatment efficacious and safe compared to placebo or no treatment?;

$\circ$ are there differences in efficacy and safety between the various drugs administered for early treatment?;

$\circ$ is early treatment better than delayed treatment?

- Outcomes. We added "time to conversion to clinically definite multiple sclerosis" as a secondary outcome.

- Assessment of risk of bias in included studies. We evaluated risk of bias of the included open-label extension studies using Cochrane 'Risk of bias' tool for RCTs (Higgins 2011) and ROBINS-I tool for NRS (Sterne 2016) for the included cohort studies.

Treatment with disease-modifying drugs for people with a first clinical attack suggestive of multiple sclerosis (Review) 
- Measures of treatment effect. We used odds ratios to estimate treatment effect in pairwise meta-analyses and network metaanalyses for included outcomes, and hazard ratios for conversion to clinically definite multiple sclerosis.

- Dealing with missing data. We used Informative Missingness Odds Ratio model to account for the impact of missing outcome rate (assumed not missing at random) for binary outcomes.

- Summary of findings table. We added the primary outcome "Withdrawls or drug discontinuation because of adverse events during 24 months of treatment" in 'Summary of findings' table one.

\section{N DEX TERMS}

\section{Medical Subject Headings (MeSH)}

Adjuvants, Immunologic [adverse effects; *therapeutic use]; Cladribine [adverse effects; therapeutic use]; Cohort Studies; Crotonates [adverse effects; therapeutic use]; Disease Progression; Glatiramer Acetate [adverse effects; therapeutic use]; Immunosuppressive Agents [adverse effects; ${ }^{*}$ therapeutic use]; Interferon beta-1a [adverse effects; therapeutic use]; Multiple Sclerosis [* drug therapy]; Publication Bias; Randomized Controlled Trials as Topic; Recurrence; Time Factors; Toluidines [adverse effects; therapeutic use]

\section{MeSH check words}

Humans 